\title{
The effect of a gender transformative life skills education and sports-coaching programme on the attitudes and practices of adolescent boys and young men in Bihar
}

Shireen J. Jejeebhoy

Rajib Acharya

Population Council

Neelanjana Pandey

Population Council

K.G. Santhya

Population Council

A.J. Francis Zavier

Population Council

See next page for additional authors

Follow this and additional works at: https://knowledgecommons.popcouncil.org/departments_sbsr-pgy

Part of the Demography, Population, and Ecology Commons, Domestic and Intimate Partner Violence Commons, Family, Life Course, and Society Commons, and the International Public Health Commons How does access to this work benefit you? Let us know!

\section{Recommended Citation}

Jejeebhoy, Shireen J., Rajib Acharya, Neelanjana Pandey, K.G. Santhya, A.J. Francis Zavier, Santosh Kumar Singh, Komal Saxena, Aparajita Gogoi, Madhu Joshi, and Sandeep Ojha. 2017. "The effect of a gender transformative life skills education and sports-coaching programme on the attitudes and practices of adolescent boys and young men in Bihar." New Delhi: Population Council. 


\section{Authors}

Shireen J. Jejeebhoy, Rajib Acharya, Neelanjana Pandey, K.G. Santhya, A.J. Francis Zavier, Santosh Kumar Singh, Komal Saxena, Aparajita Gogoi, Madhu Joshi, and Sandeep Ojha 


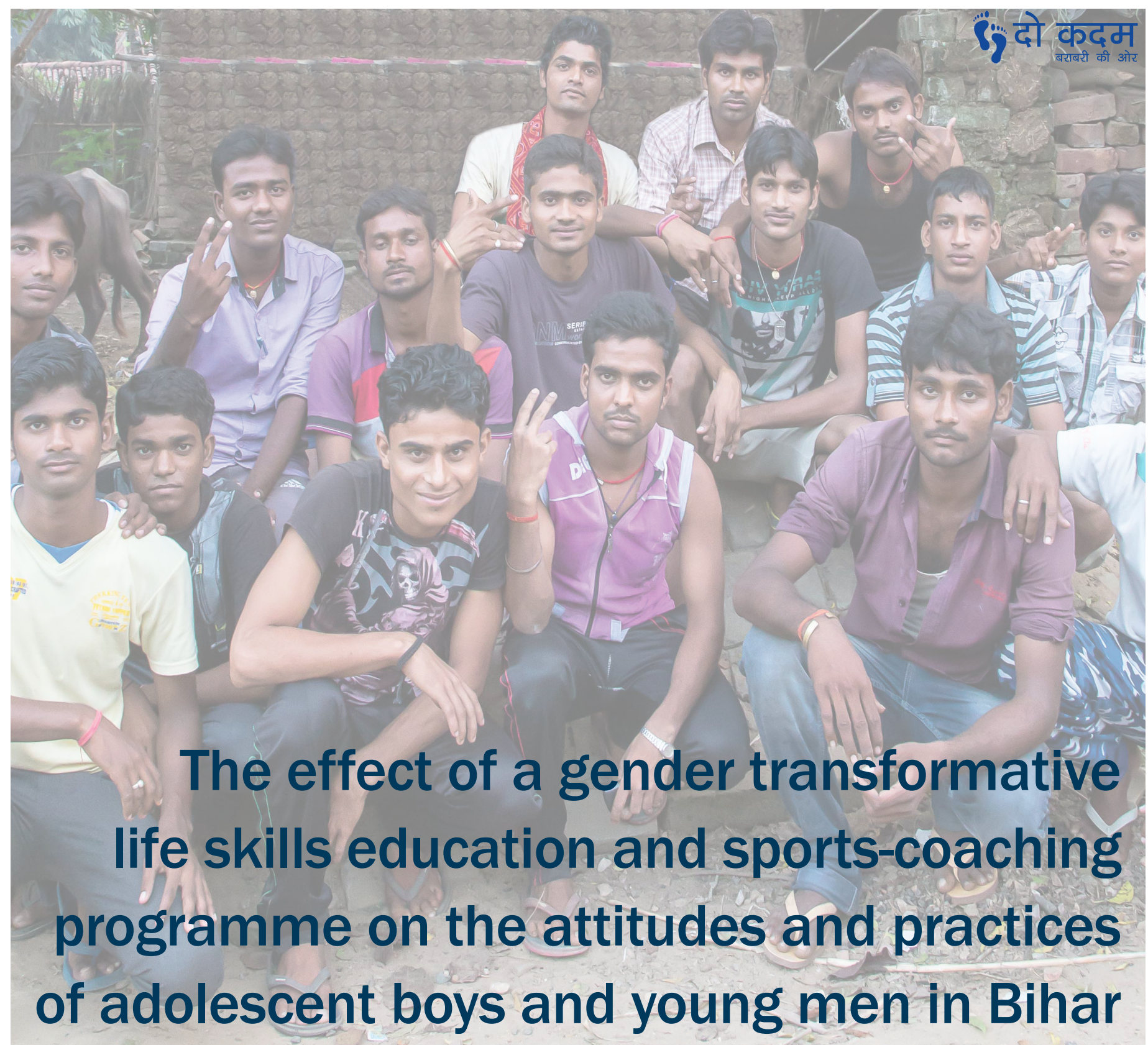

Shireen J Jejeebhoy

Rajib Acharya

Neelanjana Pandey

K G Santhya

A J Francis Zavier

Santosh Kumar Singh

Komal Saxena
Aparajita Gogoi

Madhu Joshi

Sandeep Ojha 


\section{Poppurtow
cowncil \\ Ideas. Evidence. Impact.}

The Population Council confronts critical health and development issues-from stopping the spread of HIV to improving reproductive health and ensuring that young people lead full and productive lives. Through biomedical, social science, and public health research in 50 countries, we work with our partners to deliver solutions that lead to more effective policies, programs, and technologies that improve lives around the world. Established in 1952 and headquartered in New York, the Council is a nongovernmental, nonprofit organization governed by an international board of trustees.

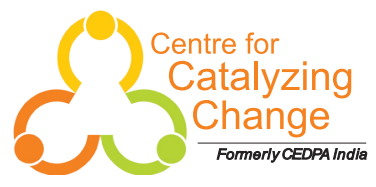

The Centre for Development and Population Activities, India is now the Centre for Catalyzing Change (C3). Over two decades of sustained work to empower and mobilize young people, men and women commemorates the journey of the organisation, that began as one of the first organizations working with life skills education for adolescents through it comprehensive programs. We are a non-governmental organization with the mission to empower women in all sectors of development and to that end we work with young people, including in and out of school adolescent boys and girls in rural and urban India. Our technical expertise extends to incubating, implementing and scaling up programs focused on its thematic areas of youth education, gender and maternal health/reproductive rights, specialising in at- scale programme implementation, monitoring and evaluation. Till date, we have reached more than one million girls and boys in India and equipped them with practical life skills, improved confidence in personal decision-making and increased self-esteem. In the past couple of years we have been using digital technology to build young people's capacities on health, life skills and gender equity issues.

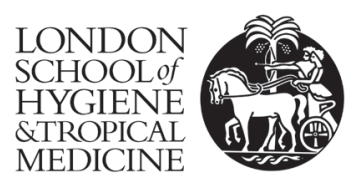

Our mission is to improve health and health equity in the UK and worldwide; working in partnership to achieve excellence in public and global health research, education and translation of knowledge into policy and practice.

Suggested Citation: Jejeebhoy, S.J., Rajib Acharya, Neelanjana Pandey et al. 2017. The effect of a gender transformative life skills education and sports-coaching programme on the attitudes and practices of adolescent boys and young men in Bihar. New Delhi: Population Council.

For additional copies of the report please contact:

\section{Population Council}

Zone 5A, Ground Floor

India Habitat Centre, Lodi Road

New Delhi, India 110003

Phone: +91-11-2464 2901

Email: info.india@popcouncil.org

Website: www.popcouncil.org

The study has been funded by UK aid from the UK Government; however the views expressed do not necessarily reflect the UK Government's official policies. 


\section{The effect of a gender transformative life skills education and sports-coaching programme on the attitudes and practices of adolescent boys and young men in Bihar}

Shireen J Jejeebhoy

Rajib Acharya

Neelanjana Pandey

K G Santhya

A J Francis Zavier

Santosh Kumar Singh

Komal Saxena
Aparajita Gogoi Madhu Joshi

Sandeep Ojha 


\section{Table of Content}

Acknowledgements $\quad$ ix

Executive summary $\quad$ xi

Chapter $1 \quad$ Introduction 1

Chapter $2 \quad$ Profile of the life of boys in NYKS clubs 10

Chapter 3 Do Kadam Barabari Ki Ore: The intervention 20

Chapter $4 \quad$ Participation in youth clubs and Do Kadam project activities 26

Chapter $5 \quad$ Effect of the intervention on the attitudes and behaviours of boys 37

Chapter $6 \quad$ Changes in attitudes and practices: Self-assessments 47

Chapter $7 \quad$ Summary and way forward 58

Appendix 1.1: $\quad$ Construction of the wealth index 61

Appendix Table 1.2: Selected baseline indicators by regularity of attendance in intervention programme, 2013, baseline survey

Appendix Table 1.3: Percentage of boys reporting egalitarian gender role attitudes and notions of masculinity by treatment arms, 2015, endline survey

Appendix Table 1.4: Percentage of boys reporting their perceptions about peer reactions to boys acting in gender equitable ways, by treatment arms, 2015, endline survey

Appendix Table 1.5: Percentage of boys reporting their perceptions about boys' and men's right to control the behaviour of their sister, girlfriend, and wife, by treatment arms, 2015, endline survey

Appendix Table 1.6: Percentage of boys reporting attitudes about men's right to perpetrate violence against women and girls in certain situations, by treatment arms, 2015, endline survey

References

Authors

List of Investigators 


\section{List of Tables}

Table 1.1: $\quad$ Selected socio-demographic indicators, Bihar state and Patna district 3

Table 1.2: Balancing conditions for allocating clubs between intervention and control arms 5

Table 1.3: $\quad$ Follow-up rate at endline and reasons for loss to follow-up, by treatment arm 9

Table 2.1: $\quad$ Background characteristics of surveyed boys

Percent distribution of surveyed boys by selected background characteristics, according to

treatment arms, 2013, baseline survey

Table 2.2: Violence at home

Percentage of boys witnessing domestic violence and experiencing physical abuse from a parent, by treatment arms, 2013, baseline survey

Table 2.3: Norms and practices relating to the perpetration of violence on girls

Percentage of boys reporting perceptions about the attitudes of peers on violence against

girls and observation of violent acts against girls by men or boys in the preceding six months, by treatment arms, 2013, baseline survey

Table 2.4: $\quad$ Gender roles attitudes

Percentage of boys reporting egalitarian gender role attitudes and notions of masculinity and mean scores of boys indicating gender egalitarian attitudes and notions of masculinity, by treatment arms, 2013, baseline survey

Table 2.5: Perceptions about peer reactions to boys acting in gender equitable ways

Percentage of boys reporting their perceptions about peer reactions to those who act in gender equitable ways in selected situations, by treatment arms, 2013, baseline survey

Table 2.6: Perceptions on right of boys and men to control the behaviour of their sister, girlfriend, and wife Percentage of boys who rejected the right of boys and men to control social interactions and freedom of sisters, girlfriends, and wives, and mean scores of boys indicating rejection of controlling behaviour, by treatment arms, 2013, baseline survey

Table 2.7: $\quad$ Attitudes about violence on girls and women

Percentage of boys holding attitudes rejecting the right of men and boys to perpetrate violence against girls and women in certain situations, and mean scores of boys indicating rejection of violence, by treatment arms, 2013, baseline survey

Table 2.8: Response to violence against girls perpetrated by others in preceding six months Percentage of boys who witnessed incidents of verbal and physical violence perpetrated on girls reporting their reaction to the incident, by treatment arms, 2013, baseline survey

Table 2.9: $\quad$ Perpetration of violence on girls and bullying of younger boys in the preceding six months Percentage of boys reporting bullying of younger boys and verbal, physical, and sexual violence on girls/women in the face-to-face interview and anonymous format, by age group and treatment arms, 2013, baseline survey

Table 3.1: Attendance of club members at gender transformative life skills and cricket-coaching sessions Percent distribution of boys by attendance at gender transformative life skills and cricket-coaching sessions, as per monthly monitoring reports, intervention arm, Patna district

Table 4.1: $\quad$ Attendance in gender transformative life skills and cricket sessions Percent distribution of boys by attendance of sessions, and percentage of boys ever missed three consecutive sessions, intervention arm, 2015, endline survey 
Table 4.2: $\quad$ Participation in gender transformative life skills sessions

Percent distribution of boys reporting participation, by frequency and facilitators of gender transformative life skills sessions, intervention arm, 2015, endline survey

Table 4.3: Recall of content and perceptions about the quality of gender transformative life skills sessions Percentage of boys reporting awareness of topic discussed, attendance, and learning experiences, intervention arm, 2015, endline survey

Table 4.4: Participation in cricket-coaching sessions

Percent distribution of boys reporting participation, by frequency and facilitators of cricket sessions, and percentage reporting participation in cricket tournaments, intervention arm, 2015, endline survey

Table 4.5: Participation in community events

Percentage of boys reporting participation in one or more community events of the Do Kadam programme, by events, intervention arm, 2015, endline survey

Table 4.6: Reasons for irregular participation and non-participation in the Do Kadam programme Percentage of boys reporting reasons for irregular participation in LSE and sports sessions and non-participation in cricket tournaments and community events, by session type and events, intervention arm, 2015, endline survey

Table 4.7: $\quad$ Perceptions about the quality of the Do Kadam programme

Percent distribution of boys who participated in the Do Kadam programme reporting their perceptions and assessment, by duration of programme and inputs of facilitators, intervention arm, 2015, endline survey

Table 5.1: Estimated intervention effect on attitudes held by surveyed boys, 2015, endline survey

Table 5.2: $\quad$ Estimated intervention effect on attitudes held by surveyed boys, 2015, endline survey

Table 5.3: Estimated intervention effect on perpetration of non-contact violence and physical and sexual violence on girls/women by surveyed boys in the six months preceding the survey, according to age group, 2015, endline survey

Table 5.4: Attitudes held by surveyed boys in ages 14-23, by treatment arms and regularity of programme attendance: GEE regression coefficients / odds ratios, 2015, endline survey

Table 5.5: Action boys took against harassment of or violence on girls/women in the six months preceding the survey, by treatment arms and regularity of programme attendance: GEE regression odds ratios, 2015, endline survey

Table 5.6: $\quad$ Perpetration of non-contact violence and physical and sexual violence on girls/women by surveyed boys in the six months preceding the survey, by treatment arms and regularity of programme attendance: GEE regression odds ratios, 2015, endline survey

Table 6.1: Perceptions about changes

Percentage of boys reporting increased exposure to information, self-efficacy, sports skills, wider social networks, and greater gender sensitivity in the year preceding the endline interview, intervention and control arms, 2015, endline survey

Table 6.2: Observation of changes in boys by others

Percentage of boys who participated in the intervention activities reporting changes in their behaviour observed by family members, friends, and others in the year preceding the endline interview, intervention arm, 2015, endline survey 


\section{List of Figures}

Figure 1: Gender role attitudes and notions of masculinity and perceptions about the right of boys and men to control the behaviour of their sister, girlfriend, and wife, among boys in the ages 13-21 by treatment arms, baseline survey, 2013

Figure 2: $\quad$ Participation of the boys in life skills sessions and cricket sessions conducted as part of the Do Kadam Barabari Ki Ore programme, intervention clubs, endline survey, 2015

Figure 3: $\quad$ Percentage of boys who disagreed with selected statements reflecting traditional gender role attitudes and notions of masculinity by treatment arms, endline survey, 2015

Figure 4: $\quad$ Percentage of boys reporting that they would be respected by their peers for behaving in non-traditional ways in selected situations by treatment arms, endline survey, 2015

Figure 5: $\quad$ Percentage of boys who rejected the right of men and boys to control selected behaviours of their sister, girlfriend, and wife by treatment arms, endline survey, 2015

Figure 6: $\quad$ Percentage of boys who rejected the right of men and boys to perpetrate violence against women and girls under selected circumstances by treatment arms, endline survey, 2015

Figure 1.1: Flow diagram of the number of eligible club members, number of boys assigned to treatment arms, and number of boys lost to follow-up 


\section{Acknowledgements}

We are grateful to the UK Department for International Development (DFID) for supporting our programme of research, Do Kadam Barabari Ki Ore (Two Steps Towards Equality), to assess what works to address violence against women in Bihar state, India. Under this programme of research and evaluation, a total of five projects were implemented in partnership with the Centre for Catalyzing Change and the London School of Hygiene and Tropical Medicine. One of the five projects, findings of which are presented in this report, provided gender transformative life skills education combined with cricket-coaching to young boys who were members of NYKS clubs, and measured its impact on boys' gender role attitudes, including their attitudes towards violence against women and girls, and thereby on their perpetration of violence against women.

This study has benefitted immeasurably from the inputs of many. In particular, we are grateful to Mamta Kohli, Nupur Barua, Nel Druce, Arundhati Choudhury, and Peter Evans from DFID India Office, for their support and to Mamta Kohli and Nupur Barua for their guidance and insights throughout the course of this project. We are extremely grateful, moreover, to several officials of Government of Bihar whose encouragement and support had made it possible to conduct the study in the state of Bihar. These included Shri Sayed Ali, Shri Hari Shankar Sukla and Shri Anil Kaushik-all who were Zonal Directors, Nehru Yuva Kendra Sangathan, Bihar at different points of time during the life of the project and Shri. Narendra Rai, District Youth Coordinator, Patna district. Lori Heise from the London School of Hygiene and Tropical Medicine and Kelly Hallman from the Population Council, New York provided valuable inputs into the intervention design and the study protocol, and critically reviewed and made comments and suggestions on the earlier draft of this report; we are most grateful to them for their insights. We are also grateful to Calum Davey from the London School of Hygiene and Tropical Medicine for his significant assistance in developing the computer programs for the randomization of clubs.

At the Population Council, several colleagues have supported us in both the technical and administrative aspects of this study. We are grateful to MA Jose for overseeing the administration of the fieldwork and to Komal Saxena, an author of this report, who was also responsible for editorial matters and for preparing the manuscript for publication. We would also like to acknowledge support from Annu Kurien for her inputs in editing the manuscript.

At the Centre for Catalyzing Change, we acknowledge the contributions of the Do Kadam team members in the Patna office, including Prakash Ranjan and Kumar Alok, and the project's three core trainers-Pramod Kumar Sinha, Manish Bharti Nishad and Kamlesh Raj-without whose dedicated work this project would not have been successful. We would also like to acknowledge the dedication of our research assistants who conducted the survey and the in-depth interviews with the boys.

Finally, we would like to record our deep appreciation of the members of the NYKS clubs who participated in the Do Kadam programme, to the parents of these boys and to the men and women in the community who took part in community wide activities. We hope that our recommendations based on the insights and experiences that they shared with us will help shape programmes intended to address the issue of violence against women and girls in Bihar.

Shireen J Jejeebhoy

Rajib Acharya

Neelanjana Pandey

K G Santhya

A J Francis Zavier

Santosh Kumar Singh

Komal Saxena
Aparajita Gogoi

Madhu Joshi

Sandeep Ojha 


\section{Executive summary}

Gender hierarchical socialisation practices in India have resulted in the emergence of attitudes and practices espousing male entitlement and female submissiveness, which are evident even among girls and boys in early adolescence (Santhya et al., 2013). By the time they reach later adolescence and young adulthood, these hierarchical and gender stratified attitudes to gender roles are firmly established, and this is indicated, in particular, by the large proportions of young women and men who express attitudes justifying violence against women and girls (International Institute for Population Sciences [IIPS] and Population Council, 2010; Jejeebhoy and Acharya, 2014).

While programmes that focus on empowering women and girls are necessary, they are not sufficient in themselves to prevent violence; men and boys are key players, and violence prevention programmes must include them. The importance of starting young to change the attitudes and behaviours of the young-and especially young boys- has been widely acknowledged, but a key challenge has been the limited evidence on the kinds of programmes that have succeeded in changing the attitudes and practices of boys.

In order to fill this gap, the Population Council, together with partners, the Centre for Catalysing Change (C3) and the London School of Hygiene and Tropical Medicine, and with support from UKaid, implemented the Do Kadam Barabari Ki Ore (Two Steps Towards Equality) project among boys. Implemented in rural areas of Patna district, this project sought to promote, among adolescent boys and young men who were members of youth clubs supported by the NYKS programme of the Ministry of Youth Affairs and Sports, egalitarian gender attitudes and abhorrence of violence against women and girls (VAWG). This report describes the Do Kadam Barabari Ki Ore project and its implementation and examines the extent to which it transformed gender role attitudes of boys and, particularly, instilled in them an abhorrence of violence against women and girls.

\section{The intervention}

The Do Kadam intervention comprised gender transformative life skills education combined with cricket-coaching. The programme was implemented among 13-21 year old boys who were members of 15 youth clubs. Each club contained 30-40 members, on average, in ages 13-21, and all members were invited to participate. The intervention was delivered over 42 weekly sessions, with one hour each week devoted to the gender transformative life skills education component and one hour to cricket-coaching. The intervention was delivered over 18 months, with sessions suspended during examinations and festivals. Gender transformative life skills sessions addressed such issues as gender roles and attitudes, forms of violence against women and girls, respectful behaviour towards women, and positive masculinities. Participatory methodologies were used, with role playing and discussion on case studies. Two members with leadership skills from each club were identified and trained to serve as peer mentors. They were responsible for imparting the gender transformative life skills education programme and engaging members in weekly cricket-coaching sessions. A team of core trainers and cricket coaches oversaw the programme implemented by these peer mentors. Over the course of the intervention, boys held periodic community events intended to build gender egalitarian attitudes at community level.

\section{Evaluation design}

A mixed method design was used to evaluate the Do Kadam programme. It included a cluster randomised trial (CRT) with panel surveys of study participants at baseline (before the intervention was initiated) and endline (after the intervention was completed). The baseline survey was conducted during May-July 2013. A total of 1,149 unmarried boys in the ages 13-21 who were listed as members of the selected clubs were successfully interviewed. Our endline assessment consisted of a follow-up survey of boys who had participated in the baseline survey and was conducted in January-March 2015, following the completion of the 18-month intervention (completed in December 2014). At the time of the endline survey, 90 percent of baseline respondents were successfully interviewed.

The evaluation also included a longitudinal qualitative component using in-depth interviews with selected club members in the intervention arm at three points in the intervention-before beginning the intervention, about 6-7 months after rolling out the intervention, and after the intervention was over. We interviewed 32 boys on the basis of their responses in the baseline survey and made efforts to follow them up and re-interview them midway through the intervention (midline) and at the time of the endline survey. In all, we were able to follow up 28 of the 32 boys at midline, and 24 at the endline survey. 


\section{Pre-intervention context}

The baseline assessment underscores the extent to which the life of boys in our programme was characterised by traditional notions of masculinity, gender stereotypes and the acceptability of violence against women and girls. For example, as evident from Figure 1 below, gender role attitudes and notions of masculinity were far from egalitarian on many indicators: just 62-65 percent of boys rejected the view that childcare was the responsibility only of females, and even fewer, 9-12 percent agreed that a woman need not take the permission of her husband for most things. Many boys adhered to attitudes justifying a boy's or a man's right to control his sister, wife, and girlfriend (for example, just 26-30 percent reject the right of a man to exercise controlling behaviour over his wife, 38-39 percent rejected the right of a man or boy to exercise control over his sister, and 60-61 percent rejected the right of a boys to exercise control over his girlfriend. Likewise (not shown in figure) just 16-20 percent of boys believed they would be respected by their peers for acting in gender equitable ways, and just 31-36 percent rejected the right of a man or boy to beat a girl if she does not obey her elders or a woman if she disobeys her husband. In addition, many boys suggested that their peers also held norms condoning the perpetration of violence.

Figure 1: Gender role attitudes and notions of masculinity and perceptions about the right of boys and men to control the behaviour of their sister, girlfriend, and wife, among boys in the ages 13-21 by treatment arms, baseline survey, 2013

Gender role attitudes and notions of masculinity
Controlling behaviour over sister
Controlling behaviour over wife
Controlling behaviour over girlfriend

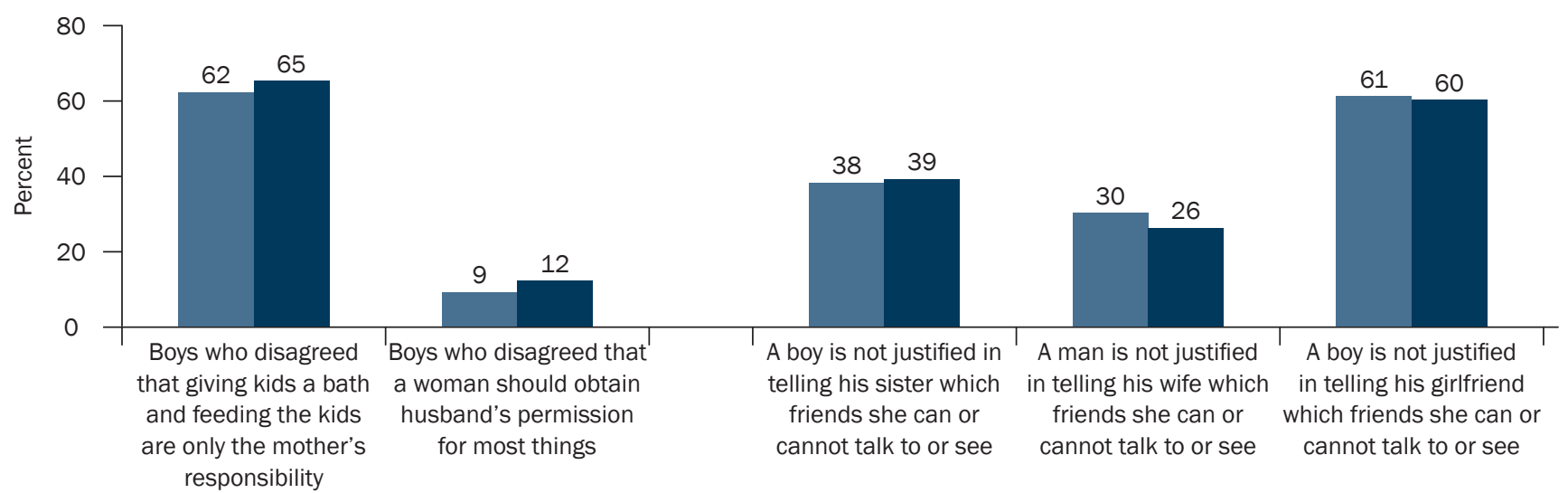

Many boys had witnessed gender-based violence, several had experienced violence while growing up, and a considerable proportion had perpetrated one or more acts of verbal, physical or sexual violence. For example, many had witnessed their father beating their mother (26-29\%), and many had themselves been the victim of violence perpetrated by a parent (49-59\%). Large proportions had moreover witnessed their peers and other community members perpetrating violence on a woman or girl: over half had witnessed someone making dirty comments to girls, 15-18 percent had witnessed someone pushing, grabbing or shoving a girl or woman, and 9-11 percent had observed someone assaulting a girl sexually.

Most boys who witnessed their peers or others committing violence on a woman or girl took no action to prevent the violence. Just one in three boys in the intervention arm and about one-fourth of those in the control arm had intervened to stop the violence.

Finally, boys had themselves perpetrated various acts of violence on a girl or woman: one-third or more boys. For example, 38-43 percent admitted that they had looked or at or started at a girl in a "bad" or threatening way, 31-32 percent that they had verbally abused a girl, that is, passed comments about, made dirty gestures at or used abusive language to a girl, 15 percent that they had physically abused a girl in the last six months, and 5-6 percent that they had touched a girl or woman inappropriately and without her consent in the six months preceding the interview. 3-4 percent of older boys (15-21 years) reported the perpetration of forced sex. 
The baseline findings also confirm that the intervention and control arms were well balanced in relation to the background characteristics of boys who were enrolled in the study as well as in the outcomes that the intervention sought to influence.

\section{The acceptability and effectiveness of the intervention}

\section{Acceptability}

Most boys in the intervention arm had participated in Do Kadam activities (Figure 2). Almost four in five had attended gender transformative life skills sessions, three in four had attended cricket sessions, and half (49\%) had participated in community-level events organised by the club. Regular attendance in gender transformative life skills sessions and cricket sessions was, however, reported by fewer: 64 percent and 57 percent, respectively. Most boys exposed to the gender transformative life skills sessions had attended sessions covering, on average, 10 of the 14 broad topics covered and reported that they had both liked the sessions on each topic and learned something new from them.

Boys were largely positive about the quality of the programme. Almost all (89\%) reported that they looked forward to sessions, and almost half believed the duration of the programme was too short. They reported, moreover, that the peer mentor was always approachable (72\%), always explained issues clearly (80\%), and could always answer their questions (70\%). More were positive about the core trainer's and the coach's ability to explain issues clearly (93\% each in life skills and cricket programme).

\section{Effectiveness: Attitudes}

The project achieved its primary objective. Findings relating to the effect of the Do Kadam project on a range of attitudes are consistently positive. Exposure to the intervention succeeded in making the attitudes of boys more gender egalitarian and changing norms with regard to notions of masculinity. For example, more boys from intervention than control clubs disagreed that childcare was the responsibility only of the mother ( $77 \%$ versus $68 \%$ ) and that a woman should obtain her husband's permission for most things (24\% versus $14 \%$ ) (Figure 3 ). In all, boys in the intervention arm expressed egalitarian gender role attitudes and notions of masculinity in 6.6 of 9 attitudes about which we probed, compared to 6.2 reported by those in the control arm (effect estimate $0.40, p<=0.05)^{1}$

There was strong evidence, in addition, to suggest that perceptions about peer reactions to boys acting in gender equitable ways had been affected by their participation in the intervention (Figure 4). For example, 21 percent of boys
Figure 2: Participation of the boys in life skills sessions and cricket sessions conducted as part of the Do Kadam Barabari Ki Ore programme, intervention clubs, endline survey, 2015

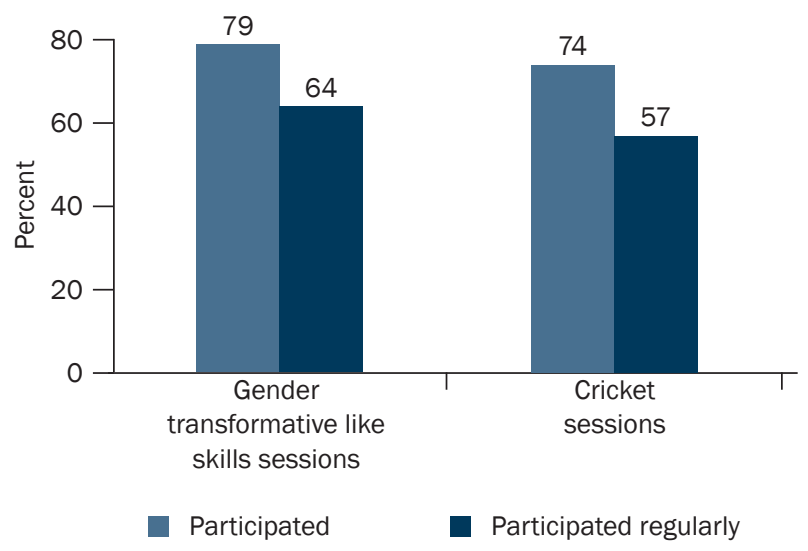

Figure 3: Percentage of boys who disagreed with selected statements reflecting traditional gender role attitudes and notions of masculinity by treatment arms, endline survey, 2015

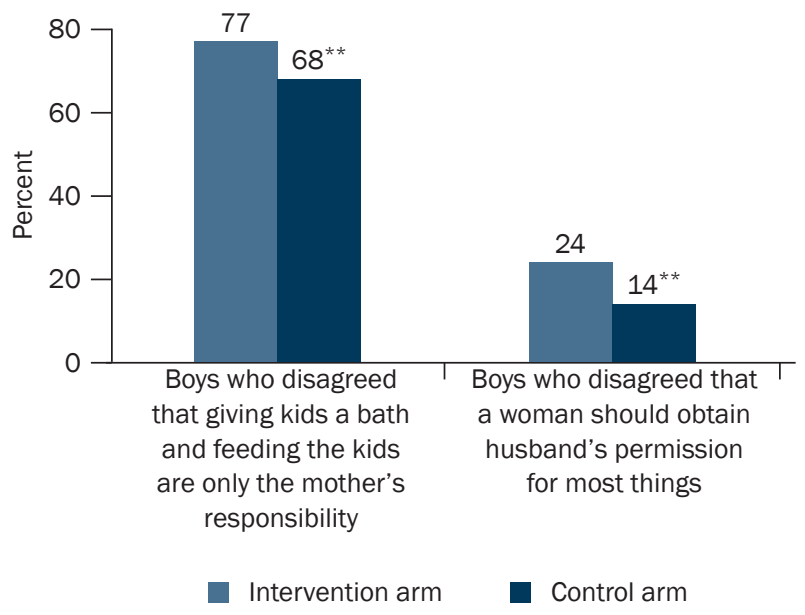

Note: ${ }^{*}$ indicates that the difference between the intervention and control arms was significant at $p<0.01$.

\footnotetext{
${ }^{1}$ Gender role attitudes index: the number of the following attitudes for which boys provided an egalitarian response: disagreed that giving the kids a bath and feeding the kids are only the mother's responsibility; a woman should obtain her husband's permission of most things, it is better for girls to marry early than complete at least Class 12, educating girls is more important than educating boys, girls cannot do well in Mathematics and Science, it is wrong for a girl to have male friends, it is necessary to give dowry, the husband mainly should decide how to spend money; and agreed that girls should be allowed to decide when they want to marry.
} 
in the intervention arm, compared to 13 percent of those in the control arm believed that their peers would respect a man who refused to beat his wife even if she disobeys him, and 13 percent compared to seven percent believed that peers would respect a boy who walks away from a fight. Overall, 20 percent of boys in the intervention arm compared with 13 percent of those in the control armbelieved that their peers would respect them for demonstrating non-traditional behaviours in at least three of four situations probed (effect estimate 7.2, $p=0.0426$, $\mathrm{p}<=0.05)^{2}$

The intervention also succeeded in enabling boys to reject men's and boys' right to exercise control over women and girls (Figure 5). For example, a significantly larger proportion of boys in the intervention than control arm rejected a man's or boy's right to dictate what clothes his sister, wife or girlfriend, respectively, may wear, and to control her freedom of movement. Overall, of nine situations probed, boys in the intervention arm rejected men's and boys' right to exercise control over women in 4.9 situations, compared to 4.2 situations reported by those in the control arm (effect estimate 0.7 , $p<=0.01)^{3}$

Finally, exposure to the intervention had a significant effect on enabling boys to reject men's and boys' right to perpetrate violence on women and girls (Figure 6). Significantly more boys from the intervention than control arm disagreed that there are times when a boy is justified in beating his girlfriend (62\% versus $53 \%$ ), and rejected a man's right to beat his wife in various situations, for example, if she goes out without telling him (72\% versus $60 \%$ ), if she disobeys him (53\% versus $43 \%$ ), or if she makes a mistake (70\% versus 59\%). Overall, of some 17 situations probed, boys from the intervention arm rejected the right of men and boys to exercise violence against women and girls in 11.7 , compared to 10.3 among those in the control arm (effect estimate 1.3, $\mathrm{P}<=0.001){ }^{4}$

Findings from in-depth interviews confirm, moreover, that notions of masculinity and men's right to perpetrate violence had been considerably tempered over the three interviews, with more boys at the endline than baseline in-depth interview expressing the view that violence is unacceptable in any situation and describing various legal and other options for women who experience marital violence.
Figure 4: Percentage of boys reporting that they would be respected by their peers for behaving in non-traditional ways in selected situations by treatment arms, endline survey, 2015

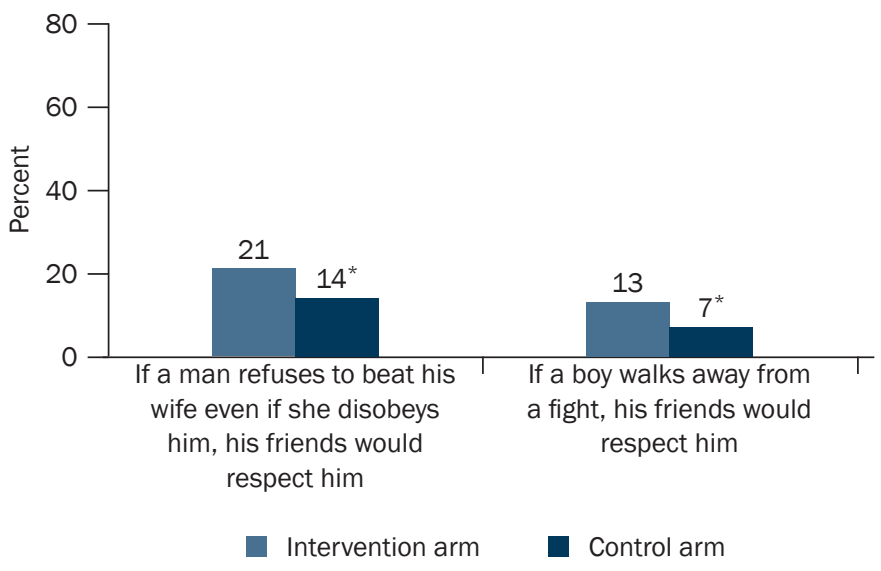

Note: *indicates that the difference between intervention and control arm is significant at $p \leq 0.05$.

Figure 5: Percentage of boys who rejected the right of men and boys to control selected behaviours of their sister, girlfriend, and wife by treatment arms, endline survey, 2015

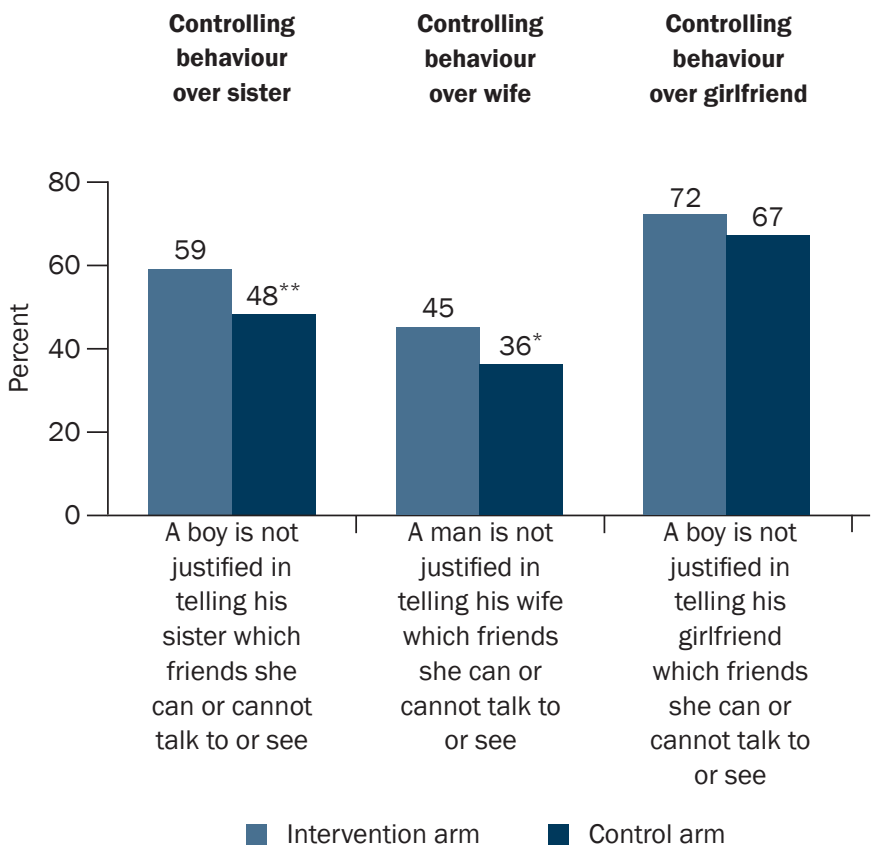

Note: * and ${ }^{* *}$ indicate that the difference between intervention and control arm is significant at $p \leq 0.05$ and $p \leq 0.01$, respectively.

\footnotetext{
${ }^{2}$ Percentage agreeing with at least three of the four situations: boys will not lose respect if they talk about their problems with their friends; if a boy helps his mother with housework, his friends will respect him; if a man refuses to beat his wife even if she disobeys him, his friends would respect him; if a boy walks away from a fight, his friends would respect him.

${ }^{3}$ Controlling behaviour index: the number of situations in which a boy rejected a boy's/man's right to control a woman/girl: a boy/man is not justified in doing the following to his sister, wife, girlfriend: telling her which friends she can or cannot talk to or see; in forbidding her to go out alone; telling her what clothes she can or cannot wear.
} 


\section{Effectiveness: Action taken to stop the perpetration of violence by others}

There is strong evidence moreover that the intervention succeeded in empowering boys take action when they observed incidents in which boys or men were teasing or otherwise verbally abusing a girl or woman, were spreading sexual rumours about a woman or girl, or were perpetrating unwanted touch on a woman or girl. Indeed, 40 percent of boys in the intervention arm, compared to 27 percent of those in the control arm had taken action - intervened to stop the incident, informed someone in a position of authority, or taken other action to stop the violence-in such situations. Narratives of boys in in-depth interviews also suggest that by the time of the endline in-depth interview, many more boys than at the time of the baseline in-depth interview reported that they had intervened to stop a boy from harassing or perpetrating violence on a girl over the year preceding the interview. Many attributed the change they had experienced directly to what was conveyed in the Do Kadam programme.

Figure 6: Percentage of boys who rejected the right of men and boys to perpetrate violence against women and girls under selected circumstances by treatment arms, endline survey, 2015

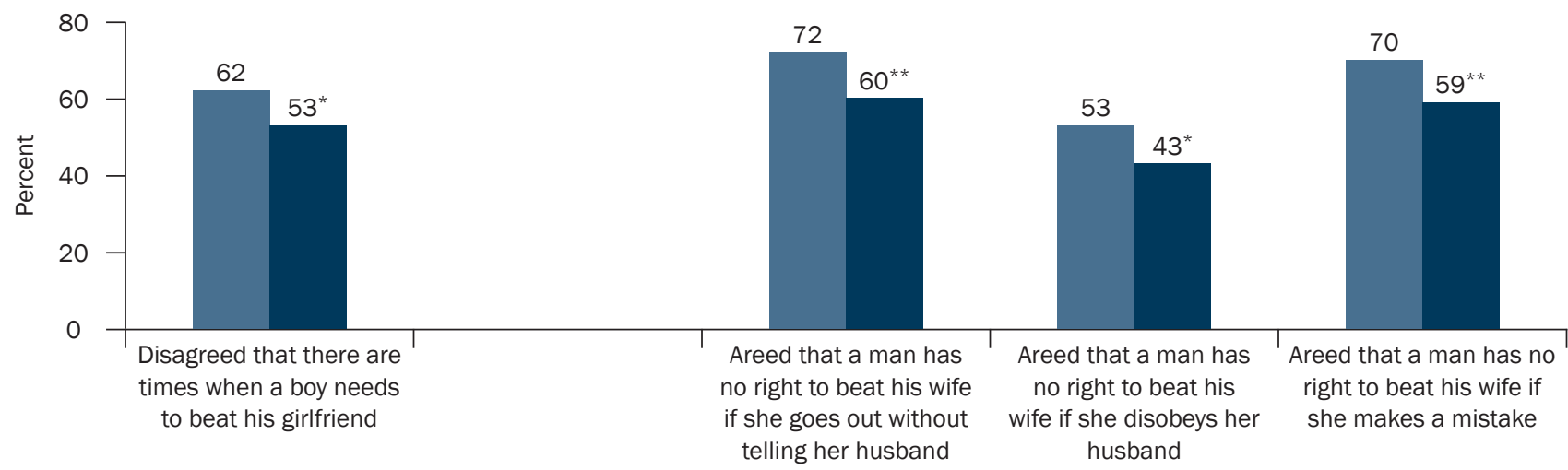

Intervention arm

Control arm

Note: * and ** indicate that the difference between intervention and control arm is significant at $p \leq 0.05$ and $p \leq 0.01$, respectively.

\section{Effectiveness: Perpetration of violence}

With regard to reduction in the perpetration of various forms of gender-based violence, there was weak evidence that non-contact forms of violence, such as stalking a girl, had declined because of the intervention. However, there was no evidence of an effect on the perpetration of other forms of non-contact violence or physical and sexual violence.

In in-depth interviews, several boys whose narratives suggested at the baseline and/or midline interview that they had participated in teasing girls in different ways reported at the endline interview that they no longer did so. Some of these boys specifically attributed the change they had experienced directly to what was conveyed in the Do Kadam programme.

\section{Effectiveness: Regularity of exposure}

Findings highlight that the effects of exposure to the programme were most pronounced for those who had regularly participated in the programme and had relatively little effect on those whose attendance was irregular. These findings confirm that a minimum of attendance in at least half of all sessions of both gender transformative life skills and cricket was essential to effect a change in boys' attitudes and practices.

\section{Effectiveness: Self-perceived changes}

Boys in both intervention and control arms perceived that over the year preceding the interview, they had experienced changes in themselves. However, on each issue explored, more boys in the intervention than control

\footnotetext{
${ }^{4}$ Violence against women and girls index: The number of situations for which boys gave an egalitarian response: Disagreed that girls like to be teased by boys, it is a girl's fault if she gets sexually harassed, rape against girls is perpetrate only by persons not related to her, a woman should tolerate violence to keep her family together, if a girl says no, it actually means yes, there are times when a boy needs to beat his girlfriend, there are times when a wife deserves to be beaten by her husband; perceived that a boy/man was not justified in perpetrating against a girl if she talks to a boy, goes out to play, stays out late, does not help with housework, does not obey her elders and has an affair with a boy; and perceived that a man was not justified in perpetrating against his wife if he suspects her of being unfaithful, if she goes out without informing him, if she disobeys him and if she makes a mistake.
} 
arm reported improvements. For example, boys from the intervention were more likely than those from the control arm to perceive that they had become better informed (90\% versus $70 \%)$ and more gender sensitive $(66 \%$ versus $35 \%$ ), that they exhibited greater self-efficacy than earlier (78\% versus $54 \%$ were more likely to speak up when they disagreed with somebody), that they had gained sports skills (70\% versus 53\%), and that they had a larger peer network than earlier (68\% versus 57\%). Many boys (58\%) in the intervention arm reported, moreover, that their family and friends had noticed the changes that had taken place in them over the course of the year.

In in-depth interviews, moreover, boys described other ways in which the intervention had changed their behaviour. For example, while large numbers of boys reported at the baseline in-depth interview that they rarely helped in household chores, many more described by the time of the endline in-depth interview that they were doing so or doing so more regularly.

\section{Potential for models relying on peer mentors}

Findings also add to the evidence about the feasibility and effectiveness of programmes for youth employing the peer mentor approach. While many studies report mixed and inconsistent results, the Do Kadam programme experience was positive. It showed that peer mentors did take on leadership roles, and that club members did indeed accept their leadership, perceive them as mentors and take the messages they transmitted seriously. Even so, we recognised that peer mentors often lacked confidence and communication skills, and were uncomfortable conveying sensitive messages (such as, for example, sexual violence). Our model incorporated two activities to overcome these challenges: repeated capacity building workshops for peer mentors on the one hand, and the inclusion of an adult mentor (in the form of the core trainer and the coach) who attended sessions and supported the peer mentor in delivering the gender transformative life skills education programme, and the spirit of fair play.

\section{Lessons for scaling up}

The Do Kadam Barabari Ki Ore project has proven to be feasible to implement, acceptable to young people and effective in engendering boys' attitudes and commitment to reducing violence against women and girls. This success was achieved notwithstanding many potentially insurmountable challenges. These included, most notably a setting characterised by deeply entrenched inegalitarian gender norms, a sense of entitlement among boys to control the women in their life and to perpetrate violence on them, as well as a weak and poorly-resourced platform, namely NYKS clubs on which to layer the Do Kadam programme. The success of the model, given these challenges, is all the more encouraging, and the programme holds great promise for replication in and upscaling to other parts of the district or state.

While the NYKS offered an appropriate platform for the Do Kadam programme, it represents, by no means, the only platform for housing an upscaled programme. Indeed, the Do Kadam programme is flexible enough to be incorporated within any programme that has potential for the formation of boys' group. The RKSK platform, with its emphasis on peer mentors, offers one such opportunity.

Several questions arise from our experience that must be addressed while replicating or up-scaling the Do Kadam programme. For one, efforts are needed to determine the ideal length of an upscaled intervention: 42 sessions may be too short to change behaviours in a sustainable way, and many boys themselves suggested the need for a longer duration intervention.

Second, our findings have confirmed that the intervention had little effect on those who attended irregularly, that is, those who attended fewer than half of the gender transformative life skills sessions and cricket sessions. Findings reiterate the importance of regular attendance, and they call for measures that accommodate work- and educationrelated time commitments of boys, are responsive to their own preferences about intervention activities during each session, and ensure that sessions are interactive and fun.

Third, programme designs are needed that offer gender transformative life skills exposure that take into consideration boys' own preferences with regard to other components. Our programme was designed keeping in mind the interest that boys had expressed in a cricket-coaching component. However, in other settings, boys may express interest in other sports and even components other than sports, such as livelihood skill building or training in English language and/or computer skills. It is important therefore to engage with club leadership at the district level to arrive at a mutually acceptable intervention design prior to initiating the intervention.

Fourth, our findings have suggested the need to invest in peer mentor capacity-building on a regular basis. While the peer mentor model is ideal in many ways to encourage behaviour change, in our programme, it required extensive efforts to change the norms held by peer mentors and build their capacity and confidence about imparting 
the programme. An upscaled programme would need to invest in pre-intervention and regular refresher training programmes for peer leaders as well as supportive supervision of intervention progress.

Fifth, the NYKS membership in general tends to include young adults rather than adolescents, and it is critical that membership drives are undertaken prior to the introduction of programmes, such as the Do Kadam Barabari Ki Ore programme, that will encourage young people to become members of NYKS clubs.

Finally, we note that while the NYKS structure is an ideal home for an upscaled Do Kadam programme, activities will require committed human and financial resources that the NYKS structure, in its current form, may not possess. Other platforms need to be identified, and their potential for housing the Do Kadam programme investigated.

The RKSK platform, with its emphasis on peer mentors whose role is to raise awareness, build gender egalitarian norms and attitudes, and enable informed and empowered decision making among adolescents, offers one such opportunity.

The NYKS youth club structure is ideal for engaging boys to foster social change at scale; the goal of the NYKS is to build leadership skills and citizenship values among the young, and the Do Kadam intervention works directly to achieve these goals. Our model has demonstrated a considerable impact on changing traditional norms and attitudes, building leadership skills and citizenship values, and laying the groundwork for a reduction in the perpetration of violence against women and girls. Findings point to the promise of the Do Kadam approach of combining gender transformative life skills education and sports coaching as a pathway toward engendering norms and behaviours among boys and young men in disadvantaged rural settings in Bihar. They also suggest that the programme is flexible and may be implemented successfully within programmes aside from NYKS clubs, such as, for example, the RKSK model and other peer-led and group forums. 


\section{Chapter 1 Introduction}

Gender hierarchical socialisation practices in India have resulted in the emergence of attitudes and practices espousing male entitlement and female submissiveness, which are evident even among girls and boys in early adolescence (Santhya et al., 2013). By the time they reach later adolescence and young adulthood, these hierarchical and gender stratified attitudes to gender roles are firmly established, and this is indicated, in particular, by the large proportions of young women and men who express attitudes justifying violence against women and girls (International Institute for Population Sciences [IIPS] and Population Council, 2010; Jejeebhoy and Acharya, 2014). Bihar is amongst the states having the widest gender-based disparities in the country (IIPS and Population Council, 2009; 2010). Indeed, among those in the ages 15-24 in Bihar, 44 percent of young men and 58 percent of young women justified marital violence in at least one situation. Moreover, among married young women in rural areas of Bihar, 26 percent had experienced physical violence and 35 percent had experienced sexual violence, and 26 percent of married young men reported perpetrating physical violence on their wife (just $10 \%$ reported perpetrating sexual violence on her). Further, among young women who had engaged in premarital sex, about one-fourth reported a forced sexual encounter (IIPS and Population Council, 2009).

The importance of changing the attitudes and behaviours of the young-especially young boys-from an early age has been widely acknowledged (Fulu, et al., 2013). Several programmes have been launched by the government, such as the Adolescence Education Programme (AEP), the Sabla programme for adolescent girls (Rajiv Gandhi Scheme for Empowerment of Adolescent Girls), and, more recently, the Rashtriya Kishor Swasthya Karyakram (RKSK, the National Adolescent Health Programme) (Ministry of Health and Family Welfare [MOHFW], 2014), that aim to build young people's life skills, empower girls, and enable the young to access health-promoting information and services. Non-governmental organisations (NGOs) also conduct programmes for adolescents and young people that aim to build life skills and change gender role attitudes. Laws and policies have been made that focus on eliminating violence against women and girls, such as the Protection of Women from Domestic Violence Act (DV), 2005, and the Protection of Children from Sexual Offences Act (POCSO), 2012. However, evidence on what is effective or not in changing notions of masculinity among the young and in reducing the perpetration of gender-based violence by boys remains limited in India.

In order to fill this gap, the Population Council, together with partners, the Centre for Catalysing Change (C3) and the London School of Hygiene and Tropical Medicine, and with support from UKaid, implemented the Do Kadam Barabari Ki Ore project (Two Steps Towards Equality) in rural areas of Patna district. The project sought to promote among adolescent boys and young men, who were members of youth clubs falling under the Nehru Yuvak Kendra Sangathan (NYKS), egalitarian gender attitudes and abhorrence of violence against women and girls (VAWG). ${ }^{5}$ The Population Council then evaluated the acceptability and effectiveness of the intervention. This report describes the Do Kadam Barabari Ki Ore project and its implementation and examines the extent to which it transformed gender role attitudes of boys and, particularly, instilled in them an abhorrence of violence against women and girls.

\section{Objective}

The objective of the evaluation was to measure the impact of the Do Kadam Barabari Ki Ore project in changing, among boys in ages 13-21 years, gender role attitudes, attitudes toward violence against women and girls, and controlling behaviours over sisters, girlfriends, and wives and, secondarily, in reducing the perpetration of various forms of violence against women and girls. In addition, it sought to assess the feasibility and acceptability of the intervention.

\section{Background and rationale}

The importance of working with men and boys to transform traditional gender norms and notions of masculinity and femininity has been expressed repeatedly in the global literature (World Health Organisation [WHO], 2007; Men Engage Global Symposium, 2014; United Nations Population Fund [UNFPA], 2016). There is also evidence of an association between men's espousal of equitable gender norms and rejection of social expectations of hierarchical

\footnotetext{
${ }^{5}$ The Do Kadam Barabari Ki Ore programme entailed, aside from this project, the development and evaluation of a number of other interventions for the prevention of violence against women and girls in Bihar and incorporated evidence-based best practices from India and globally. The projects that were included focused on changing attitudes and practices at the community level through targeting women of self-help groups (SHGs) and their husbands, locally elected representatives (Panchayati Raj Institution [PRI] members), and frontline health workers.
} 
relations between men and women and rejection of the use of violence against women (Pulerwitz and Barker, 2008). The need to engage boys and young men in and introduce them from an early age to gender transformative programmes is evident from the findings of the recent multi-country study of men and violence, which observed that violent men had begun to perpetrate violence in adolescence: indeed, half of those who had perpetrated sexual violence on a woman had committed such acts while in adolescence (Fulu, et al., 2013).

There are a number of well-documented recent interventions that have aimed to change gendered norms among boys and young men. These interventions have been implemented in varying settings, including schools, clubs and other institutions, sports teams, and workplaces. Many were pioneered abroad but have been adapted and replicated in India. Among the best known are the Stepping Stones intervention implemented in South Africa as well as in Karnataka in India and Programme $\mathrm{H}$ implemented in Brazil as well as in India and Tanzania. Both interventions used participatory learning approaches, were group-based, encouraged boys and young men to question traditional views on masculinity, and aimed to change traditional notions of masculinity and femininity as well as such behaviours as men's perpetration of violence against women. Findings of both interventions suggested that exposure to these gender transformative programmes did indeed result in a change in attitudes, improved relationships with friends and partners, and a reduction in the perpetration of physical and sexual violence (Jewkes et al., 2006; Jewkes et al., 2008). The Gender Equity Movement in Schools in South Asia and Vietnam was implemented in India (Achyut, et al., 2011), and, particularly noteworthy from the perspective of our intervention, the Parivartan progamme (Coaching Boys Into Men) was also implemented. The Parivartan programme was conducted among school-going boys in Mumbai and incorporates a gender transformative curriculum in a format that has appeal for adolescent boys generally, namely, sports-coaching. The intervention programme aimed to reduce violence against women and girls and foster norms espousing gender equality, using coaches and mentors as change agents; results suggest that the year-long intervention significantly reduced the perpetration of violence against girls by boys and resulted in adherence to gender egalitarian attitudes and attitudes denouncing gender-based violence (Das et al., 2012).

Another opportunity that can be used to reach boys is through the platform of youth clubs established widely across India under the Nehru Yuvak Kendra Sangathan (NYKS) and sponsored by the Ministry of Youth Affairs and Sports. Under this programme, youth clubs are established at the village level and are open to all those in the ages 13-35. The objective of youth clubs is to offer young people leadership development opportunities through a range of activities intended to raise awareness among youth, encourage participation in sports, build leadership skills and a sense of citizenship, and engage youth in community development activities. Youth clubs can be found in every state of the country and receive nominal financial support from the NYKS (www.nyks.org). According to its most recent annual report (2010-11), there was a total of more than one lakh functional clubs located in more than half of the villages of India; a 2010 survey reported a total of 37 lakh club members. Although not so mandated, the large majority of youth club members are boys and young men: the 2010 survey suggests that there was a total of 27 lakh male members and just 10 lakh female members (Government of India, Ministry of Youth Affairs and Sports, NYKS, n.d.).

\section{Study setting}

Our study was conducted in the state of Bihar. Bihar is the third largest state in the country and has a population of 104.1 million, constituting nine percent of India's population (in 2011). In Bihar, 17 percent of the population belong to the socially disadvantaged scheduled castes (SC) and scheduled tribes (STs) (Office of the Registrar General and Census Commissioner, India, 2013). It is one of the most poorly developed states in the country: 34 percent of the state's population was estimated to be living below the poverty line (Planning Commission, 2013), and a significant proportion of the population remains illiterate (for example, 52 percent of women were illiterate) (Office of Registrar General and Census Commissioner, 2013). Child marriage is more widespread in Bihar than in any other state in the country: 69 percent of 20-24 year old women were married before age 18, with 33 percent married below age 15, and 10 percent below age 13 in 2005-06 (IIPS and Macro International, 2007). Moreover, Bihar ranks highest among all states in India with regard to women's experience of violence within marriage: 56 percent of women reported the experience of marital violence (IIPS and Macro International, 2007). Norms justifying partner violence are strongly held by both men and women in Bihar-57 percent of women and men alike justified wife beating (IIPS and Macro International, 2007). ${ }^{6}$

Young people in Bihar hold norms that condone violence against women and girls, and the perpetration and experience of violence is also evident among them. As many as 20 percent of young men and women in Bihar had

\footnotetext{
${ }^{6}$ Findings from the NFHS-4 suggest that the percentage of women reporting marriage prior to age 18 had declined to 39 percent, and the experience of spousal violence had declined to 45 percent by 2015 (IIPS, 2016), steep declines that require further investigation.
} 
witnessed their father beating their mother, and 55 percent and 11 percent, respectively, had experienced violence perpetrated by a parent. Attitudes of the young continue to justify violence against women and girls: indeed, 44 percent of young men and 58 percent of young women agreed that women should be beaten in some circumstances. As described earlier, large proportions of young women reported marital violence, both physical and sexual, and a forced sexual encounter was reported by one-fourth of women who had engaged in premarital sex.

Our intervention was based in Patna district, the district housing the state capital, and in which there exists a total of 102 NYKS clubs. Table 1.1 presents a comparative profile of socio-demographic indicators in Patna district as compared with Bihar state as a whole. Patna district has six percent of the state's population, and given that it houses the state capital, it is far less rural than the state as a whole. A somewhat larger proportion of the population of Patna compared with Bihar as a whole is Hindu (92\% versus 83\%), although percentages belonging to socially disadvantaged castes and religions are similar (16-17\%). With regard to socio-demographic indicators, Patna district is clearly better off than the state as a whole. Literacy rates are higher among both men and women in Patna district than in the state as a whole. Fertility and infant mortality rates are far lower in Patna than in Bihar. Of note, however, is that, the sex ratio of the population and the child sex ratio are somewhat more adverse in Patna district than in the state as a whole. Marriage continues to take place in childhood for considerable percentages of girls and boys in both Patna district and Bihar state: 11-12 percent of girls in both were married and as many as 36 percent of married girls in ages 15-19 in Patna were already mothers, a somewhat larger proportion than in Bihar as a whole (30\%) in 2011.

Table 1.1: Selected socio-demographic indicators, Bihar state and Patna district

\begin{tabular}{|c|c|c|}
\hline & Bihar & Patna district \\
\hline Population ${ }^{1}$ & $104,099,452$ & $5,838,465$ \\
\hline Rural $^{1}$ & 88.7 & 56.9 \\
\hline Scheduled castes and tribes ${ }^{1}$ & 17.2 & 15.9 \\
\hline Hindu $^{2}$ & 82.7 & 91.7 \\
\hline Muslim² & 16.9 & 7.5 \\
\hline Male literacy ${ }^{1}$ & 71.2 & 78.5 \\
\hline Female literacy ${ }^{1}$ & 51.5 & 62.0 \\
\hline Overall sex ratio $(\mathrm{F} / \mathrm{M})^{1}$ & 918 & 897 \\
\hline Child sex ratio $(0-6$ years $)(F / M)^{1}$ & 935 & 909 \\
\hline Total fertility rate, $2012-13^{3}$ & 3.5 & 2.6 \\
\hline Infant mortality rate, $2012-13^{3}$ & 48 & 31 \\
\hline $15-21$-year-old boys who were ever married ${ }^{4}$ & 11.8 & 11.2 \\
\hline 15-17-year-old girls who were ever married ${ }^{4}$ & 11.6 & 11.2 \\
\hline 15-19-year-old married girls who were already mothers ${ }^{5}$ & 29.7 & 35.8 \\
\hline
\end{tabular}

Sources: ${ }^{1}$ Directorate of Census Operations, Bihar, 2014; ${ }^{2}$ Office of the Registrar General and Census Commissioner, 2015a, ${ }^{3} \mathrm{Ibid}$., n.d, ${ }^{4}$ Ibid., 2015b, ${ }^{5}$ Ibid., $2015 c$.

\section{Intervention}

The Do Kadam intervention focused on promoting egalitarian gender attitudes and abhorrence of violence against women and girls through gender transformative life skills education combined with cricket-coaching. The intervention drew on previous successful programmes conducted among boys, notably, the Parivartan programme among schoolgoing boys in Mumbai implemented by the International Center for Research on Women (ICRW) (ICRW, n.d. http:// www.icrw.org/where-we-work/parivartan-coaching-boys-men). This programme demonstrated that an intervention that combined gender transformative education sessions with cricket-coaching among school-going boys was effective in changing gender role attitudes of boys and that combining cricket-coaching with classroom sessions succeeded in sustaining their interest in the programme. We adapted key ideas from this intervention to suit the implementation of Do Kadam at the community level among boys in youth clubs in rural Bihar.

The Do Kadam programme was implemented among 13-21 year old boys who were members of 15 youth clubs supported by the NYKS programme of the Ministry of Youth Affairs and Sports. As mentioned earlier, although both 
boys and girls are eligible for membership in youth clubs, few girls are members of youth clubs, and in the selected clubs, not a single girl was a member. Each club contained 30-40 members, on average, in ages 13-21, and all members were invited to participate. The intervention was delivered over 42 weekly sessions, with one hour each week devoted to the gender transformative life skills education component and one hour to cricket-coaching. The intervention was delivered over 18 months, with sessions suspended during examinations and festivals. Gender transformative life skills sessions addressed such issues as gender roles and attitudes, forms of violence against women and girls, respectful behaviour towards women, and positive masculinities. Participatory methodologies were used, with role playing and discussion on case studies. Two members with leadership skills from each club were identified and trained to serve as peer mentors. They were responsible for imparting the gender transformative life skills education programme and engaging members in weekly cricket-coaching sessions. A team of core trainers and cricket coaches oversaw the programme implemented by these peer mentors. Over the course of the intervention, boys held periodic community events intended to build gender egalitarian attitudes at community level. The programme was conducted with inputs from the NYKS authorities, Department of Youth Affairs, Sports and Culture in the Government of Bihar. The intervention is discussed in greater length in Chapter 3.

Progress of the intervention was monitored through regular field visits and process documentation reports made by $\mathrm{C} 3$ and Population Council project implementers. There were also monthly monitoring reports that recorded attendance of the boys at gender transformative life skills sessions, at cricket sessions, and at community events.

\section{Study design}

A mixed method design was used to evaluate the Do Kadam programme. It included a cluster randomised trial (CRT) with panel surveys of study participants at baseline (before the intervention was initiated) and endline (after the intervention was completed). It included in-depth interviews with selected club members in the intervention arm at three points in the intervention-before, during, and at the conclusion of the intervention. The endline survey was initiated after an average of two months following the conclusion of the intervention, with the shortest gap of one month for one club in which activities had been delayed.

Randomised trials are preferred over non-randomised trials for evaluating the impact of the intervention, because a true randomisation of subjects into treatment groups takes care of any biases and nullifies any association between the intervention and outcomes that are due to any factors other than the intervention and thus makes it possible to separate out the true effect of the programme on the intervention group. Two types of randomisation are availablerandomising individuals within a community into different treatment arms or randomising communities into different treatment arms. Since the Do Kadam intervention was targeted at the club level rather than at the individual level, it made more sense to randomise at the cluster level (club level) rather than at the individual level. The intervention was targeted at club level also because it was logistically easier to implement a programme at the club level than at the individual level.

\section{Determining number of study clubs}

In our cluster randomised trial to evaluate the Do Kadam programme for boys, a cluster was defined as a functional youth club organised by NYKS (typically there is only one youth club in a village irrespective of its size).

The main outcome of the intervention was the attitudes of boys about violence against women and girls, and, more specifically, the proportion of boys in the ages 13-21 who condoned violence against women and girls. In calculating the required number of clubs per treatment arm, we made a set of assumptions. First, we assumed that the intervention would reduce the proportion of boys in the ages 13-21 who condoned violence against women and girls by at least 20 percent; we used estimates available from the National Family Health Survey-3 on boys in the ages 15-19 who condoned violence against women and girls, which stood at 52 percent in 2005-06, for calculating the required number of clubs (IIPS and Macro International, 2007). Second, we assumed an intra-cluster correlation of 0.05 (or between-cluster coefficient of variation, $k, 0.21$ given the baseline value of the outcome-52\%) and an average cluster size of 10 boys per club. Based on these assumptions, calculation of the number of clubs per treatment arm was performed by using the following formula:

$$
c=1+\left(z_{\alpha / 2}+z_{\beta}\right)^{2} \frac{\pi_{0}\left(1-\pi_{0}\right) / m+\pi_{1}\left(1-\pi_{1}\right) / m+k^{2}\left(\pi_{0}^{2}+\pi_{1}^{2}\right)}{\left(\pi_{0}-\pi_{1}\right)^{2}}
$$

where $c$ is the required number of clubs per arm; $\pi_{0}$ and $\pi_{1}$ are the levels of the outcome indicators, namely, the proportion condoning violence against women and girls before and after exposure to the intervention, respectively; 
$m$ is the average club size and $k$ is the between-club coefficient of variation. Further, we assumed 80 percent power and a 95 percent confidence interval for our main outcome indicator. Thus, using the formula above, we estimated that we would require a minimum of 15 clubs and a sample of 150 member boys in the ages 13-21 per treatment arm. We further assumed a 15 percent non-response and 30 percent loss to follow-up at the endline survey, giving us the minimum of 225 target boys per treatment arm. However, while in the field for data collection, we found that there were far more members in each club than we had assumed, and, as a result, we ended up interviewing 1,149 boys in ages 13-21 from 30 clubs. This increased sample size will allow us to measure programme impact with greater statistical power than the assumed 80 percent and, at the same time, to measure impact even if the change in attitudes over time is less than the assumed 20 percent.

\section{Choosing study clubs}

In Patna district, at the time we were designing the study, there were 102 NYKS clubs distributed across nine blocks, of which 42 were considered eligible for selection into the study. Reasons for excluding the remaining 60 clubs were varied: the club was non-functional, all members were aged above our study age group of 13-21 years, there were too few members to form a cluster, the club contained only female members, the club was located in an urban area, or the village in which the club was located shared a boundary with another village containing an eligible club. After this initial selection of 42 clubs, further selection of 30 clubs was made in such a way that each club was at least 1.5-2.0 kilometres away from any other club. This further minimised the possibility of spillover.

\section{Randomisation of clubs}

The next step was to randomly allocate each of these 30 selected clubs into one of two treatment groups. As such, there were ${ }^{30} \mathrm{C}_{15}$ or $155,117,520$ possible "allocations" (that is, combinations of the 30 clubs into two equal groups), of which one would be selected randomly. In cluster randomised trials that have small numbers of clusters, it is also important to achieve a balance between the two treatment arms in terms of the outcome of the trial or factors that affect the outcome. A way to achieve such balance is a scheme known as "restricted randomization", which entails restricting the number of possible allocations to a smaller set fulfilling certain pre-determined criteria (Hayes and Moulton, 2009). Typically, restricted randomisation uses cluster-level baseline data or any other available data to achieve balance between the treatment arms.

The village-level female literacy rate, as reported in the 2011 census (Directorate of Census Operations, Bihar, 2014) and baseline survey data from all 30 clubs were used for restricted randomisation. Post-baseline, analysis was conducted to identify the most important factors that explained the variation in club members' attitudes towards violence against women and girls. From the baseline survey data, the following variables were used for restricted randomisation-the number of members in the ages 13-21 in the club, their mean number of years of education, mean standard of living index, percent who had witnessed violence at home during childhood, percent reporting that men in their community justify wife beating in at least one situation, percent reporting that their friends condone violence against women and girls in at least one situation, and percent who watch pornography. As such, we stipulated that a particular allocation of clubs between intervention and control arms would be balanced if the conditions described in Table 1.2 were met.

Table 1.2: Balancing conditions for allocating clubs between intervention and control arms

\begin{tabular}{lc}
\hline Indicators & $\begin{array}{c}\text { Difference between } \\
\text { the two arms does } \\
\text { not exceed }\end{array}$ \\
\hline $\begin{array}{l}\text { Percent females literate at the village level } \\
\text { Total number of NYKS club members }\end{array}$ & 2 \\
Mean number of years of schooling of the club members & 1 \\
Mean score on standard of living index of the club members (point) & 1 \\
Percent of club members who had witnessed violence at home during childhood & 1 \\
Percent of club members reporting that men in their community justify wife beating in at least & 1 \\
$\quad$ one situation & 1 \\
Percent of club members reporting that their friends condone violence against women and girls & 1 \\
Percent of club members exposed to pornography & 1 \\
\hline
\end{tabular}


We used a computer program to randomly select 100,000 allocations from the $155,117,520$ possible allocations discussed above. Each of these 100,000 allocations was then assessed against the above-mentioned criteria for balance between the two treatment arms. We excluded 72,260 allocations that did not meet all of the abovementioned criteria and retained the remaining 27,740 acceptable allocations for possible selection. We then confirmed the validity of the design by means of a validity matrix whose elements were the number of times each pair of clusters (clubs) was allocated to the same arm (intervention or control). The restricted randomisation process would be invalid if any of the pairs was "always" or "never" allocated to one particular arm (Moulton, 2004). In our restricted randomisation scheme, we found that each of the possible pairs of clubs had about 50 percent probability of being allocated in the intervention or control group, confirming the validity of the randomisation scheme adopted. Next, from the remaining 27,740 allocations, we randomly selected 1,000 allocations (serially numbered from 000 to 999) for the purpose of the public randomisation event.

A public randomisation event was held in Patna, in which representatives of each of the 30 clubs, the zonal director of the NYKS programme, and the programme implementation teams were present. The study team explained the purpose of the randomisation event and acknowledged that as a result of the proceedings, some clubs would receive the intervention and some would not.

The final selection was a two-step procedure. In the first step, a three-digit number was selected, which indicated the serial number of the selected allocation from the list of 1,000 allocations. For this, we invited three club members from the audience to draw a random number between 0 and 9 each, which together gave us the serial number of the selected allocation. In the second step, a random selection was made to determine which of the two treatment arms would receive the intervention. For this, we labelled the two groups, each with 15 clubs, of the selected allocation as $A$ and $B$ and invited one club member to make the selection: to do so, he picked one of two cards placed in a bowl; if he picked a card marked $A$, the group designated "A" would be assigned to the intervention arm (and the group designated "B" would become the control arm) and vice-versa.

As will be seen in later chapters, the randomisation scheme we used was successful in achieving overall balance between the intervention and control arms in terms of most covariates and outcomes of interest to our study.

\section{Baseline and endline surveys}

As mentioned earlier, a panel design was employed, with surveys conducted before launching the intervention (baseline) and at its completion (endline) in intervention and control arms. In the baseline survey conducted during May-July 2013, we interviewed 1,149 boys in ages 13-21 from 30 clubs. While the baseline respondents in the intervention clubs participated in the intervention (Do Kadam) after the baseline survey, those in control clubs had no such exposure. In order to minimise loss to follow-up at the time of the endline survey, we undertook a tracking exercise in the control arm during the period between the baseline and endline surveys to follow-up baseline respondents and obtain the whereabouts of those who may have moved away.

Our endline assessment consisted of a follow-up survey of boys who had participated in the baseline survey (now in ages 14-23) and was conducted in January-March 2015, following the completion of the 18-month intervention (completed in December 2014). During the endline survey, research assistants visited each household containing a baseline respondent. They used addresses collected the time of baseline survey and during the tracking exercise of boys in control clubs in order to contact all baseline respondents. Efforts were made to interview baseline respondents irrespective of whether they were living in the project site or elsewhere, including outside the study district.

Statistical analyses of the intervention effect were performed using Stata 13. Effect estimates were computed as the difference in club-level proportions or means, as appropriate. Analysis was by intention to treat. We compared unadjusted cluster-level summary measures across arms using an unpaired $t$-test for the main outcomes. For outcomes that showed evidence of an intervention effect, we applied a t-test with unequal variances to check whether precision improved (see Chapter 5 for more details).

\section{Qualitative component}

A longitudinal qualitative assessment of programme effect was also made using in-depth interviews with boys from intervention clubs at three points in time-before beginning the intervention, about 6-7 months after rolling out the intervention, and after the intervention was over. At baseline, we selected 32 boys on the basis of their responses in the baseline survey and interviewed them in-depth; we selected a sample of boys who reported very gendered and somewhat gendered attitudes and who had reported the perpetration of physical violence as well as all boys 
who reported perpetration of sexual harassment or violence at baseline. We followed up with those who could be contacted and had consented for re-interview about halfway through the intervention (midline) and about the time of the endline survey.

\section{Study instruments}

Two study instruments were developed: a survey questionnaire (at baseline and endline) to gather information from boys in intervention and control youth clubs; and an in-depth interview guide to collect insights from selected boys at about the time of the baseline survey, midway through the intervention (midline), and at about the time of the endline survey. The baseline survey instrument focused on respondents' family background, their own sociodemographic characteristics, media exposure, friendship networks, and agency; it also assessed their knowledge about the Protection of Women from Domestic Violence (DV) Act and services for women who experience violence. In particular, the instrument focused on assessing their attitudes, including gender role attitudes, notions of masculinity, attitudes about the right of men and boys to control women and girls; and attitudes about men's and boy's right to perpetrate violence against women and girls. With regard to behaviours, the study instrument assessed boys' perpetration of gender-based violence, including both non-contact behaviours, such as verbal comments, whistling at girls, and so on, and contact behaviours, including unwanted touch, attempted rape, and rape or forced sex as well as substance misuse. Additionally, recognising the reluctance of study participants to disclose perpetration of violence against girls in a survey situation, at the conclusion of the interview, all respondents were asked three questions-whether they had teased a girl, perpetrated physical violence on a girl, and forced a girl to engage in sexual relations-and then they were asked to mark three blank cards with a " $\sqrt{ }$ " or a "X" as applicable for each of these questions, place the cards in an envelope, seal them and return them to the interviewer. Respondents were informed that the envelope would not be opened in the field and that only the principal investigators would be able to link the information provided in the envelope with what was provided in the main body of the questionnaire. Finally, we probed their participation in the youth club.

For the endline survey, we used an identical questionnaire except for an additional module that probed boys in intervention clubs about their participation in the Do Kadam programme and their assessment about its quality. The module contained questions on the extent to which respondents had been exposed to the activities of the programme, their experiences and perceptions about its acceptability and quality, and the extent to which they perceived that their participation in the programme had influenced their attitudes and behaviours in the period between the baseline and endline interviews.

The in-depth interview (IDI) guide for boys in intervention clubs included broad thematic areas to be covered and key questions that served as prompts under each broad theme. At baseline, the in-depth interview focused on the life experiences of the respondent, his relations and interaction with parents and family members, socialisation experiences, including performance of tasks traditionally assigned only to girls, perceptions of masculinity and femininity, gender role attitudes including those relating to control over and violence against women and girls, alcohol and substance use practices, and, finally, experience and perpetration of emotional, physical, and sexual violence and the circumstances in which the violence took place. At midline and endline interviews, many of these questions were repeated in order to explore the extent to which attitudes had become more gender egalitarian and behaviours modified. Additionally, we probed the perceptions of study participants about the intervention and the lessons, if any, they had learned from it, the perceived effectiveness and acceptability of the gender transformative life skills and cricket-coaching model, and whether exposure to it did indeed make their gender attitudes more egalitarian and enable them to condemn violence against women and girls. In-depth interviews were taped, transcribed, and translated into English.

All study instruments were prepared in English, translated into Hindi, pre-tested, and revised in light of the insights obtained during pre-testing.

\section{Recruitment, training, and fieldwork}

A total of eight young men underwent training for administering the baseline survey instrument to boys. These research assistants are graduates in science or social science streams, are proficient in Hindi, and have at least 3-4 years of experience in conducting field-based studies. The training team monitored each trainee's progress on a regular basis and selected as interviewers only those trainees who demonstrated a full understanding of the questionnaire as well as the ability to ask questions appropriately and record responses accurately. All eight trainees were selected to administer the baseline survey and seven of them also administered the endline survey. Training, conducted by Population Council staff members, with input from C3 staff, focused on interviewing methods, the details of the questionnaire, and research ethics including issues of confidentiality and privacy. Training lasted seven 
days and five days, for the baseline and endline survey, respectively, and comprised a combination of classroom sessions, mock interviews, and field practice. Interviewers were also familiarised with computers, and in particular, the computer-assisted personal interviewing (CAPI) technique that was used to collect data for this study.

Interviewers were divided into two teams to conduct the fieldwork. Each team had one supervisor who was responsible for quality control of interviews as well as for the overall management of fieldwork and team-related logistics. A field coordinator supervised the fieldwork.

Principal investigators and the field coordinator made frequent visits to monitor and supervise data collection operations and provided on-going supervision and support to the interviewers.

\section{Ethical considerations}

We recognised that boys may fear adverse repercussions if they disclosed experiences of perpetrating violence. To allay these fears, we assured respondents that all the data gathered were entirely anonymous and that the interviewers would not share their responses with anyone, including their family members, other club members, or the authorities.

Maintenance of privacy and confidentiality was stressed. Interviewer training emphasised the respondent's right to refuse to participate or answer any question and to give informed consent. We also trained interviewers on how to ask sensitive questions regarding violence and alcohol abuse in empathetic and non-judgemental ways and emphasised the importance of offering to refer those in need to appropriate nearby organisations. In addition, before entering a village containing a youth club and initiating fieldwork, interviewer teams were instructed to acquaint community leaders and club leaders with the study as well as with the intervention and seek their support. This step ensured that community support was forthcoming and enabled team members to build rapport within the community easily. We note that despite the sensitive nature of the questions, not a single club refused permission to our teams on the grounds of study content.

Every effort was made to maintain privacy in the course of the interview and to ensure that interviews were not overheard by family members or others. Interviewers, therefore, conducted the interview in a separate room in the respondent's home, or at the club premises, or any other place that the boys suggested would provide privacy. Interviewers were permitted to skip to relatively non-sensitive sections in case the interview was observed by others. Finally, the interviewers were instructed that if privacy could not be ensured, the interview must be terminated without asking sensitive questions.

All the questionnaires were anonymous and names were never recorded on them. In order to preserve the confidentiality of the respondent, signing the consent form was optional; however, the interviewer was required to sign on the consent form that he had explained the content of the consent form to the respondent. Consent forms were stored carefully. Finally, we also recognised the need for responding appropriately to requests from respondents for help or information related to violence and help-seeking options. Our field staff members were trained and equipped to refer such requests to local NGOs or concerned government authorities in the selected blocks as appropriate.

The Population Council's Institutional Review Board approved the protocol for this study.

\section{Response rates}

A total of 1,316 unmarried boys in the ages 13-21 who were listed as members of the selected clubs were invited for interview at baseline, and 1,149 or 87 percent of these boys were successfully interviewed (see Figure 1.1). The remaining boys could not be interviewed, as they were not available in the village (even after making three visits), expressed their lack of interest in joining the programme, or refused to participate in the survey. At the time of the endline survey, 90 percent of baseline respondents were successfully interviewed.

Reasons for loss to follow-up are presented in Table 1.3 and show that the leading reason was that the respondent had migrated out of the district or state on his own or along with his family (73-75\% of all boys who were lost to follow-up), followed by refusal by the respondent or his parents (14-16\%). Notably, five boys had died in the intervening period; in addition seven boys could not be tracked or reached at home even after three attempts.

With regard to repeated in-depth interviews, as mentioned earlier, we interviewed 32 boys on the basis of their responses in the baseline survey and made efforts to follow them up and re-interview them midway through the intervention (midline) and at the time of the endline survey. In all, we were able to follow up 28 of the 32 boys at midline, and 24 at the endline survey. Our findings therefore draw on the insights of all 32 boys, but focus on the 24 boys for whom we have information at endline as well as at baseline and midline. 
Table 1.3: Follow-up rate at endline and reasons for loss to follow-up, by treatment arm

\begin{tabular}{lcc}
\hline & Intervention & Control \\
\hline Boys interviewed at baseline & 583 & 566 \\
Boys interviewed at endline & 516 & 517 \\
Follow-up rate at endline (\%) & 88.5 & 91.3 \\
Reasons for loss to follow-up at endline & 2 & 10 \\
Not at home/hostel & 1 & 7 \\
Respondent refused & 1 & 0 \\
Respondent's parents refused & 2 & 2 \\
Respondent not tracked & 3 & 2 \\
Respondent died in the previous year & 49 & $\mathbf{3}$ \\
Respondent/Family migrated outside the study district/ state & $\mathbf{6 7}$ & $\mathbf{4 9}$ \\
Total lost to follow-up at endline & & \\
\hline
\end{tabular}

Figure 1.1: Flow diagram of the number of eligible club members, number of boys assigned to treatment arms, and number of boys lost to follow-up

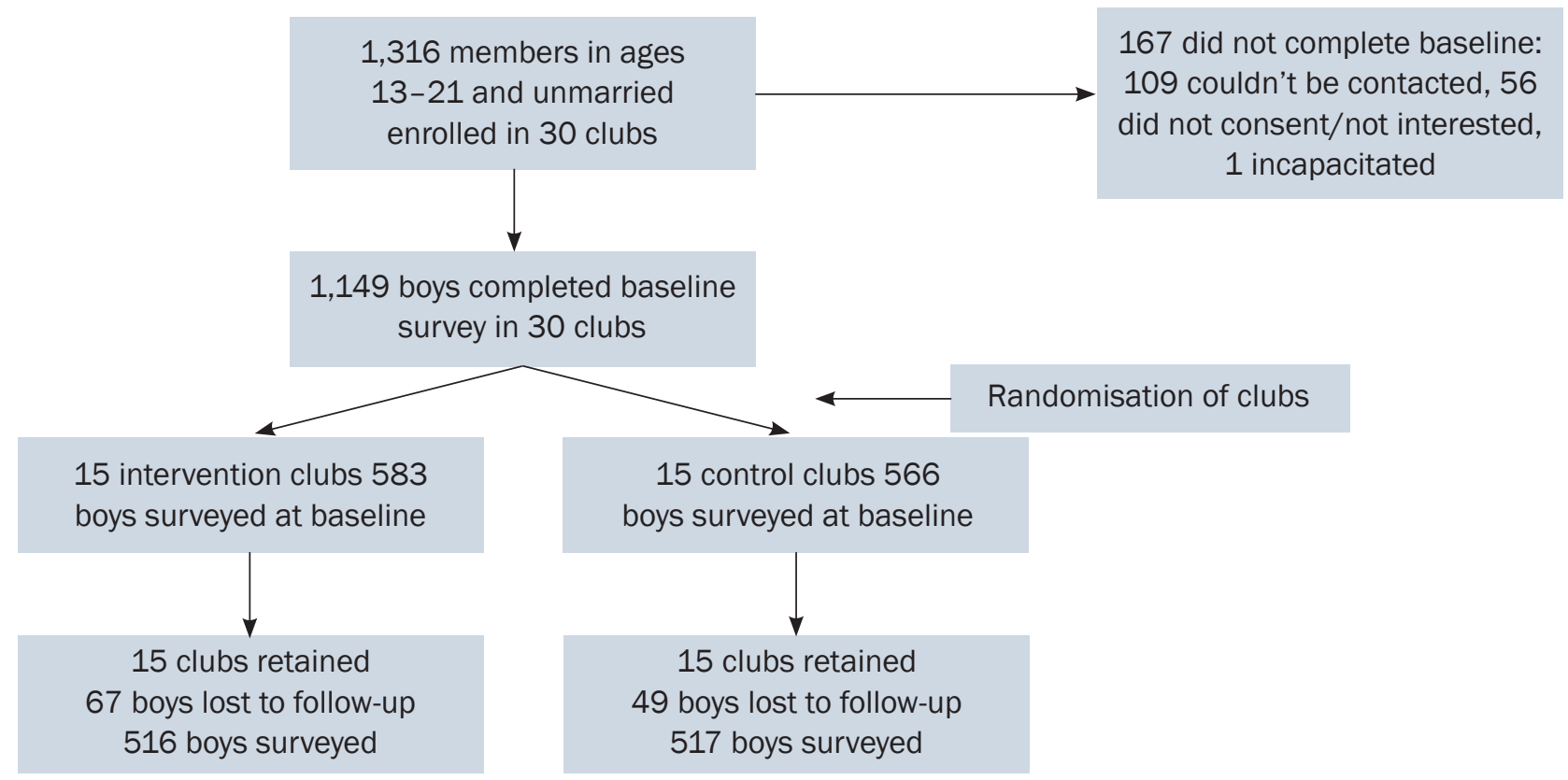

\section{Structure of the report}

The report is divided into seven chapters, including this introductory chapter. In Chapter 2, we present a sociodemographic profile of boys along with an assessment of their gender role attitudes, violence-related attitudes and behaviours, and participation in youth club activities as reported in the baseline survey. Chapter 3 describes the objectives and the design of the intervention, the key components of the intervention, and the challenges faced in implementing the intervention; drawing from data used for monitoring the intervention, we also describe the exposure of boys to intervention activities. Drawing on survey data, Chapter 4 describes the participation of boys in the Do Kadam programme and their perceptions about the quality and usefulness of the programme. In Chapter 5 , we draw on survey findings with regard to the effect of the intervention in changing gender role attitudes, notions of masculinity, perceptions about controlling behaviours over women, and attitudes about the acceptability of and justification for violence against women and girls; the chapter also presents changes in boys' experience in intervening to stop incidents of violence they observe as well as their perpetration of non-contact and contact forms of violence against women and girls. Chapter 6 describes the changes that boys in intervention and control arms perceived in their own attitudes and practices over the six months preceding the endline interview and the perceived impact of the intervention, as revealed by the narratives of boys from the intervention arm who were interviewed in-depth about these issues at three points: before, during, and at the completion of the intervention. The final chapter (Chapter 7) summarises the main findings of the study and highlights lessons learnt for future programme and research implementation. 


\section{Chapter 2 \\ Profile of the life of boys in NYKS clubs}

Drawing on baseline survey data, this chapter provides a brief profile of the lives of boys in intervention and control arms prior to the start of the Do Kadam Barabari Ki Ore project. We start with a description of the context of the life of boys, notably, their socio-demographic characteristics and the extent of violence in their environments. We follow this by a discussion of the attitudes and behaviours our intervention aimed to modify. We assess their gender role attitudes, attitudes about masculinity and the right of men and boys to control women and girls, and attitudes towards violence against women and girls. We then assess their behaviours and actions on witnessing violence, and we explore their experiences of perpetration of violence by others and themselves.

As discussed in the previous chapter, all eligible club members in the ages 13-21 of the intervention clubs were invited to participate in the Do Kadam Barabari Ki Ore project. As membership in each club varied considerably, we observed fairly large variations in the size of the clusters-ranging from 19 members to 51 members, with a mean of 39.5 members per club and a standard deviation of 6.1. In order to account for the variations in club size, in this chapter we present the cluster summaries, calculated as the mean of all cluster-level means instead of individuallevel means.

\section{Background characteristics}

In this section, we discuss socio-demographic characteristics of the study participants and the extent to which their home and community environments are characterised by violence.

\section{Socio-demographic characteristics}

Table 2.1 presents a profile of boys who participated in the baseline survey. Findings show that background characteristics of boys enrolled in intervention and control arms were by and large similar, with the exception of differences in the proportion of Hindus and those from socially disadvantaged groups-SCs, STs, and other backward castes (OBCs). We note that since the clusters were allocated randomly into intervention and control arms, these differences were purely by chance.

Boys were aged, on average, 16 years, with about two out of five boys in ages 13-14 (37-39\%) and ages 15-17 (35-39\%), and somewhat fewer in the ages 18-21 (21-28\%).

Almost all study participants were Hindu: 100 percent in intervention clubs and 89 percent in control clubs. Most boys came from socially disadvantaged groups; while 70 percent of boys from intervention clubs belonged to SCs, STs, and OBCs, 85 percent of those from control clubs belonged to these caste groups.

On average, boys in both intervention and control arms had completed nine years of schooling. Less than one percent had never been to school. Most boys were pursuing their education and were in school or college at the time of the baseline interview (89-93\%).

Participation in paid economic activity was reported by relatively few boys in both control and intervention arms. Some 18-23 percent of boys had been engaged in paid work in the 12 months preceding the interview.

The economic status of the household was measured using an index composed of household asset data based on the ownership of selected durable goods, including means of transportation as well as access to a number of amenities. The wealth index was constructed by allocating scores to a household's reported assets or amenities, with a possible minimum value of zero and a maximum value of 56 (for details of the scores, see Appendix 1.1). The majority of boys came from households with low or average economic status (mean score of 23-25).

\section{Violence at home}

To better understand the extent to which violence pervaded the family life of boys, we explored whether they had witnessed their parents verbally or physically abusing each other, and whether they ever had been beaten by a parent since the age of 12 (Table 2.2). Findings suggest that two-thirds had observed their father verbally abusing their mother (65-68\%) and fewer had observed their mother verbally abusing their father (33-41\%). While more than one-fourth of boys had observed their father beating their mother (26-29\%), just 1-2 percent had observed their mother beating their father. Large proportions of boys, moreover, had themselves been beaten since the age of 12 by a parent $(49-59 \%)$. 
Table 2.1: Background characteristics of surveyed boys Percent distribution of surveyed boys by selected background characteristics, according to treatment arms, 2013 , baseline survey

\begin{tabular}{lcc}
\hline Background characteristics & Intervention & Control \\
\hline Age & & 39.3 \\
$13-14$ & 36.5 & 39.3 \\
$15-17$ & 35.2 & 21.3 \\
$18-21$ & 28.2 & 15.6 \\
Mean (years) & 15.9 & 88.9 \\
Religion & & \\
Hindu & 99.6 & 23.8 \\
Caste & & 61.5 \\
SCs or STs & 19.8 & 14.7 \\
OBCs & 50.5 & \\
General castes ${ }^{1}$ & 29.7 & 0.9 \\
Number of years of education & & 36.3 \\
None & 0.4 & 39.5 \\
1-8 years & 44.3 & 23.3 \\
9-10 years & 34.1 & 9.0 \\
Mean yere years of schooling & 21.2 & \\
Current schooling status & 8.7 & 93.4 \\
Currently studying in school/college & & \\
Engagement in economic activities & 89.0 & 17.8 \\
Engaged in paid work in the last 12 months & & \\
Household standard of living & 22.9 & $\mathbf{1 5}$ \\
Mean score, household wealth index (range 0-56) & & $\mathbf{5 6 6}$ \\
Number of clusters & 24.5 & $\mathbf{1 5}$ \\
Number of respondents & $\mathbf{5 8 3}$ & \\
\hline
\end{tabular}

Note: $\mathrm{SC}=$ scheduled caste; $\mathrm{ST}=$ scheduled tribe; $\mathrm{OBC}=$ other backward caste, ${ }^{1}$ Includes those who do not belong to SCs, STS, or OBCs.

Table 2.2: Violence at home

Percentage of boys witnessing domestic violence and experiencing physical abuse from a parent, by treatment arms, 2013, baseline survey

\begin{tabular}{lcc}
\hline Violence & Intervention & Control \\
\hline Witnessing verbal abuse & 67.5 & 61.1 \\
Respondent has seen his father shouting or threatening his mother & & 33.3 \\
Respondent has seen his mother shouting or threatening his father & 28.5 \\
Witnessing physical violence & 2.2 & 26.3 \\
Respondent has seen his father beating his mother & & 0.9 \\
Respondent has seen his mother beating his father & 58.7 \\
Experience of physical violence & $\mathbf{1 5}$ & $\mathbf{5 8 3}$ \\
Respondent has been beaten by parents since he was 12 years old & $\mathbf{1 5}$ \\
Number of clusters & $\mathbf{5 6 6}$ \\
Number of respondents & \\
\hline
\end{tabular}

\section{Violence in the community: Peer norms and practices with regard to the perpetration of violence} on girls

Similarly, in order to better understand the extent to which violence pervaded the social life of boys, we explored their perceptions about attitudes of their peers towards violence against women and girls and violence perpetrated by their peers and others in their community. Findings are mixed (Table 2.3). About three-fourths of boys believed that the majority of their peers would find it unacceptable to pressurise a girl to have sex if she refused their advances. 
Somewhat fewer-56-63 percent-believed that most of their peers would not approve of teasing or harassing girls. In contrast, just one-third (31-35\%) perceived that the majority of their peers believed that a girl who is raped had not provoked it by her behaviour or clothing. Their responses also brought out the influence of peer pressure. Fewer than one half-44-47 percent-believed that the majority of their peers would not make fun of them if they refused to take part in teasing or harassing girls.

A considerable number of boys had also recently witnessed the perpetration of various forms of violence on a woman or girl by a peer or someone else from their community over the six months preceding the baseline survey (Table 2.3). Large proportions of boys reported that they had witnessed someone passing dirty comments about a girl (53$56 \%)$, teasing a girl (32-37\%), and spreading sexual rumours about a girl (26-30\%). While fewer, a considerable proportion of boys reported that they had witnessed someone perpetrating unwanted touch on a girl (15-18\%) and, among those in ages 15-21, assaulting or molesting a girl (9-11\%) over the six months preceding the interview.

Table 2.3: Norms and practices relating to the perpetration of violence on girls Percentage of boys reporting perceptions about the attitudes of peers on violence against girls and observation of violent acts against girls by men or boys in the preceding six months, by treatment arms, 2013, baseline survey

\begin{tabular}{lcc}
\hline Attitudes of peers/practices of boys and men & Intervention & Control \\
\hline Peer attitudes on the perpetration of physical and sexual violence & & \\
Most friends believe that it is unacceptable to pressurise a girl to have & 73.9 & 72.5 \\
$\quad$ sex if she refuses their advances & 31.4 & 35.2 \\
Most friends believe that a girl who is raped has not provoked the & 55.7 & 62.6 \\
$\quad$ incident & & 46.9 \\
Most friends do not like to tease or harass girls & 43.7 & \\
Most friends would not make fun of respondent if he refused to join in & & 53.4 \\
$\quad$ teasing girls & 55.8 & 31.8 \\
Observation of violent acts committed on a woman or girl by a man or & 37.0 & 30.3 \\
$\quad$ a boy in the community in last $\mathbf{6}$ months & 26.1 & 15.0 \\
Making dirty comments about a girl & 17.5 & 10.5 \\
Teasing a girl & 8.8 & $\mathbf{1 5}$ \\
Spreading sexual rumours about a girl & $\mathbf{1 5}$ & $\mathbf{5 6 6}$ \\
Pushing/grabbing or shoving a woman or girl & $\mathbf{5 8 3}$ \\
Assaulting or abusing a girl sexually, or molesting her ${ }^{1}$ & \\
Number of clusters & & \\
Number of respondents &
\end{tabular}

Note: ${ }^{1}$ Asked only of those in ages 15-21.

\section{Attitudes relating to gender roles and violence against women and girls}

We probed norms and attitudes held by boys through their responses on four sets of statements: their gender role attitudes and notions of masculinity in general; their perceptions about peer reactions to boys acting in gender equitable ways; their perceptions about the right of men and boys to control the women and girls in their life; and their attitudes about the acceptability of committing violence against a girl and against a wife. For each set, statements were read out to the boys, of which some were posed in egalitarian ways and others in inegalitarian ways; boys were asked to indicate whether they agreed or disagreed with the statement. Because of the mixed direction of statements and because our aim was to measure the positive impact of the intervention on attitudes, in this section, as in Chapter 5, we opted to present responses in a consistent way to reflect gender egalitarian responses.

\section{Gender role attitudes and notions of masculinity}

A series of nine questions were posed in the baseline survey that probed boys' attitudes to gender roles, and the changes in these attitudes were assessed in the endline survey. We created an index from the responses of boys to these questions. The index is additive; each item takes a value of zero $(0)$ if the response was gender inegalitarian and one (1) if gender egalitarian. The internal consistency of the index, as measured by Cronbach's alpha, was fairly high (0.70). 
Findings, presented in Table 2.4, suggest a mixed picture. Large proportions of boys-between 81 and 96 percentdisagreed on three statements, namely, that girls had inferior capacity in mathematics and science, that girls were better off being married early than completing higher secondary education, and that educating boys is more important than educating girls; between 55 percent and 70 percent disagreed on four statements-that it is wrong for a girl to have a male friend, that childcare is just the woman's responsibility, that the husband should decide, for the most part, about spending money, and that it is necessary to give a dowry. Fewer than half (45-46\%) agreed that a girl has the right to decide on when she will marry. Indeed, hardly any boys (9-12\%) disagreed with the statement that a woman should obtain her husband's permission for most things.

The average number of statements in which boys expressed gender egalitarian attitudes was six (out of nine), indicating that attitudes were moderately egalitarian. Differences between intervention and control arms were not observed.

Table 2.4: Gender roles attitudes

Percentage of boys reporting egalitarian gender role attitudes and notions of masculinity and mean scores of boys indicating gender egalitarian attitudes and notions of masculinity, by treatment arms, 2013, baseline survey

\begin{tabular}{|c|c|c|}
\hline Statements on attitudes & Intervention & Control \\
\hline $\begin{array}{l}\text { Giving the kids a bath and feeding the kids are only the mother's } \\
\text { responsibility (Disagreed) }\end{array}$ & 62.3 & 65.4 \\
\hline $\begin{array}{l}\text { A woman should obtain husband's permission for most of the things } \\
\text { (Disagreed) }\end{array}$ & 8.9 & 11.7 \\
\hline $\begin{array}{l}\text { It is better for girls to get married early than completing at least class } \\
\text { (Disagreed) }\end{array}$ & 84.5 & 82.0 \\
\hline Educating boys is more important than educating girls (Disagreed) & 81.3 & 83.3 \\
\hline Girls cannot do well in Mathematics and Science (Disagreed) & 95.9 & 93.9 \\
\hline It is wrong for a girl to have male friends (Disagreed) & 69.2 & 67.6 \\
\hline It is necessary to give dowry (Disagreed) & 61.8 & 64.4 \\
\hline Husband alone/mainly should decide how to spend money (Disagreed) & 61.3 & 54.8 \\
\hline Girls should be allowed to decide when they want to marry (Agreed) & 45.9 & 44.6 \\
\hline $\begin{array}{l}\text { Gender role attitudes and notions of masculinity: Mean number of } \\
\text { egalitarian gender role attitudes expressed }{ }^{1} \text { (range: } 0-9 \text {, Cronbach's } \\
\text { alpha: } 0.70)\end{array}$ & 5.7 & 5.7 \\
\hline Number of clusters & 15 & 15 \\
\hline Number of respondents & 583 & 566 \\
\hline
\end{tabular}

Note: ${ }^{1}$ Statements listed above.

\section{Perceptions about peer reactions to boys acting in gender equitable ways}

We also explored perceptions of boys regarding peer reactions to boys who acted in gender equitable ways. We explored the extent to which they believed that their peers would not lose respect if they discussed their personal problems with their friends, if they helped their mother in housework, if they walked away from a fight, and if a man refused to beat his wife even if she "disobeyed" him. In this instance, we opted for a summary measure that reflects the percentage of boys who perceived that their peers would respect boys who act in gender equitable ways in at least three of the four situations posed; we acknowledge that we opted for this measure as attempts to create an additive index, as in the above and other dimensions of boys' attitudes, were unsuccessful, with relatively weak internal consistency as measured by Cronbach's alpha.

Findings again are mixed. As reported in Table 2.5, most boys (77\%) believed that a boy would not lose respect if he discussed personal problems with his peers; and somewhat fewer believed that a boy would be respected if he helped his mother with housework (61-64\%). In contrast, far fewer (19-24\%) believed that a man who did not beat his wife in certain situations would be respected by his peers, and hardly any boys believed that friends would respect a boy who refused to participate in a fight (6-7\%). Finally, on average, in both arms, 16-20 percent of boys believed that their peers would still respect them if they acted in gender equitable ways in at least three of the four situations that we probed. 
Table 2.5: Perceptions about peer reactions to boys acting in gender equitable ways Percentage of boys reporting their perceptions about peer reactions to those who act in gender equitable ways in selected situations, by treatment arms, 2013, baseline survey

\begin{tabular}{|c|c|c|}
\hline Situations & Intervention & Control \\
\hline $\begin{array}{l}\text { Boys will not lose respect if they talk about their problems with } \\
\text { friends or peers }\end{array}$ & 77.2 & 77.0 \\
\hline $\begin{array}{l}\text { If a boy helps his mother do her housework, his friends would re } \\
\text { him }\end{array}$ & 64.4 & 61.2 \\
\hline $\begin{array}{l}\text { If a man refuses to beat his wife even if she disobeys him, his } f \\
\text { would respect him }\end{array}$ & 24.2 & 19.4 \\
\hline If a boys walks away from a fight, his friends would respect him & 7.1 & 5.8 \\
\hline Boys would be respected in at least three of the four situations & 19.7 & 15.6 \\
\hline Number of clusters & 15 & 15 \\
\hline Number of respondents & 583 & 566 \\
\hline
\end{tabular}

\section{Perceptions about the right of men and boys to exercise control over the females in their life}

We explored the perceptions of boys about the right of men and boys to control the practices of the females in their life in three sets of questions described in Table 2.6. We inquired whether a boy is justified in limiting the socialisation, mobility, and dress choice of his sister and that of his girlfriend; and whether a man is justified in limiting the practices of his wife in these ways. Findings suggest that relatively few boys held egalitarian views about controlling women and girls, that is, relatively fewer boys rejected the idea that men and boys should control the behaviours of the women and girls in their life, notably their sister, girlfriend, and wife.

Findings show, for example, that only a minority of boys rejected the notion that men and boys must control the mobility of their sister and wife (17-18\% and $19-21 \%$, respectively) and the clothing that their sister and wife may and may not wear (23-26\% and 15-16\%, respectively). A somewhat larger proportion of boys rejected the notion that boys and men, respectively, are justified in controlling the extent of interaction that their sister (38-39\%) and wife (26-30\%) may have with their friends. Somewhat more boys rejected the notion that a boy is justified in exercising the same authority over his girlfriend. Even so, less than half (43-48\%) disagreed that a boy is justified in controlling what clothes his girlfriend may wear and her freedom of movement, and about three-fifths did not believe that a boy should control with whom his girlfriend socialises (60-61\%).

Four summary measures were created-one each for measuring rejection of attitudes justifying a boy's or man's right to exercise control over his sister, wife, or girlfriend and one overall index. Each index was created by summing items representing respondents' rejection of attitudes justifying a man's or boy's right to exercise control over the behaviours of his sister, wife, or girlfriend ( 1 if he rejected a man's or boy's right to exercise control, and 0 if he agreed that a man or boy should exercise control). Our fourth summary measure summed responses on all nine items. The internal consistency, as measured by Cronbach's alpha was high (ranging from 0.67-0.80 for responses about controlling behaviours over a sister, wife, and girlfriend, and 0.80 for the overall summary measure).

Findings suggest that relatively small proportions of boys rejected a man's or boy's right to control the women and girls in their life. Indeed, boys rejected a man's or boy's right to control his sister or wife in less than one of the three situations about which we probed, and they rejected a boy's right to exercise control over his girlfriend in 1.5-1.6 situations probed. On the whole, boys rejected a man's or boy's right to exercise control over their sister, wife or girlfriend in just three of the nine situations probed. No differences between intervention and control arms are noted.

\section{Attitudes about violence against women and girls}

We explored boys' attitudes about violence against women and girls in three ways. We first explored the extent to which boys rejected some seven traditional attitudes condoning violence against women and girls. We then assessed the extent to which they rejected a boy's or man's right to beat an unmarried adolescent girl in six situations, and a man's right to beat his wife in four situations, as described in Table 2.7. As above, four summary measures were created-one each for measuring rejection by boys of traditional attitudes condoning violence, their rejection of a man's or boy's right to beat an unmarried adolescent girl, and their rejection of a man's right to beat his wife. The summary measures are additive indexes, summing the number of situations in which a boy expressed attitudes rejecting a man's or boy's right to perpetrate violence on a woman or girl ( 1 if attitudes rejected the perpetration of 
Table 2.6: Perceptions on right of boys and men to control the behaviour of their sister, girlfriend, and wife Percentage of boys who rejected the right of boys and men to control social interactions and freedom of sisters, girlfriends, and wives, and mean scores of boys indicating rejection of controlling behaviour, by treatment arms, 2013, baseline survey

\begin{tabular}{|c|c|c|}
\hline Situations & Intervention & Control \\
\hline \multicolumn{3}{|l|}{ Controlling behaviour over sister } \\
\hline $\begin{array}{l}\text { A boy is not justified in telling his sister which friends she can or cannot } \\
\text { talk to or see }\end{array}$ & 38.2 & 39.4 \\
\hline A boy is not justified in forbidding his sister to go out alone & 17.8 & 17.3 \\
\hline $\begin{array}{l}\text { A boy is not justified in telling his sister what clothes she can or } \\
\text { cannot wear }\end{array}$ & 23.1 & 25.6 \\
\hline $\begin{array}{l}\text { Number of situations in which respondent perceives that a boy is not } \\
\text { justified in controlling his sister (range } 0-3 \text {, alpha: } 0.60 \text { ) }\end{array}$ & 0.8 & 0.8 \\
\hline \multicolumn{3}{|l|}{ Controlling behaviour over wife } \\
\hline $\begin{array}{l}\text { A man is not justified in telling his wife which friends she can or cannot } \\
\text { talk to or see }\end{array}$ & 29.6 & 25.8 \\
\hline A man is not justified in forbidding his wife to go out alone & 20.6 & 18.5 \\
\hline $\begin{array}{l}\text { A man is not justified in telling his wife what clothes she can or } \\
\text { cannot wear }\end{array}$ & 16.4 & 14.8 \\
\hline $\begin{array}{l}\text { Number of situations in which respondent perceives that a man is not } \\
\text { justified in controlling his wife (range } 0-3 \text {, alpha: } 0.67 \text { ) }\end{array}$ & 0.7 & 0.6 \\
\hline \multicolumn{3}{|l|}{ Controlling behaviour over girlfriend } \\
\hline $\begin{array}{l}\text { A boy is not justified in telling his girlfriend which friends she can or } \\
\text { cannot talk to or see }\end{array}$ & 61.4 & 59.8 \\
\hline A boy is not justified in forbidding his girlfriend to go out alone & 48.1 & 43.2 \\
\hline $\begin{array}{l}\text { A boy is not justified in telling his girlfriend what clothes she can or } \\
\text { cannot wear }\end{array}$ & 46.4 & 43.8 \\
\hline $\begin{array}{l}\text { Number of situations in which respondent perceives that a boy is not } \\
\text { justified in controlling his girlfriend (range } 0-3 \text {, alpha: } 0.73 \text { ) }\end{array}$ & 1.6 & 1.5 \\
\hline $\begin{array}{l}\text { Overall index of attitudes about controlling behaviour: Mean number of } \\
\text { situations in which the respondent rejected men's right to exercise } \\
\text { controlling behaviour (range:0-9, Cronbach's alpha: 0.80) }\end{array}$ & 3.0 & 2.9 \\
\hline Number of clusters & 15 & 15 \\
\hline Number of respondents & 583 & 566 \\
\hline
\end{tabular}

violence and 0 if attitudes justified violence). Our fourth summary measure summed responses on all 17 statements. The internal consistency, as measured by Cronbach's alpha ranged from moderate to strong on individual indexes, and 0.79 for the overall summary measure.

With regard to attitudes condoning violence against women and girls, findings presented in Table 2.7 show that more than 7 out of 10 boys rejected the notion that girls like to be teased, that it is a girl's fault if she is sexually harassed, and that only persons from outside family rape a girl (76-92\% and $72-93 \%$ in intervention and control arms, respectively). A somewhat smaller proportion disagreed with the remaining four statements (that a woman should tolerate violence to keep her family together; there are times when a boy needs to beat his girlfriend; there are times when a woman deserves to be beaten by her husband; and if a girl says no, it actually means yes). On average, respondents from both intervention and control arms disagreed with five of the seven statements posed.

With regard to attitudes about a boy's right to beat an unmarried adolescent girl, about one-third of boys believed that a boy is not justified in beating a girl if she stays out late (28-34\%) or disobeys her elders (31-36\%); between one half and two-thirds did not justify violence on a girl if she does not help in housework (45-52\%), talks to a boy (58-66\%), or has an affair (52-54\%). A large proportion of boys also disagreed with the statement that a girl should be beaten if she goes out to play (84-88\%). On the whole, boys rejected attitudes favouring a man's or boy's right to beat an unmarried adolescent girl in three of the six situations that we probed, and differences between those in the intervention and control arm were negligible (mean: 3.3 and 3.0, respectively).

With regard to the acceptability of wife beating, just one-third of boys believed that a man is not justified in beating his wife if she disobeys him (31-35\%), and just half did not justify wife beating if a woman makes a mistake 
Table 2.7: Attitudes about violence on girls and women

Percentage of boys holding attitudes rejecting the right of men and boys to perpetrate violence against girls and women in certain situations, and mean scores of boys indicating rejection of violence, by treatment arms, 2013, baseline survey

\begin{tabular}{|c|c|c|}
\hline Attitudes & Intervention & Control \\
\hline \multicolumn{3}{|l|}{$\begin{array}{l}\text { Attitudes condoning men's right to perpetrate violence against women } \\
\text { and girls }\end{array}$} \\
\hline Girls like to be teased by boys (Disagreed) & 92.3 & 93.2 \\
\hline It is a girl's fault if she gets sexually harassed (Disagreed) & 82.4 & 80.4 \\
\hline $\begin{array}{l}\text { Rape against girls is perpetrated only by persons not related to her } \\
\text { (Disagreed) }\end{array}$ & 76.4 & 71.8 \\
\hline $\begin{array}{l}\text { A woman should tolerate violence to keep her family together } \\
\text { (Disagreed) }\end{array}$ & 62.6 & 61.1 \\
\hline If a girl says no it actually means yes (Disagreed) & 59.8 & 70.4 \\
\hline There are times when a boy needs to beat his girlfriend (Disagreed) & 47.7 & 51.6 \\
\hline $\begin{array}{l}\text { There are times when a wife deserves to be beaten by her husband } \\
\text { (Disagreed) }\end{array}$ & 36.4 & 40.9 \\
\hline $\begin{array}{l}\text { Index of rejection of violence against women/girls: mean number of } \\
7 \text { situations in which respondent rejected men's right to perpetrate } \\
\text { violence against women and girls (range 0-7, Cronbach's alpha: 0.47) }\end{array}$ & 4.6 & 4.7 \\
\hline \multicolumn{3}{|l|}{$\begin{array}{l}\text { Attitudes rejecting a man's or boy's right to beat an unmarried } \\
\text { adolescent girl }\end{array}$} \\
\hline \multicolumn{3}{|l|}{$\begin{array}{l}\text { Did not justify a boy's/man's right to beat an unmarried adolescent girl } \\
\text { in selected situations }\end{array}$} \\
\hline If she talks to a boy & 66.3 & 58.3 \\
\hline If she goes out to play & 87.8 & 84.0 \\
\hline If she stays out late & 33.7 & 28.4 \\
\hline If she does not help in housework & 52.2 & 45.2 \\
\hline If she does not obey her elders & 35.6 & 30.8 \\
\hline If she has an affair with a boy & 54.3 & 51.9 \\
\hline $\begin{array}{l}\text { Index of attitudes rejecting the right of a man/boy to beat a girl (range } \\
0-6 \text {, Cronbach's alpha: } 0.78 \text { ) }\end{array}$ & 3.3 & 3.0 \\
\hline \multicolumn{3}{|l|}{ Attitudes rejecting a man's right to beat his wife } \\
\hline \multicolumn{3}{|l|}{ Did not justify a man's right to beat his wife in selected situations } \\
\hline If he suspects her of being unfaithful & 70.5 & 65.6 \\
\hline If she goes out without telling her husband & 57.8 & 47.3 \\
\hline If she disobeys her husband & 35.2 & 31.3 \\
\hline If she makes a mistake & 47.2 & 45.6 \\
\hline $\begin{array}{l}\text { Index of attitudes about a man's right to beat his wife (range 0-4, } \\
\text { Cronbach's alpha: } 0.71 \text { ) }\end{array}$ & 2.1 & 1.9 \\
\hline $\begin{array}{l}\text { Overall index of attitudes toward violence against women and girls: Mean } \\
\text { number of situations in which respondent rejected attitudes justifying } \\
\text { violence against women and girls (range: } 0-17 \text {, Cronbach's alpha: 0.79) }\end{array}$ & 10.0 & 9.6 \\
\hline Number of clusters & 15 & 15 \\
\hline Number of respondents & 583 & 566 \\
\hline
\end{tabular}

(46-47\%), or goes out without telling her husband (47-58\%). Surprisingly, somewhat more (66-71\%) rejected a man's right to beat his wife if he suspects her of being unfaithful. On average, boys disagreed that a man is justified beating his wife in just two of the four situations probed.

Our overall summary index of attitudes toward violence against women and girls reveals that boys from both intervention and control arms held attitudes rejecting violence against women and girls in just 10 of the 17 situations that we probed. 


\section{Practices relating to the perpetration of violence on women and girls}

Our survey explored two aspects of the behaviour of boys with regard to violence: whether and what action they had taken when they had witnessed a person perpetrating any form of violence on a girl and whether they had perpetrated non-contact and contact forms of violence on a girl.

\section{Action taken when incidents of violence were observed}

Boys who had witnessed the perpetration of various forms of violence in the six months preceding the interview were asked about their reaction to the violence observed, namely, witnessing others making dirty comments about a girl, teasing a girl, spreading sexual rumours about a girl, or perpetrating unwanted touch on a girl, such as pushing, grabbing, or shoving a girl deliberately.

Findings suggest that relatively few who had witnessed any such violence took action to stop it (Table 2.8). Thus, between 65 percent and 91 percent of boys who had witnessed others making dirty comments about a girl, teasing a girl, spreading sexual rumours about a girl, and pushing or grabbing a girl had done nothing to stop the incident, or, at most, had just felt uncomfortable. A small proportion (2-10\%) admitted that they had joined in or laughed at the abuse in at least one such instance. Some 7-31 percent of boys in ages 13-21 reported that they had intervened

Table 2.8: Response to violence against girls perpetrated by others in preceding six months Percentage of boys who witnessed incidents of verbal and physical violence perpetrated on girls reporting their reaction to the incident, by treatment arms, 2013, baseline survey

\begin{tabular}{|c|c|c|}
\hline Incidents of violence & Intervention & Control \\
\hline \multicolumn{3}{|l|}{ Reaction to someone making dirty comments about a girl } \\
\hline Joined or laughed & 6.4 & 10.2 \\
\hline Did nothing, felt uncomfortable & 74.0 & 75.5 \\
\hline Told him to stop, intervened, reported the incident, confided to someone & 19.6 & 14.3 \\
\hline $\begin{array}{l}\text { Number of boys who saw someone making dirty comments about a gir } \\
\text { in last } 6 \text { months }\end{array}$ & 332 & 303 \\
\hline \multicolumn{3}{|l|}{ Reaction to someone teasing a girl } \\
\hline Joined or laughed & 3.9 & 2.9 \\
\hline Did nothing, felt uncomfortable & 65.3 & 75.9 \\
\hline Told him to stop, intervened, reported the incident, confided to someone & 30.8 & 21.2 \\
\hline Number of boys who saw someone teasing a girl in last 6 months & 223 & 182 \\
\hline \multicolumn{3}{|l|}{ Reaction to someone spreading sexual rumours about a girl } \\
\hline Joined or laughed & 4.9 & 2.3 \\
\hline Did nothing, felt uncomfortable & 78.6 & 90.7 \\
\hline Told him to stop, intervened, reported the incident, confided to someone & 16.5 & 7.0 \\
\hline $\begin{array}{l}\text { Number of boys who saw someone spreading sexual rumours about a } \\
\text { girl in last } 6 \text { months }\end{array}$ & 163 & 171 \\
\hline \multicolumn{3}{|l|}{ Reaction to someone pushing/grabbing or shoving a woman or girl } \\
\hline Joined or laughed & 4.3 & 3.5 \\
\hline Did nothing, felt uncomfortable & 74.7 & 77.6 \\
\hline Told him to stop, intervened, reported the incident, confided to someone & 21.0 & 18.9 \\
\hline $\begin{array}{l}\text { Number of boys who saw someone pushing/grabbing or shoving a } \\
\text { woman or girl in last } 6 \text { months }\end{array}$ & 105 & 85 \\
\hline Taken action on any of the four situations above & 33.7 & 23.0 \\
\hline $\begin{array}{l}\text { Number of boys who saw any of the violent acts against women and } \\
\text { girls in last } 6 \text { months }\end{array}$ & 390 & 347 \\
\hline Number of clusters & 15 & 15 \\
\hline
\end{tabular}


or taken action to stop the abuse, namely, that they had told the perpetrator to stop, had physically intervened to stop the violence, had reported the incident to the authorities, or had confided in an adult about the incident. Boys reporting such intervention in response to abuse of girls constituted 14-20 percent when dirty comments were passed, 21-31 percent when a girl was teased, 7-17 percent when sexual rumours were spread, and 19-21 percent when the perpetration of physical violence was observed.

Our overall summary measure, namely, the percentage of boys who took action when they had observed an incident of verbal abuse (dirty comments, teasing, spreading sexual rumours) or physical violence reveals that 23 percent of boys from the control arm and 34 percent of those from the intervention arm had taken action to stop the incident of violence that they had observed.

\section{Perpetration of violence by respondents}

We sought to understand the extent to which boys had engaged in various forms of violence. We asked all boys whether they had bullied younger boys as well as whether they had committed a range of violent acts against girls, including verbal and non-verbal forms of harassment, forcing a girl to watch pornographic films or materials, or touching a girl without her consent. In addition, boys in ages 15-21 were asked if they had ever forced sex on a girl. As mentioned in the first Chapter, we also posed three questions to those in ages 15-21 to which they responded anonymously via the sealed envelope format; we asked respondents whether they had teased a girl, perpetrated physical violence on a girl, and forced a girl to engage in sexual relations.

Findings presented in Table 2.9 refer to the responses of boys in ages 13-21 and those of boys in ages 15-21 with regard to the questions that were universally posed as well as responses of boys in ages 15-21 to questions specifically addressed to them, as described above. We report boys' responses about their perpetration of violence in the six months preceding the interview.

Table 2.9: Perpetration of violence on girls and bullying of younger boys in the preceding six months Percentage of boys reporting bullying of younger boys and verbal, physical, and sexual violence on girls/women in the face-to-face interview and anonymous format, by age group and treatment arms, 2013, baseline survey

\begin{tabular}{|c|c|c|c|c|}
\hline \multirow{2}{*}{$\begin{array}{l}\text { Violent acts perpetrated in the six months } \\
\text { preceding the interview }\end{array}$} & \multicolumn{2}{|c|}{ Boys in ages 13-21 } & \multicolumn{2}{|c|}{ Boys in ages 15-21 } \\
\hline & Intervention & Control & Intervention & Control \\
\hline \multicolumn{5}{|l|}{ Face-to-face response } \\
\hline Bullied boys of younger age & 43.0 & 38.4 & 41.3 & 38.1 \\
\hline $\begin{array}{l}\text { Verbally abused a girl or a woman (passed } \\
\text { comments, said bad words, made dirty gesture, } \\
\text { shouted/yelled/used abusive language) }\end{array}$ & 30.9 & 31.7 & 33.3 & 33.5 \\
\hline Followed/stalked a girl & 7.7 & 1.5 & 9.5 & 7.4 \\
\hline $\begin{array}{l}\text { Forced a girl to watch pornographic films/see } \\
\text { pornographic materials }\end{array}$ & 1.1 & 0.6 & 1.2 & 0.8 \\
\hline Hit/slapped/kicked/pushed/pulled hair of girl & 14.9 & 14.7 & 13.7 & 11.8 \\
\hline Forcibly touched a girl when she did not want & 5.7 & 4.7 & 6.3 & 5.5 \\
\hline \multicolumn{5}{|l|}{ Face-to-face interview or anonymous format } \\
\hline $\begin{array}{l}\text { Verbally abused a girl or a woman (passed } \\
\text { comments, said bad words, made dirty gesture, } \\
\text { shouted/yelled/used abusive language) }\end{array}$ & & & 36.0 & 36.6 \\
\hline $\begin{array}{l}\text { Physically hit/slapped/kicked/pushed/pulled hair } \\
\text { of girl }\end{array}$ & & & 17.4 & 17.9 \\
\hline Had forced any girl/woman to have sex & & & 2.8 & 3.7 \\
\hline Number of clusters & 15 & 15 & 15 & 15 \\
\hline Number of respondents & 583 & 566 & 378 & 342 \\
\hline
\end{tabular}

Findings confirm that acts of violence perpetrated by boys in our sample were quite widespread, irrespective of age group, in the six months preceding the interview. Thus, about two out of five boys from both intervention and control arms (38-43\%) admitted that they had bullied younger boys. About one-third (31-32\% of all boys, 33-34\% of boys in ages 15-21) reported that they had verbally abused a girl. Fewer reported that they had followed or stalked a girl ( $2-8 \%$ of all boys, $7-10 \%$ of boys in ages $15-21)$ or forced a girl to watch pornographic films or look at pornographic 
materials (1\%). Further, 15 percent of all boys and 12-14 percent of boys in ages 15-21 admitted that they had physically abused a girl in the last six months, and one out of 15 boys of both groups (5-6\%) reported that they had touched a girl or woman inappropriately and without her consent in the six months preceding the interview. Finally, in the face-to-face interview for those in ages 15-21, fewer than one percent reported having forced a girl or woman to have sex (responses are not shown separately in Table 2.9).

Among those in ages 15-21, the opportunity to report the perpetration of violent acts anonymously did indeed result in higher levels of reported perpetration. While percentages reporting teasing a girl hardly increased as compared with the face-to-face response (33-34\% versus 36-37\% in the face-to-face interview or anonymous format), reports of the perpetration of physical and sexual violence increased considerably. Indeed, 17-18 percent reported the perpetration of physical violence in the face-to-face interview or anonymous format (compared with 12-14\% in the face-to-face response format), and 3-4 percent reported the perpetration of sexual violence in the face-to-face interview or anonymous format (compared with less than one percent in the face-to-face response format, not shown in Table 2.9).

\section{Summary}

This chapter has described the context of boys' life in the settings in which the Do Kadam programme was implemented.

Most boys in our sample (89-93\%) were studying at the time of the baseline survey. Many boys reported an environment of violence: they had witnessed their father beating their mother (26-29\%) and their peers and other community members perpetrating violence on a woman or girl (for example, more than half had witnessed someone making dirty comments to a girl or woman, 9-18\% had witnessed someone abusing a girl physically or sexually). Many suggested moreover that many of their peers held norms condoning the perpetration of violence.

Findings confirm the extent to which the attitudes of boys were gendered and the extent to which they condoned violence against women and girls. Gender role attitudes and notions of masculinity remained traditional for many (a score of 5.7 of 9 on a scale measuring egalitarian gender role attitudes) as did perceptions about peer reactions to boys acting in gender equitable ways (for example, only 16-20\% boys perceived that they would be respected for acting in gender equitable ways in at least three out of four situations). Many boys adhered to attitudes justifying a boy's or a man's right to control his sister, wife, and girlfriend and to perpetrate violence on a girl or a wife; indeed, on average, boys rejected a man's or boy's right to exercise control over his sister, girlfriend or wife in just 3 of 9 situations).

Most boys who witnessed their peers or others committing violence on a woman or girl took no action to prevent the violence. Indeed, irrespective of the act of violence witnessed, the majority of boys (75\% or more) reported that they had done nothing to stop the violence, or, at most, had felt uncomfortable. One in three boys in the intervention arm and about one-fourth of those in the control arm had intervened to stop the violence.

Finally, one-third of boys-those both in ages 13-21 and in ages 15-21-had verbally abused a girl. Further, more than one in eight boys admitted that they had physically abused a girl in the last six months, and one out of 15 reported that they had touched a girl or woman inappropriately and without her consent in the six months preceding the interview. Among those in ages 15-21 who reported the perpetration of violent acts both in the face-to-face interview and in the anonymous reporting format, 17-18 percent reported the perpetration of physical violence, and 3-4 percent reported the perpetration of forced sex.

The findings presented in this chapter also show that the intervention and control arms were well balanced in relation to the background characteristics of boys who were enrolled in the study as well as in the outcomes that the intervention sought to influence.

Findings underscore a context in which violence and adherence to inegalitarian gender norms pervade the life of boys. They emphasise both the need for programmes intended to transform attitudes and behaviours among boys, as well as the difficulties that may be encountered in doing so in a setting in which traditional norms and practices are so deeply entrenched. 


\section{Chapter 3 \\ Do Kadam Barabari Ki Ore: The intervention}

It is during adolescence that unequal gender norms and norms justifying the right of men and boys to commit violence on women and girls are established (as discussed in the first Chapter). Therefore, it is important that programmes promoting egalitarian norms are initiated in adolescence and before traditional norms and practices become internalised. While programmes to change norms and practices among rural boys are limited, there is evidence from programmes conducted among school-going boys in urban areas and girls in rural areas that adolescent norms may indeed be changed by exposure to gender transformative programmes implemented among adolescents (ICRW, n.d.; Santhya et al., 2013). Given the background of limited evidence on promising approaches to counter the establishment of traditional gender norms among boys, the Centre for Catalysing Change (C3) and the Population Council designed, implemented, and assessed the effectiveness and acceptability of a model intended to effect these changes among boys who were members of boys' clubs of Patna district, Bihar. While the Population Council and C3 worked in partnership, C3 was primarily responsible for programme design and implementation, and the Population Council was responsible for programme evaluation. In addition, the Gender, Violence and Health Centre at the London School of Hygiene and Tropical Medicine provided inputs into the design of the evaluation.

In this chapter, we briefly describe the objectives, the design of the intervention, and its key components. Drawing on project monitoring data collected by $\mathrm{C} 3$, we also describe the extent to which boys in selected clubs had participated in the intervention activities. Finally, we discuss the challenges faced in implementing the intervention.

\section{Objectives of the Do Kadam Barabari Ki Ore intervention}

The goal of the intervention was to change attitudes towards violence against women and girls among adolescent boys in ages 13-21. The intervention targeted boys in this age group who were members of youth clubs that fall under the NYKS programme. The NYKS programme is sponsored by the Ministry of Youth Affairs and Sports. We selected 15 youth clubs that were spread across seven blocks of Patna district.

More broadly, the objective was to implement our intervention within an existing government structure that has a wide reach in order to enable replication and upscaling of the model if it proved successful. Hence, we partnered with the NYKS for implementation of the intervention. NYKS is a group-based programme with wide outreach across the country at the village level. Its network was established with the objective of engaging youth in nation-building and developing their leadership skills. Given its focus on promoting citizenship, skill development, personality development, and engagement in sports among the young, the NYKS was a suitable fit and provided a sustainable framework to introduce a programme on changing gendered norms, imparting new norms of masculinity, and fostering abhorrence of violence against women.

\section{Main components of the intervention programme}

The outreach of the NYKS structure is its key strength. With a network of 28 zonal offices, 501 district-level offices, and 1.25 lakh youth clubs in about half of the villages of the country, the NYKS programme has huge potential for empowering youth and building their leadership skills and citizenship values. Youth clubs falling under the NYKS programme are established at village level and are open to all those in ages 13-35. Clubs are expected to offer young people a range of leadership development opportunities; activities are wide-ranging but are intended to inform youth, build leadership skills, and engage youth in community development activities. Youth clubs exist in every state of the country and receive nominal financial support from the NYKS. Although open to young men and women in ages 13-35, the membership of NYKS clubs tends to exclude adolescents and youth and includes, for the most part, men aged 25 and above.

The Do Kadam programme for boys was implemented among youth club members in ages 13-21 from 15 clubs. The project sought to enlist all such members across 15 youth clubs. As such, the intervention was group based; each youth club group had 30-40 participants in ages 13-21. The intervention consisted of a gender transformative life skills education programme combined with cricket-coaching and thus sought to build leadership skills and team spirit, while focusing on changing inegalitarian gender norms.

\section{The gender transformative life skills curriculum}

The curriculum drew upon and adapted various tested curricula that have focused on transforming gender norms, encouraging communication and negotiation in conflict resolution, and channelling sports-related activities in ways 
that build team spirit and leadership skills. Key curricula upon which we drew included the "It's All in One Curriculum", developed by the Population Council and partners (Haberland et al., 2009); the "Yaari Dosti" curriculum for men, developed and tested by the Population Council (Population Council, 2006); the "Better Life Options" curriculum for adolescent girls and boys, developed and tested by the Centre for Development and Population Activities (CEDPA, now C3 India) (Centre for Development and Population Activities (CEDPA), 2003); the "Udaan-Towards a Better Future" model for school settings, also developed and implemented by C3 India (CEDPA, 2006); the "Parivartan: Coaching Boys into Men" programme for boys, a sports-based programme implemented in urban schools, implemented and tested by ICRW (International Centre for Research on Women, 2009); and the "Working with Men on Gender, Sexuality, Violence and Health" model, developed jointly by SAHAJ, SAHAYOG, and TATHAPI (Fernandes et al., 2005).

The Do Kadam curriculum comprised:

1. Information on growing-up matters, ranging, as appropriate, from physical maturation and emotional development to sexual and reproductive health as well as vocational and career opportunities and where to go to seek help, if needed.

2. Participatory learning sessions-case studies, role play, and group discussions-that aimed to promote critical thinking about gender roles and violence and the consequences of violence against women and girls. These sessions also aimed to enable boys to challenge social norms and understand concepts of power, respect, and consent in relationships. It highlighted gender issues and positive notions of masculinity and made boys aware of the rights of women and girls, and it encouraged boys to adopt gender egalitarian practices and to denounce violence against women and girls. It also sought to build communication and negotiation as a way of resolving conflict within the family.

3. Introspection about boys' own behaviour-teasing, verbal harassment, unwanted touch, forced sex, and so onand about ways in which boys and young men can intervene in situations in which verbal or physical harassment of girls takes place.

\section{Capacity-building of peer mentors responsible for imparting the curriculum}

In each club, two peer mentors were identified from among NYKS youth club members and were trained by C3 India to impart the curriculum and lead group activities. One trained peer leader was responsible for delivering the gender transformative life skills sessions, using participatory learning techniques, with support from C3. The second was responsible for conducting cricket sessions, supporting the cricket coach, and ensuring group participation. Peer mentors were selected on the basis of their educational attainment levels, their communication skills, commitment to the goals of the project, and willingness to spend the stipulated time on project activities.

Peer mentors underwent an initial four-day training workshop prior to the initiation of the intervention. This workshop sensitised peer mentors about gender construction and masculinity, violence and consequences of violence against women and girls as well as inequitable gender norms, concepts of power, respect, and consent in relationships, and the role of men as caregivers and men's participation in domestic activities. At the same time, peer mentors were oriented about programme content and approach, particularly on participatory education methods as well as on how to engage boys in cricket activities and develop team spirit among them. Finally, peer mentors were apprised about their responsibilities as facilitators of programme activities, such as mobilising club members, maintaining an attendance register, ensuring that supplies and equipment necessary for the session were in place, and discouraging the use of abusive language. Over the course of the intervention, all 30 peer mentors underwent three subsequent refresher training workshops lasting two days, each of which equipped them to implement subsequent sections of the curriculum and review experiences. Participatory methodology was used to impart training, including role plays, case studies, and discussions.

Peer mentors were supported by the Do Kadam programme's two core trainers. Core trainers were engaged in both training peer mentors and supporting them in implementing the gender transformative curriculum and the cricketcoaching sessions. Core trainers supported peer mentors in ensuring that sessions were conducted as per the guidelines, that questions raised by participants were answered adequately, and that peer mentors were able to maintain discipline during the session.

\section{Gender transformative life skills sessions}

Sessions were organised weekly over 18 months, with sessions being suspended during festivals and examinations. There were thus a total of 42 two-hour sessions. In these sessions, gender transformative life skills modules were 
imparted for one hour or half of the session, and cricket-coaching and practice were given for the other half or remaining one hour of the session. Sessions were led by peer mentors selected from amongst club members and supported by a project-based core trainer. Club members met at a designated space and time convenient to all. Peer mentors used the training module to deliver each session, using the guidelines and participatory methodologies recommended for each session. Core trainers were present at most sessions to support the peer mentors to explain difficult concepts and ensure that the sessions were interactive.

We note that the leadership and communications skills of peer mentors across the 15 clubs varied. Some were confident and able to engage club members, convey complex ideas to them, and encourage active participation in group discussions, role plays, and other activities. Others were more reticent. Among peer mentors who needed to be supported in their roles, the core trainer played a far more active role in conducting sessions than we had envisaged. In most sessions, the core trainer's role was prominent in the early days of the project and became less prominent as peer leaders gained confidence and authority. While the core trainer attended all or part of most sessions, their role varied according to need-from serving as an observer in many sessions, especially after the first few months of the intervention, to serving as the facilitator, especially in early sessions and sessions in which peer mentors were shy or unable to communicate ideas. Core trainers supported peer mentors by ensuring that sessions were held on a regular basis and proceeded according to the curriculum, responding to questions from club members if it was obvious that the peer mentor was unable to answer them, resolving conflicts between members, and so on.

\section{Sports-coaching component}

Sports-coaching activities entailed not only cricket-coaching, but also efforts to develop among boys a better understanding of commitment to the team, of complying with rules and regulations of the sport, and of the importance of team spirit and the spirit of fairness. A cricket kit was given to each club in both intervention and control groups.

Cricket sessions were preceded by a short discussion about healthy practices, appropriate diet for a sportsperson, fair play, team spirit, and use of respectful language. Coaching sessions were held by a professional cricket coach, who instructed the boys about the rules of the game, on the one hand, and provided individual attention to improving each one's playing techniques, on the other. The sports coach visited each club at least four times during the intervention phase. Although the intention was to hold cricket sessions following each gender transformative life skills session, we recognised that this was not always possible (weather, availability of playing fields, etc.) and, as such, a total of 35 cricket sessions were held in each club.

At the end of the intervention, a cricket league tournament was organised. League matches were conducted according to the rules set by the coach and had a fixed programme agenda. At these matches, team members shared experiences of personal change that they attributed to the Do Kadam Barabari Ki Ore sessions. At the beginning of each match, team members took a collective symbolic oath to stop violence against women and girls. At the end of each match, a Man of the Match was declared and all team members were given a certificate of participation. Cricket matches were generally well attended by club members as well as the communities they represented. Elected panchayat representatives, teachers, and local NYKS coordinators were invited as chief guests at these events.

\section{Community events}

Aside from the cricket matches, several clubs held activities that aimed to engage communities more generally. Over the course of the intervention, clubs organised a total of 20 community events that were attended by NYKS club members and their families as well as other community members. As in cricket tournaments, in an effort to reach out to community members and leaders, elected panchayat representatives, teachers, and local NYKS coordinators were invited as chief guests to these events.

In all, ten clubs held painting and essay competitions on themes related to violence against women and girls and ways to prevent violence in their community; in some events, girls were invited to join in the competition. Other activities, which were conducted in three villages, included slow cycling and gender power walks aimed at encouraging a violence-free community and preventing gender discrimination. Events thus provided space for NYKS club members to discuss the Do Kadam project and its activities and to engage with their parents, key community leaders, as well as with girls in their community on issues related to violence against women and girls. Each event concluded with the distribution of certificates to young people who had participated in the drawing competitions, slow cycling, and gender power walks and with a public pledge-taking ceremony in which all club members pledged to end violence against women and girls. 


\section{Monitoring progress}

Progress was monitored in two ways. C3 and Population Council project implementers conducted regular field visits to observe sessions; their process documentation reports highlighted challenges faced in implementing the programme and possible solutions to resolve these challenges. Each club also maintained registers that recorded activities conducted at each session and each member's attendance. Progress was assessed through monthly monitoring reports that consolidated the information recorded in these registers. These reports outlined the progress made in each club in imparting the curriculum and recorded boys' attendance at gender transformative life skills sessions as well as at cricket sessions. Monthly reports were then entered in computers.

In all, 583 boys, who were members of intervention clubs at about the time the Do Kadam programme was initiated, were interviewed in the baseline survey. As mentioned in the first Chapter, 67 boys had moved away in the course of the intervention and could not be interviewed for the endline survey. Table 3.1 presents the attendance levels recorded in the monitoring system; we define those who attended at least half of the 42 gender transformative life skills sessions or half of the 35 cricket sessions as having regular attendance, those who had attended 3-20 gender transformative life skills sessions (3-11 as having very irregular attendance and 12-20 as having somewhat irregular attendance) or 3-17 cricket sessions (3-9 as having very irregular attendance and 10-17 as having somewhat irregular attendance) as having irregular attendance, and those who had never attended or attended just 1-2 sessions as non-attenders.

Of the 583 boys enrolled in the clubs at the beginning of the intervention, just 38-39 percent had regularly attended the gender transformative life skills sessions as well as cricket-coaching and practice sessions. At the other extreme, 18 percent and 19 percent had never attended the gender transformative life skills sessions and the cricket games and coaching sessions, respectively. The remaining 43-44 percent of boys were reported to have attended irregularly.

Table 3.1: Attendance of club members at gender transformative life skills and cricket-coaching sessions Percent distribution of boys by attendance at gender transformative life skills and cricket-coaching sessions, as per monthly monitoring reports, intervention arm, Patna district

\begin{tabular}{|c|c|c|}
\hline Attendance & $\begin{array}{c}\text { Gender } \\
\text { transformative life } \\
\text { skills sessions } \\
\text { (Number of } \\
\text { sessions }=42 \text { ) }\end{array}$ & $\begin{array}{c}\text { Cricket-coaching } \\
\text { and play sessions } \\
\text { (Number of } \\
\text { sessions }=35 \text { ) }\end{array}$ \\
\hline $\begin{array}{l}\text { Never attended } \\
\quad \text { (None of the sessions or } 1-2 \text { sessions) }\end{array}$ & 17.5 & 19.0 \\
\hline $\begin{array}{l}\text { Attended very irregularly } \\
\text { (3-11 sessions for LSE, 3-9 sessions for cricket-coaching) }\end{array}$ & 24.3 & 22.5 \\
\hline $\begin{array}{l}\text { Attended somewhat irregularly } \\
\quad(12-20 \text { sessions for LSE, } 10-17 \text { sessions for cricket-coaching) }\end{array}$ & 19.5 & 20.9 \\
\hline $\begin{array}{l}\text { Attended regularly } \\
\text { (21-42 sessions for } L S E, 18-35 \text { sessions for cricket-coaching) }\end{array}$ & 38.6 & 37.6 \\
\hline Number of club members & 583 & 583 \\
\hline
\end{tabular}

Note: $L S E=$ Life skills education.

In the monitoring activities conducted by implementing partners, moreover, peer mentors reported considerable changes in their own self-confidence and their perceptions about changes experienced by club members. Thus, most peer mentors reported that their most valuable experience during the project period was the respect they had earned from their club members and community members. They reported that initially no one was ready to listen to them in the sessions. They were themselves not very confident, as the issues they were discussing were new to them and had not been addressed in school. They read the manual before each session and discussed topics with core trainers to compensate for their lack of awareness of the topics. Many observed positive changes in themselves, including better leadership and communication skills, ability to convince others and make decisions, greater awareness of various issues, and awareness of own attitudes about gender equality and violence against women. Boys pointed out that the body language and behaviour of club members had also changed significantly. In the beginning they used to laugh at others, pass lewd comments, whistle, use abusive language, etc. during the life skills sessions and cricket sessions, but gradually they learned to listen to others patiently, pay attention to the topic being discussed, and relate these topics to their own family and society too. 


\section{Challenges faced in implementing intervention activities}

We faced a number of challenges when implementing the intervention. Perhaps the biggest challenge was ensuring regular attendance of club members in all sessions. Boys who were pursuing their education also attended afterschool coaching classes or they were attending schools and colleges outside their village, because of which they found it difficult to attend intervention sessions on a regular basis; those working commuted often to places outside their village and faced similar difficulties in ensuring regular attendance. A few boys reported that they were uninterested in the content of sessions, some reported that their parents had objected to their participating in intervention activities, and a few boys had migrated out of the village for education or employment over the course of the programme. Many boys suggested, moreover, that a programme that had also included livelihood-training opportunities would have attracted more regular attendance.

Attending the cricket sessions posed additional challenges. Although the programme had accommodated the preference of boys for coaching in cricket rather than other sports that required smaller playing fields, fulfilling the requirements for this game proved difficult in some clubs. In some villages, for example, it was difficult to identify a playing field that was suitable, accessible, and within a reasonable distance; in inclement weather, cricket sessions had to be suspended or conducted in the early morning or late evening as in peak summer months. We made efforts to resolve this problem by holding extra sessions to make up for missed sessions, but recognised that despite this, some boys faced difficulty in attending the cricket sessions regularly for reasons described above.

A second challenge was the lack of confidence and skills in public speaking and in organising and leading meetings and other public events among peer mentors. Many peer mentors held, as did the boys in their community, traditional gender role attitudes and views about the acceptability of perpetrating violence on women and girls.

The initial training workshop focused considerably in supporting peer mentors to question these norms. Other club members held the same traditional norms, and, as such, peer mentors initially found it difficult to elicit the respect of their peers in a group situation, and many were hesitant to impart topics such as gender discrimination and violence against women and girls to their peers. To enable peer mentors to overcome these inhibitions, we held frequent and regular refresher workshops in which they had an opportunity to act out what they would do in the following sessions with their club members. We also encouraged core trainers to take on a more prominent role than originally intended in supporting peer mentors to conduct sessions, narrate case stories, organise role play, and initiate discussion among participants. We note that by the end of the intervention, most peer mentors did indeed demonstrate greater confidence and skills in leading sessions. Even so, our experience calls for greater introspection into ways of modifying the model-the use of a peer mentor who is somewhat older and commands more respect from boys than a boy of their own age; a longer capacity-building period during which peer mentors can be identified, trained, and supported to conduct sessions independently; and the incorporation in peer mentor capacity-building activities a strong focus on their own gender transformation.

Third, peer mentors were also challenged by intra-group conflict. As mentioned above, peer mentors came from the same society as other club members, and some had to deal with deeply entrenched caste-based dynamics, on the one hand, and unruly club members who mocked their authority, on the other. Core trainers made efforts to hold discussions with affected groups to resolve these conflicts, emphasising team spirit and group solidarity as key in addressing gender discrimination and fighting against violence against women and girls.

A fourth challenge was turnover among peer mentors. Given that boys in the ages 13-21 are hugely mobile, several of them had migrated out of their village over the course of the intervention (a few were disqualified for lack of discipline as well), and, as a result, we had to replace these peer mentors mid-programme; recruiting new mentors from the existing pool of club members posed a challenge in a few instances where more than one boy sought to take on this role. Special training sessions had to be conducted, moreover, for these new peer mentors.

Finally, working through the NYKS structure, while ideal in many ways, also posed some challenges. For one, as mentioned earlier, the membership of NYKS clubs tends to concentrate on those aged 25 and above, and a special membership drive was undertaken prior to the initiation of the project to inform boys and their parents about the eligibility of boys for membership in NYKS clubs and to enrol those interested in becoming members. In addition, the NYKS programme is poorly resourced, and because of their limited human and financial resources, their engagement in the Do Kadam programme was more limited than envisaged and was restricted to attending a few community events and cricket tournaments. Moreover, at village level, meetings were held irregularly, and social issues were rarely addressed under the broader auspices of the NYKS programme. As such, and in the absence of a strongly supported NYKS structure, a major challenge faced was in integrating the structured design of the Do Kadam initiative into the regular work of youth clubs. In short, while NYKS youth clubs offered an attractive platform for the 
Do Kadam programme, given its spread and potential for upscaling, it may be useful to explore other opportunities to deliver such a programme at scale-for example, through the school setting and networks proposed through the recently launched Rashtriya Kishor Swasthya Karyakram (RKSK) programme.

These challenges underline the message that the intervention programme operated in less than ideal situations and that programme implementers need to be alert to the need for modification to accommodate "real life" situations.

\section{Activities conducted in control clubs}

As mentioned in the first Chapter, a public randomisation event was held in order to assign clubs into the intervention and control groups. At this event, on behalf of the project, the Zonal Director, NYKS, provided each club with a cricket kit and promised those in control clubs that at the conclusion of the project, a series of inter-club matches would be held in control clubs. The Population Council met this commitment and held inter-club matches among the 15 control clubs after the entire intervention (including inter-club matches among the 15 control clubs) had been completed in intervention clubs. Prior to each of these matches, teams took an oath to play fairly and maintain team spirit.

\section{Summary}

The intervention programme was delivered from August 2013 to December 2015, excluding days coinciding with school and college examinations or festivals, to boys in ages 13-21 who were members of NYKS youth clubs. It comprised two main components delivered weekly-exposure to a gender transformative life skills education curriculum and cricket-coaching and games sessions. The gender transformative life skills curriculum covered 14 broad topics relating to gender discrimination, notions of masculinity, and violence against women and girls; the sports component sought to build team spirit and sportsmanship, aside from developing cricketing skills. Sessions were delivered by club members selected as peer mentors, who underwent several pre-programme and refresher training programmes, often together with core trainers from the implementing agency, C3 India. Project activities also included preparing a curriculum to engage boys in NYKS clubs on topics related to gender discrimination, notions of masculinity, and violence against women and girls; building team spirit and sportsmanship among boys; addressing capacity-building and sensitisation of peer mentors about these topics and supporting them to serve as mentors to their peers; supporting peer mentors to take their peers through a gender transformative life skills curriculum; enabling boys, through the cricket-coaching component, to build cricketing skills as well as team spirit; and motivating them to join the Do Kadam programme. Just 38-39 percent attended more than half the sessions.

Many challenges were noted in the implementation of the Do Kadam programme for boys, and questions have arisen regarding the ideal length of a programme necessary to make fundamental changes in norms and practices espoused by boys. Irregular attendance was perhaps the leading challenge, and it is one that will confront any community-based programme intended for boys in this dynamic age group. Almost two in five boys did not attend at all or attended just one or two sessions, because, for most of these boys, the timing of the sessions was inconvenient; efforts are needed to resolve these and other challenges of attendance. In addition, while the peer mentor model is ideal in many ways to encourage behaviour change, in our programme, it required extensive efforts to change the norms held by peer mentors and build their capacity and confidence about imparting the programme. Indeed, project staff played a more active role than originally envisaged in engaging boys, encouraging discussion, explaining difficult concepts, and addressing intra-club conflict. Finally, we note that while the NYKS structure is an ideal base for an upscaled Do Kadam programme, its limited human and financial resources may inhibit the expansion of the programme. 


\section{Chapter 4 \\ Participation in youth clubs and Do Kadam project activities}

Drawing on data from the endline survey of intervention club members as well as monitoring data and data from in-depth interviews with selected survey respondents from the intervention arm, this chapter focuses on study participants' experiences of the Do Kadam project.

All endline survey participants ( 516 from the intervention arm and 517 from the control arm) were probed about their membership status in the club and whether they had participated in activities undertaken by their club in the preceding 12 months. Almost all boys reported that they were members of their youth club at the time of the endline survey interview (98\% and 100\% in intervention and control arms, respectively, not shown in Table 4.1). However, while just 42 percent of those in clubs in the control arm reported participating in any club activity (mostly sports), as many as 84 percent of those in the intervention arm had done so-clearly the result of the Do Kadam programme. Other activities, such as cleanliness drives, celebration of festivals and national days, and so on were rarely reported by boys in both intervention and control arms (1-2\%) (not shown in Table 4.1).

\section{Participation in gender transformative life skills sessions and cricket sessions}

In total, 516 boys were interviewed during both the baseline and the endline survey from the 15 intervention clubs, and 24 of these boys were also interviewed in-depth at the time of the baseline survey, midway through the intervention, and at the time of the endline survey (six boys who were interviewed in-depth about the time of the baseline survey could not be followed up for the endline interview). This section describes their exposure to the programme as recalled by the boys at the time of the endline survey. On the whole, 79 percent of boys in the intervention arm had participated in one or more of the gender transformative life skills sessions and 74 percent had attended at least one cricket session (Table 4.1). We assessed the regularity of their attendance in gender transformative life skills sessions and in cricket sessions separately by the proportion of boys whose attendance was considered regular, defined as participation in half or more of the 42 sessions held, or irregular, which refers to participation in fewer sessions as in once a month or less. More than three-fifths (64\%) reported that they had participated in the gender transformative life skills sessions regularly, that is, at least twice a month. In contrast, 15 percent reported that they had attended irregularly, and 21 percent reported that they had never attended. Onefourth acknowledged, however, that they had at least once missed three consecutive sessions.

Reported attendance at cricket sessions was similar. In all, 57 percent reported that they had attended most sessions (at least twice a month), 17 percent had attended less often, and 26 percent reported that they had never attended a session. In addition, 22 percent reported that they had at least once missed three consecutive sessions.

Table 4.1: Attendance in gender transformative life skills and cricket sessions Percent distribution of boys by attendance of sessions, and percentage of boys ever missed three consecutive sessions, intervention arm, 2015, endline survey

\begin{tabular}{lcc}
\hline Attendance & $\begin{array}{c}\text { Gender transformative } \\
\text { life skills sessions }\end{array}$ & Cricket sessions \\
\hline Attended one or more sessions & 78.9 & 73.6 \\
Regular: attended all sessions (whenever the session was held/once a & 42.6 & 41.3 \\
$\quad$ week) & 21.1 & 15.5 \\
Regular: attended most sessions (2-3 times a month) & 15.2 & 16.9 \\
Irregular: attended 1-2 sessions a month or less frequently & 21.1 & 26.4 \\
Never attended & 24.6 & 22.1 \\
Ever missed three consecutive sessions & $\mathbf{5 1 6}$ & $\mathbf{5 1 6}$ \\
Number of respondents in intervention clubs & & \\
\hline
\end{tabular}

Note: ${ }^{1}$ Includes 7.6 percent and 7.6 percent who reported attending 1-2 sessions per month and fewer gender transformative life skills sessions, respectively; and 6.8 percent and 10.1 percent, who reported attending $1-2$ sessions per month and fewer cricket sessions, respectively. 
We note that the extent of participation reported by boys at the time of the endline survey was higher than attendance assessed from monitoring data (Chapter 3). It is possible that at the endline survey, boys were asked to recall their attendance over the entire 42 sessions, and recall bias may result in boys reflecting attendance in the latter part of the programme rather than over the course of all 42 sessions. It is also possible that boys displayed a social desirability bias, that is, they reported more frequent than actual levels of attendance to interviewers.

\section{Perceptions about the gender transformative life skills sessions}

Among boys who had attended one or more sessions, almost all (91\%) reported that sessions were held weekly; six percent reported that sessions were held 2-3 times a month, and just three percent suggested that they were held less frequently. They reported that, by and large, sessions were held by peer mentors with support from core trainers (79\%). In a few instances, boys reported that the core trainer (8\%) or the peer mentor (13\%) had independently conducted most sessions; we note that in some clubs, there had been a turnover in peer mentors and core trainers during part of the programme and, as such, the sessions were, for a period of time, conducted by the available team member (Table 4.2).

Table 4.2: Participation in gender transformative life skills sessions Percent distribution of boys reporting participation, by frequency and facilitators of gender transformative life skills sessions, intervention arm, 2015, endline survey

\begin{tabular}{lr}
\hline Gender transformative life skills sessions & Percent \\
\hline Frequency of gender transformative life skills sessions & 91.4 \\
Once a week & 5.7 \\
2 -3 times a month & 0.5 \\
Once a month & 2.5 \\
Rarely & 12.8 \\
Facilitators of gender transformative life skills sessions & 7.6 \\
Peer mentor & 79.4 \\
Core trainer & 0.3 \\
Peer mentor with support from the core trainer & $\mathbf{4 0 7}$ \\
Cannot remember & \\
Number of respondents who had participated in LSE sessions & \\
\hline
\end{tabular}

Note: $L S E=$ Life skills education.

The 42-session curriculum covered a total of 14 broad topics on egalitarian relations with women and girls and reducing various forms of emotional and physical violence against them. Consensual sexual relations was also covered under the topics to sensitise boys on this matter. Each broad topic was covered over a varying number of sessions. Boys who reported attending one or more sessions were asked whether they were aware that each broad area covered in the session had been imparted, whether they had attended the session, whether they had learned something new from the session, and whether they had enjoyed the session.

Between 64 percent and 93 percent were aware that sessions had been held on each of the 14 topics, while more than eight out of ten boys were able to recall that sessions had been held on helping with housework, respecting women and girls, maintaining healthy relationships with family and friends, team spirit and team building, teasing women and girls, and substance abuse. The majority of boys-between 54 percent and 92 percent-recalled attending at least one session in which a particular topic had been addressed. Notably, just between half and two-thirds reported that they had attended sessions on new notions of masculinity, healthy sexual relationships, importance of never committing violence on a woman, violence and aggression, bragging about relationships with girls, and taking responsibility for one's own behaviour with girls (Table 4.3).

Boys were also asked whether they had learned something new and whether they had liked what was imparted in each topic. Almost all boys who had attended sessions on each topic reported that they had learned something new and had liked the sessions attended.

On the whole, more than one in three recalled that all 14 topics had been imparted, 20 percent reported that they had attended sessions relating to all 14 topics, and similar percentages $(17-19 \%)$ reported that they had learned something new from and had liked all 14 topics. On average, boys attended sessions relating to 10 of the 14 topics imparted and had liked and learned from all ten. 
Table 4.3: Recall of content and perceptions about the quality of gender transformative life skills sessions Percentage of boys reporting awareness of topic discussed, attendance, and learning experiences, intervention arm, 2015, endline survey

\begin{tabular}{|c|c|c|c|c|}
\hline \multirow[t]{2}{*}{ LSE session topics } & \multirow[t]{2}{*}{$\begin{array}{l}\text { Aware that } \\
\text { topic was } \\
\text { addressed }\end{array}$} & \multirow[t]{2}{*}{$\begin{array}{l}\text { Attended the } \\
\text { session }\end{array}$} & \multicolumn{2}{|c|}{$\begin{array}{l}\text { Learning experiences among } \\
\text { those who attended the } \\
\text { sessions }\end{array}$} \\
\hline & & & $\begin{array}{c}\text { Learned } \\
\text { something } \\
\text { new }\end{array}$ & $\begin{array}{l}\text { Liked the } \\
\text { session }\end{array}$ \\
\hline \multicolumn{5}{|l|}{ Topics covered } \\
\hline Helping with housework & 93.1 & 91.9 & 97.3 & 99.2 \\
\hline Respecting women and girls & 90.7 & 88.0 & 96.6 & 99.4 \\
\hline Healthy relationship with family and friends & 84.8 & 77.9 & 97.8 & 98.7 \\
\hline Team spirit and team building & 87.2 & 80.8 & 98.8 & 99.7 \\
\hline Life skills and how to use these skills in own life & 75.2 & 69.8 & 99.3 & 99.6 \\
\hline New notions of masculinity & 69.0 & 59.2 & 98.3 & 99.2 \\
\hline Healthy sexual relationship & 63.9 & 53.6 & 98.2 & 99.5 \\
\hline Teasing women and girls & 93.4 & 88.7 & 95.6 & 99.7 \\
\hline $\begin{array}{l}\text { Importance of never committing violence on a } \\
\text { woman }\end{array}$ & 75.4 & 65.8 & 96.3 & 99.3 \\
\hline Violence and aggression & 76.5 & 66.6 & 97.4 & 100.0 \\
\hline Bragging about relationship with girls & 74.0 & 67.1 & 99.3 & 99.6 \\
\hline Responsibility for own behaviour towards girls & 72.5 & 63.4 & 99.2 & 100.0 \\
\hline Substance abuse and links to violence & 86.7 & 79.6 & 96.6 & 100.0 \\
\hline Sexual abuse towards women and girls & 77.4 & 70.5 & 96.9 & 98.6 \\
\hline \multicolumn{5}{|l|}{ Perceptions about quality } \\
\hline $\begin{array}{l}\text { Aware about, who attended, learned from, and } \\
\text { liked all } 14 \text { topics (\%) }\end{array}$ & 36.1 & 19.7 & 17.2 & 19.2 \\
\hline $\begin{array}{l}\text { Mean number of topics about which the } \\
\text { respondent was aware, that the respondent hac } \\
\text { attended, from which the respondent learned } \\
\text { something new, and that the respondent liked }\end{array}$ & 11.2 & 10.2 & 9.9 & 10.2 \\
\hline Number of respondents attended LSE sessions & 407 & 407 & NS & NS \\
\hline
\end{tabular}

Note: LSE= Life skills education; NS=Not shown; the denominator for each row varied, and therefore, not shown.

In in-depth interviews, boys elaborated on what they had learned in the course of the gender transformative life skills sessions. While most boys were aware of the focus of the sessions, some elaborated on their experiences and reactions. A large number of boys discussed such topics as sexual harassment and spreading rumours about girls (13 boys) and violence against women and girls (13 boys). Several also recalled sessions about the importance of developing new notions of masculinity and helping in household chores (12 boys), the importance of communication (how to speak to others, how to resolve conflicts through discussion) ( 9 boys), and the importance of friendships ( 7 boys). Positive responses of boys to gender transformative life skills sessions are evident from their narratives that follow.

Yes, I liked it a lot and had fun too. Because there we were taught about how to talk to people, how to live well in the home, to study well, to help in household chores, not to harass girls, to live in peace with everyone and we were also taught about sports as well..... Whatever sessions I attended I liked it,. [Hindu, age 15, completed Class 7, selection criterion: highly gendered, ID6]

We learned that there should be no domestic violence and if domestic violence takes place then we should stop it. We also learned that there should not be child marriages, we should help in household chores, that we should not spread rumours and wrong things about any girl..... The sessions gave us the opportunity to live life in a healthy and better way. [Hindu, age 20, undergraduate student, selection criterion: perpetrated physical violence, ID16] 
I felt good because I got to learn good things. I mean I got to learn what is good and bad in this world, what all to do. It included educational discussions so that is why I liked it. I learned many things, like, if there is domestic violence going on, then we should explain, stop it, and not encourage it. I already told you about domestic violence and I will tell you one more thing that I learnt there: even if we see an adult member doing something wrong then it is our responsibility to explain to them not to do these things. Like if they are hitting or abusing their wife, we should explain to them not to do it.... We learned a lot about domestic violence, I mean what to do and what not to. This is what I liked. [Hindu, age 18, completed Class 12, selection criterion: perpetrated sexual violence, ID28]

We were taught nice things in it like how to live in a society, how to talk, how to work in a group, and if a woman is facing violence then how to stop it from taking place. All these things were taught. We were taught how to behave outside the home, we were taught that we should do household chores. [Hindu, age 21, completed Class 12, selection criterion: moderately gendered, ID15]

We learned about domestic violence, I learned that at home everyone should make decisions together; it should not depend on one person's interest. We should help in household work. I also learned that one should not hit his wife after getting drunk, all this was taught... Yes they taught us about teasing girls and they told us, like on the road how boys tease a girl by tugging on her dupatta, that is wrong, we should not tease girl/woman. As much rights as we boys have, the same rights should be given to girls, all this was taught.... what I like there is that when I went there I got to meet lots of friends. I even learned how to study properly. [Hindu, age 16, completed Class 10, selection criterion: moderately gendered, ID25]

I participated in everything. In Jivan Kaushal sessions I learned about what is being a man, I learned that teasing girls is not love. I got to learn so much, along with our friends. Lots of things, like earlier I used to think that girls cannot be friends with a boy, but now I don't think that, they can be our friends. Violence against woman or teasing girls is wrong, doing any kind of drugs is wrong, I learned all these things..... Sir, we went there and were taught good things, got to know new stuff. To help with household work, not to sit idle in our free time, instead to do something, not to tease girls and to see everyone as equal, all this was taught. [Hindu, age 15, completed Class 11, selection criterion: perpetrated physical violence, ID31]

I learned that one should not waste their precious time on useless things. We should not tease girls and if someone is doing this then we should stop it from happening. If a man is helping in household chores then his value is not getting reduced because of doing this kind of work, we should help in household work and in our village, if there is any big or even small kind of violence taking place then we should help the victim. [Hindu, age 19, completed Class 12, selection criterion: sexual violence, ID17]

Yes, I enjoyed the programme. The class on how boys exaggerate a normal conversation between them and a girl was very good because it is reality and this actually happens. [Hindu, age 15, completed Class 8, selection criterion: perpetrated physical violence, ID8]

Yes, they taught us that if one of my friends misbehaves with a girl then I am supposed to make him understand or I should explain to him not to do it as it is a bad behaviour or inappropriate. All these things were taught to us in the programme. [Hindu, age 16, completed Class 8 , selection criterion: moderately gendered, ID18]

\section{Perceptions about the cricket sessions}

Two out of three boys who had attended at least one cricket session (67\%) reported that sessions had been held weekly, while 19 percent reported that they were held 2-3 times a month. Most boys reported that the cricket sessions they attended had been led by the core trainer and/or sports coach together with the peer mentor (69\%); seven percent reported that sessions were led by the core trainer and/or coach on his own, and 21 percent reported that sessions were led only by the peer mentor (Table 4.4).

A key component of the Do Kadam programme was the organisation of inter-club cricket matches. Half (51\%) of all boys had participated in the cricket tournament, either as a team member (38\%) or as a spectator (14\%).

All 24 boys interviewed in-depth had also participated in cricket sessions, and 15 of them narrated their experiences extensively. Almost all described how their cricket technique had improved, and many noted that their team spirit and courtesy on the playing field had also improved. Aside from cricket, several boys described how the sessions had strengthened their bonds of friendship with team-mates, while others spoke of the oath they would take to uphold 
Table 4.4: Participation in cricket-coaching sessions

Percent distribution of boys reporting participation, by frequency and facilitators of cricket sessions, and percentage reporting participation in cricket tournaments, intervention arm, 2015, endline survey

\begin{tabular}{lr}
\hline Cricket sessions & Percent \\
\hline Frequency of cricket sessions & 67.1 \\
Once a week & 19.2 \\
$2-3$ times a month & 7.9 \\
Once a month & 5.8 \\
Rarely & 21.3 \\
Facilitators of cricket sessions & 6.6 \\
Peer mentor & 69.2 \\
Core trainer/coach & 2.9 \\
Peer mentor and core trainer/coach & $\mathbf{3 8 0}$ \\
Cannot remember & \\
Number of respondents who participated in cricket sessions & \\
Participation in cricket tournament & 51.2 \\
Participated in cricket tournament & 37.6 \\
As a team member & 13.6 \\
As spectator & $\mathbf{5 1 6}$ \\
Number of respondents in intervention clubs & \\
\hline
\end{tabular}

team spirit and ethics and also not to tease girls, and still others suggested that participating in the cricket sessions had boosted their self-confidence. The following narratives show the impact that the cricket-coaching sessions had on the boys.

Yes in the past six months, I played in a tournament. The coach came to teach us. He taught me how to hold the bat well and how to bowl. All these basic things he taught me. Yes, definitely I have started playing very well; there has been a change in the way I play the game now. We won two matches. [Hindu, age 18, completed Class 8, selection criterion: moderately gendered, ID5]

Yes, I got training for cricket.... One coach used to come and he would teach us how to bowl and how to bat and as well as how to field. The coach taught us how to plan a game, how long the pitch is, what is the weight of a ball, how long and wide a bat should be and how to hold the bat. We were taught that before playing, we should take an oath not to tease girls, not to cheat in the game, and not to make mistakes in the game. Now I think if I had been taught these things earlier, my life would have been a lot better now. I play a lot better than before...... [Hindu, age 21, completed Class 12, selection criterion: moderately gendered, ID15]

I play cricket in school and in the village too; there is a park in this village that is where I play. I like it because in the evening, it is a good form of time pass and it also makes our body fit, our body gets exercise. Friendship becomes stronger. When one plays a sport with friends and spends maximum time with friends then friendship becomes stronger. We start understanding each other and enjoy each other's company so friendship becomes stronger.... Also the class on cricket was good; there were many things I was not aware of so I go to learn lot of things about cricket so I enjoyed it. [Hindu, age 15, completed Class 8, selection criterion: perpetrated physical violence, ID8]

Yes, I do play games -cricket and football. We were taught that playing is good for healthy life. I enjoy cricket a lot. When we play on a regular basis, eventually we start knowing each other well and this leads to friendship. When we meet each other quite often then we get much better and our friendship becomes much stronger, thicker. Yes, I enjoyed the training session a lot. Because they taught us how to hold the ball in a proper way, how to hold the bat so that we can make more runs. They taught us how to bowl.... Yes, there was change. Earlier I didn't know how to bowl, but now I bowl well. [Hindu, age 16, completed Class 8, selection criterion: perpetrated physical violence, ID32]

In the cricket tournament I was selected as a bowler in the team. I took part in playing cricket in the club as well....Yes, I liked all these activities, everything was enjoyable and I was enjoying every bit of it....Yes. 
I learnt how to behave with people; before I could not play so well, but in the club we were taught to play sports well, I also took part in the training given for playing cricket so in that I learned how to catch the ball, how to bowl, how to hold a bat and where one is supposed to stand for fielding. [Hindu, age 17, completed Class 9, selection criterion: perpetrated physical violence, ID19]

\section{Participation in community events organised by intervention clubs}

As mentioned earlier, aside from cricket tournaments, events organised by club members to engage other community members included special events, such as cycling, drawing and essay competitions, a gender power walk, and public events at which eminent individuals addressed the community. Findings presented in Table 4.5 show that about half of the boys in the intervention arm had attended one or more community events.

Among those who had participated in a community event, more than three in five had attended events at which eminent individuals shared their views on discrimination and violence against women and girls (63\%), 44 percent had participated in a drawing competition, and 23 percent had participated in the gender power walk. In contrast, much fewer had participated in an essay competition, a slow cycling competition, or any other competition organised by the club (5-13\%).

Table 4.5: Participation in community events Percentage of boys reporting participation in one or more community events of the Do Kadam programme, by events, intervention arm, 2015, endline survey

\begin{tabular}{lr}
\hline Community events & Percent \\
\hline Participation in any community event & 49.0 \\
Participated in any community event during Do Kadam programme & $\mathbf{5 1 6}$ \\
Number of respondents in intervention clubs & 22.9 \\
Community events in which respondent participated & 5.1 \\
Gender power walk & 13.1 \\
Essay competition & 43.9 \\
Slow cycling competition of boys and girls & 4.7 \\
Drawing competition & 62.9 \\
Any other competition & $\mathbf{2 5 3}$ \\
Attended any event at which an eminent/influential person spoke on social issues & \\
Number of respondents who participated in one or more community event & \\
\hline
\end{tabular}

\section{Reasons for irregular participation or non-participation in Do Kadam activities}

Earlier findings have shown that attendance in various Do Kadam programme activities-the gender transformative life skills sessions, the cricket sessions and inter-club cricket competitions, and the community events-was irregular for a number of boys and that several club members had never attended or participated in these activities. Table 4.6 explores the reasons among boys who reported irregular attendance or non-attendance in the endline survey.

Among those who had never participated or had participated irregularly in the gender transformative life skills sessions and the cricket sessions, more than half (50-53\%) attributed their non-participation to the inconvenient timing of sessions. One-third of all boys reported that the timing of the gender transformative life skills sessions (31\%) did not suit them or that session timings clashed with their school or work responsibilities (14-23\%). A second major reason was out-migration: a large proportion of boys (21-24\%) reported that they had moved away from their village for work or education and had revisited their homes only occasionally and hence had attended gender transformative life skills sessions sporadically.

Other reasons reflected a host of personal reasons. Notably, about one-fifth of those who had never attended sessions or had attended sessions irregularly reported that they were not aware about the location or timing of the session (19-22\%). A small proportion of boys reported conflicts as the reason for their lack of participation: caste related dynamics (3-4\%) and conflict among group members (5-9\%).

With regard to reasons for non-participation in inter-club cricket competitions and community events, 34 percent and 43 percent, respectively, attributed their lack of participation to inconvenient timings of these events. At the 
Table 4.6: Reasons for irregular participation and non-participation in the Do Kadam programme Percentage of boys reporting reasons for irregular participation in LSE and sports sessions and non-participation in cricket tournaments and community events, by session type and events, intervention arm, 2015, endline survey

\begin{tabular}{|c|c|c|c|c|}
\hline \multirow{2}{*}{$\begin{array}{l}\text { Reasons for irregular participation and non- } \\
\text { participation }\end{array}$} & \multicolumn{2}{|c|}{ Irregular participation ${ }^{1}$} & \multicolumn{2}{|c|}{ Non-participation } \\
\hline & $\begin{array}{c}\text { Gender } \\
\text { transformative } \\
\text { life skills } \\
\text { sessions }\end{array}$ & $\begin{array}{l}\text { Cricket } \\
\text { sessions }\end{array}$ & $\begin{array}{c}\text { Inter-club } \\
\text { cricket } \\
\text { competitions/ } \\
\text { tournament }\end{array}$ & $\begin{array}{l}\text { Community } \\
\text { events }\end{array}$ \\
\hline \multicolumn{5}{|l|}{ Unsuitable timing } \\
\hline Time did not suit & 31.0 & 30.9 & 17.9 & 23.2 \\
\hline Clashed with school timing & 13.9 & 18.8 & 12.7 & 12.9 \\
\hline Clashed with work responsibilities & 22.5 & 22.0 & 9.5 & 17.5 \\
\hline Any reason related to inconvenient timing & 50.3 & 53.4 & 34.1 & 43.4 \\
\hline \multicolumn{5}{|l|}{ Other } \\
\hline $\begin{array}{l}\text { Out-migration: respondent had moved away from } \\
\text { village for schooling/work }\end{array}$ & 24.1 & 20.6 & 18.3 & 19.0 \\
\hline $\begin{array}{l}\text { Lack of awareness: respondent not aware about } \\
\text { session/activity }\end{array}$ & 18.7 & 21.9 & 18.7 & 32.4 \\
\hline Caste issues & 4.3 & 3.1 & 2.4 & 3.0 \\
\hline Conflict among group members & 4.8 & 9.0 & 4.0 & 4.6 \\
\hline Not selected in team & - & - & 24.2 & - \\
\hline Location did not suit & 1.1 & 0.9 & 0.0 & 0.0 \\
\hline No friends in the group & 0.5 & 0.0 & 0.0 & 0.4 \\
\hline Respondent did not like the group activities & 1.6 & 2.7 & 2.4 & 1.1 \\
\hline Parents refused & 1.1 & 0.4 & 0.8 & 0.8 \\
\hline Any other reason (illness, got married, etc.) & 2.1 & 1.8 & 2.3 & 0.0 \\
\hline $\begin{array}{l}\text { Number of respondents who participated once a } \\
\text { month/rarely or not at all }\end{array}$ & $187^{2}$ & 223 & 252 & 262 \\
\hline
\end{tabular}

Notes: LSE = Life skills education; ${ }^{1}$ Boys who reported participation in gender transformative life skills sessions and cricket sessions irregularly or had not participated at all were asked about the reasons for their irregular participation; ${ }^{2}$ Among 187 boys, nine did not give specific reasons for irregular participation.

same time, a sizable proportion, one-fourth of boys, attributed their non-participation in cricket matches to the fact that they were not selected to play on the club team. Again, one-third of boys who did not attend a community event reported that they were not aware that such an event was being held.

Findings from in-depth interviews with 24 boys held at the time of the endline survey also suggest that the leading reasons for non-/irregular participation related to inconvenient timing of the sessions. Indeed, while 12 boys reported that they had attended almost every session, nine reported they had sometimes attended sessions, and two reported they had rarely attended sessions. Most of those who had attended sometimes or rarely reported that the timing of the sessions did not suit them. These boys had work or school commitments, and some had lived away from home for some weeks or months during the course of the intervention. Notably, not a single boy attributed his irregular attendance to lack of interest. Given below are the narratives of boys who discussed the reasons for their irregular attendance of the Do Kadam programme.

I have participated in the sports sessions and the Jivan Kaushal sessions, but not the tournaments because I wasn't in the village all the time. Sometimes I had to go out so I missed the sessions, but whenever I was in this village I made sure to be a part of this club. [Hindu, age 15, completed Class 8, selection criterion: had perpetrated physical violence, ID8]

The reason that I didn't take part in club activities was because I wasn't in the village all the time, and when I was here, I was not aware of the programme timings, etc. I was working in another area, so I was moving a lot from one place to another. [Hindu, age 17, completed Class 9, selection criterion: highly gendered, ID13] 
Yes, I went a few times and at times I did not attend it. I attended less than half of all sessions. If there were 100 sessions in total, I attended only 20-25 sessions. I took part in Jivan Kaushal sessions along with sports sessions. Due to my studies I could not get time. From morning to evening I was out of the house and in the evenings when I came back home, I give tuitions to a few children and then I have to work on the field as well. Yes, this programme was scheduled on every Friday in our village, but I would like it to take place on Sundays, because on Sunday we are free and there is no work, whereas on Fridays I have coaching classes. [Hindu, age 19, completed Class 12, selection criterion: perpetrated sexual violence, ID17]

I took part in 15-20 sessions, in the cricket tournament as well; I was selected as a bowler in the team. I also used to play cricket in the club.... I was not able attend these regularly because I was working so I had to go out. I don't think that I would be able to participate in your sessions or programme regularly because of my work commitments. I mean if you want you can make as many changes as you want but still I won't be able to attend it regularly, I will have to miss 2-3 sessions. [Hindu, age 17, completed Class 9, selection criterion: perpetrated physical violence, ID 20]

\section{Perceived quality of the Do Kadam programme}

Boys who reported participation in any Do Kadam programme activities provided their perspectives on the quality of the intervention (Table 4.7). Almost all (89\%) reported that they looked forward to participating in activities; however, while 37 percent believed that the programme duration was sufficient, almost half (46\%) believed that the duration of the programme was too short and needed to be extended.

We also explored boys' perceptions about the quality of the gender transformative life skills sessions, the cricket sessions, and, more specifically, the cricket-coaching sessions (Table 4.7). In general, most boys were satisfied with the contributions of peer mentors as well as the core trainer and cricket coach. Indeed, 75 percent and 80 percent of boys reported that the sports peer mentor and the gender transformative life skills peer mentor, respectively, always explained session content clearly; somewhat more-93 percent-reported that the core trainer and the sports coach had done so. A large proportion of boys -72 percent- also reported that the gender transformative life skills peer mentor and the core trainer were always approachable, and 70 percent reported that peer mentors of the gender transformative life skills sessions were always able to answer effectively the questions that boys raised during discussions. Negative assessments were reported by less than 10 percent of boys who had ever participated in Do Kadam programme activities.

Among the 24 boys who were interviewed in-depth about the time of the endline survey, perceptions about the quality of the programme were overwhelmingly positive. Indeed, they noted that the peer mentors were, by and large, punctual, able to convey new ideas, and able to respond to queries of boys (18 boys). They also believed that the strategy of combining the gender transformative life skills sessions with sports encouraged participation and built cohesiveness among club members. Positive responses of boys to the programme are evident from the following narratives.

They were able to run the sessions well. They would make us understand things pretty well. For example, there were situations in which I was not able to understand three things out of five so I would ask them. They would also ask during the session if someone had not understood any point. So then I would say that I did not understand the domestic violence session, or the psychological and physical violence session, and they would explain these things to us, even taking an extra two hours time to do so. [Hindu, age 16, completed Class 9, selection criterion: perpetrated physical violence, ID7]

Yes, they were able to direct and run this programme well. No he (the peer mentor) did not lack in anything, he was fine. When we had a session, he would call students from his cell phone or he would go to their homes to call them. No other peer mentor would have done this. [Hindu, age 15, completed Class 8 , selection criterion: perpetrated physical violence, ID8]

Both the peer mentors were good. They would give information to every member and would seat everyone in a group before starting the class. They were also good in maintaining discipline while the class was going on; they would do everything nicely; they would make everything understandable to us and they would concentrate on everyone and everyone would listen to what they were saying.... I would ask them to explain this or that if I was not able to understand something, and if they had the information they would definitely help me. If they didn't have the answer to my question, they would get the information from elsewhere and give me my answer. [Hindu, age 21, completed Class 12, selection criterion: perpetrated physical violence, ID11] 
Table 4.7: Perceptions about the quality of the Do Kadam programme Percent distribution of boys who participated in the Do Kadam programme reporting their perceptions and assessment, by duration of programme and inputs of facilitators, intervention arm, 2015, endline survey

Perceptions about the Do Kadam programme in general

Looked forward to attending Do Kadam programme activities

Assessment of the duration of the Do Kadam programme

Too long

Too short

Just right

Not sure

Number of respondents who participated in any Do Kadam activity (LSE/cricket/community events)

Perceptions about the gender transformative life skills sessions

Peer mentor explained things clearly during sessions

Always

Sometimes

Rarely

Peer mentor was approachable for queries/problems

Always

Sometimes

Rarely

Peer mentor was able to answer questions posed by group members

Always

Sometimes

Rarely

Core trainer explained things clearly during sessions

Always

Sometimes

Rarely

Core trainer was approachable for queries/problems

Always

Sometimes

Rarely

Number of respondents participated in gender transformative life skills sessions

Perceptions about cricket sessions

Sports peer mentor explained things clearly

Always

Sometimes

Rarely

Number of respondents who participated in cricket sessions

Perceptions about cricket-coaching sessions

Coach or core trainer explained activities clearly during coaching sessions

Always

Sometimes

Rarely

Number of respondents who participated in cricket-coaching sessions

Note: $L S E=$ Life skills education. 
They were very nice. There wasn't any issue. They explained thing properly, both were okay. Yes they had proper knowledge, and apart from them, we could ask $X$ sir too (the core trainer). There wasn't any weakness in the peer mentors, they gave good quality lessons, explained thing properly, looked after every boy in the group, and if someone was not paying attention they would talk to him and tell him to pay attention so that that everyone understands everything; that way they kept everyone in order. [Hindu, age 16, completed Class 10, selection criterion: moderately gendered, ID25]

Some dissatisfaction was also expressed: a few boys reported that the core trainer and/or the peer mentor did not hold sessions regularly or punctually, that the peer mentor could not manage the sessions or convey its messages appropriately, and some complained about unfair distribution of snacks in each session.

\section{Recommendations for change in the programme}

Boys interviewed in-depth were also asked their perceptions, on the whole, about the Do Kadam programme and the extent to which they recommended changes in it, if it was repeated. Most boys agreed that the programme was useful and should be replicated. Indeed, narratives of 14 boys highlight their perception about the need to repeat the programme, and several also made recommendations about how the programme should be modified. Key suggestions included: the inclusion of a parallel programme for girls (10 boys), introduction of additional sports or activities ( 5 boys), and maintenance of better club-level discipline ( 3 boys), punctuality of peer mentors, coaches, and core trainers ( 4 boys), and better quality peer mentors ( 3 boys). One boy made a strong plea for introducing the programme at school level, so that girls and boys and younger students as well, would be exposed to it. Some examples of their recommendations are given here.

According to me there should be more programmes like Do Kadam because boys will join it and with what they learn, they won't think about doing violence like this ever. Girls too should be included so that they know their rights, what they should do and not. It will be better if sessions are held separately for girls, so that their parents won't stop them from attending, and boys and girls won't feel embarrassed if they want to ask something; they won't hesitate to ask questions in front of their brother or sister [same sex peers]. [Hindu, age 16, completed Class 10, selection criterion: moderately gendered, ID25]

I think this programme should be introduced again so that people who were not able to take part in it and whose thinking didn't change will have a chance. I don't think there is a need to change anything in it, but girls should be a part of it. They should have different sessions and different classes and, to teach them, there should be a female because then only will people in the village allow their daughters to attend. [Hindu, age 21, completed Class 12, selection criterion: perpetrated physical violence, ID11]

Now if you put cricket in your programme then it should take place regularly. This is where it failed; there should be a proper routine or schedule for cricket. It should be done properly and punctually. [Hindu, age 18, completed Class 9, selection criterion: highly gendered, ID3]

Your programme is good; you were successful to bring about changes in our attitudes towards women and girls....You were able to change say 40 percent of the group.... People who are smart and educated they were able to change their mindset, whereas the remaining 60 percent are fools and uneducated, therefore, there has been no impact on them and they still abuse women someway and somehow.... think you should also introduce these sessions to girls as well along with boys.... And I think there should be a film screening where men and women sit and watch; the movie should be based on violence against women. [Hindu, age 20, undergraduate student, selection criterion: perpetrated physical violence, ID16]

Everything in it is good, keep everything as it is but please add football to it. Please also remove or replace $X$ (peer mentor) with someone else. This programme of yours, Do Kadam, was good and it has made a lot of changes in this village. I think this should be started once again. [Hindu, age 17, completed Class 9, selection criterion: perpetrated physical violence, ID19]

Whatever was organised by you people was good in a way. I mean the way you people came and made a group of so many boys and educated them was good. But giving them sweets and snacks was not good. I am being honest that the sweets and snacks actually made boys bad because they think, "Come at least we will get one plate of snacks", so they come, eat and go. [Hindu, age 17, completed Class 11, selection criterion: perpetrated physical violence, ID22]

See the way boys are getting educated, in the same way girls' education is also important, so then a programme should be started for girls as well. Better if it is introduced at school level, then it will be very 
successful and reach more boys and girls. Some may have found what you tried to teach them cheap and controversial, so if it is taught to students as a subject in school, then there will definitely be a transformation. We all know that there are examinations for topics printed in books so then students and guardians take it seriously. Guardians insist that children learn and understand the topic because they will be examined in it. Like you know, we were taught about traffic signals in our childhood days and we still remember them. In the same way, if we learn about teasing or domestic violence in class, if we have classes on how to behave with girls, then students will pay attention to it and the situation will improve. Boys will always remember this and won't behave nastily with girls. I think it is important to generate this kind of knowledge in school level because then only mentality will change or else it won't. [Hindu, age 18, completed Class 12, selection criterion: moderately gendered, ID29]

\section{Summary}

The findings presented in this chapter confirm that far more boys in the intervention than control arm reported engagement in club activities. While those in intervention clubs reported participation in a wide range of activities, mostly those who were initiated through the Do Kadam programme, almost all those in the control arm who reported participation in club activities had been engaged in sports.

Most boys in the intervention arm participated in Do Kadam activities. Almost four in five had attended gender transformative life skills sessions, three in four had attended cricket sessions, and half had participated in community-level events organised by the club. Regular attendance in gender transformative life skills sessions and cricket sessions was, however, reported by fewer: 64 percent and 57 percent, respectively. Reasons for irregular or non-participation were largely related to inconvenient timings, out-migration, and lack of information about the timing and location of sessions or events.

Most boys reported that sessions had been indeed conducted by the peer mentor in conjunction with the core trainer or coach (69\%). Among those exposed to the gender transformative life skills sessions, most were aware of the 14 broad topics discussed in these sessions (64\%-93\% were aware that sessions had been held on each of these topics) and had attended sessions covering, on average, 10 of these sessions; one in five had attended sessions relating to all 14 topics. Almost all those who had attended sessions reported that they had both liked the sessions on each topic and learned something new from them.

Boys were largely positive about the quality of the programme. Almost all (89\%) reported that they looked forward to sessions, and almost half believed the duration of the programme was too short. They reported, moreover, that the peer mentor was always approachable (72\%), always explained issues clearly (80\%), and could always answer their questions (70\%); more were positive about the core trainer's and the coach's ability to explain issues clearly (93\% each in life skills and cricket programme). Those interviewed in-depth confirmed the perceptions that the quality of the programme was good, although a few boys did indeed suggest that the sessions had not been held punctually or regularly, that the peer mentor could not manage the session, and that he could not always convey its messages appropriately. Well over half those interviewed in-depth suggested the need to expand the programme to other clubs, and suggestions for modifications included adding a component for girls, introduction of additional sports and other activities, maintenance of better club-level discipline, punctuality, and uniformly high-quality peer mentors. 


\section{Chapter 5 \\ Effect of the intervention on the attitudes and behaviours of boys}

The main outcomes that the Do Kadam project sought to influence were gender role attitudes and notions of masculinity held by boys, perceptions about peer reaction to boys acting in gender equitable ways, perceptions about controlling behaviours over women and girls, and attitudes about gender-based violence. The secondary outcomes it sought to affect were to encourage boys to intervene if they witnessed violence perpetrated against women and girls and to reduce the perpetration of gender-based violence by boys. This chapter presents findings with regard to the effect of the intervention on influencing these outcomes, that is, the attitudes and behaviours of boys. We begin with a discussion of the method used for analysing the effect on main outcomes, followed by a description of the results of the effect analysis.

\section{Method used for effect analysis}

We used data from the endline survey of boys to analyse the effect of the intervention. As mentioned in the first Chapter, out of 1,149 respondents of the baseline survey, we were able to successfully interview 1,033 respondents in the course of the endline survey. Analysis of the effect of the programme was carried out on those for whom both baseline and endline data were available. We note that the endline survey was carried out about 20 months after the baseline survey, and respondents who were in ages 13-21 at the time of the baseline survey were in ages 14-23 at the time of the endline survey. Only 68 respondents were aged 14 and the remaining 965 were in ages 15 or above.

In the first part of this chapter, we estimate the overall impact of the programme on both primary and secondary outcomes; the impact of the programme was estimated using cluster summary measures. Following this, we explore whether the impact of the intervention differed by the regularity of attendance in the programme; our analysis uses Generalised Estimating Equations models to do so. We describe the two methodologies below.

\section{Cluster summary approach}

As described in Chapter 2, the outcomes for which effect is to be estimated and the factors that might affect these outcomes were well balanced between intervention and control arms at baseline level, which thereby ruled out the need for covariate-adjusted impact analysis. Thus, using the endline data, we compared cluster-level summary measures of the outcome measures between intervention and control arms. As discussed earlier, there was considerable variation in cluster size, and thus we preferred to present cluster summaries over point estimates from individual values.

We applied the intention to treat (ITT) analysis for estimating the effect of the intervention, or, in other words, the analysis is based on the initial treatment assignment (that is, which club receives intervention). Effect estimates were computed as the difference in cluster-level proportions or means, as appropriate. We also examined the distribution of each outcome in each of the two arms and they all appeared fairly normally distributed (that is, no significant positive or negative skewness was apparent). Hence, no further transformation of data was required prior to the analysis (Hayes and Moulton, 2009). We compared unadjusted cluster-level summary measures across the two arms using unpaired t-test for the outcomes. For outcomes that showed evidence of an intervention effect, we applied the t-test with unequal variances to check whether precision of the variance estimates improved.

\section{Generalised Estimating Equations (GEE) approach}

In order to assess whether the impact of the programme differed by the regularity of attendance in intervention activities, we defined regular programme participants to include boys who had attended at least two of the four monthly sessions on gender transformative life skills education as well as cricket-coaching. All those in the intervention sites who had never participated in either the gender transformative life skills sessions or the cricket sessions were defined as "non-participants in intervention sites". All other participants from intervention sites were defined as "irregular participants". With this definition, 53 percent of boys in the intervention arm $(\mathrm{N}=273)$ were considered regular, 29 percent $(\mathrm{N}=149)$ of participants were considered irregular, and the remaining 18 percent $(N=94)$ were defined as non-participants. Survey participants from the control clubs $(N=517)$, where no intervention was offered, served as the reference group for all the three groups described above. 
In order to ensure that the four groups may be compared, we first examined the balance between the four groups described above, and then adjusted during regression analysis for the differences in those covariates for which considerable differences were observed. Our investigation revealed that the four groups continued to be balanced in terms of most of the indicators reported at the baseline level. Differences were however observed in some indicators, notably the wealth score, engagement in paid work in the 12 months preceding the baseline, witnessing their father beating their mother, and the index measuring gender role attitudes and notions of masculinity. A table comparing key baseline indicators for these four groups is presented in Appendix 1.2.

The effect of regularity of attendance in intervention activities has been estimated through Generalised Estimating Equations (GEE) models. GEE models provide a method of individual-level regression modelling that allows for clustering without incorporating additional terms in the model for estimating cluster effects. GEE models assume that observations within the same cluster are correlated and adjust for such correlation (Hayes and Moulton, 2009).

For dichotomous outcomes the GEE model can be written as follows:

$$
\operatorname{logit}\left(\pi_{i j k}\right)=\log \left(\frac{\pi_{i j k}}{1-\pi_{i j k}}\right)=\alpha+\beta_{i}+\sum_{l} \gamma_{l} z_{i j k l}
$$

where, $\Pi_{i \mathrm{jk}}$ is a parameter related to the outcome of interest and refers to the $\mathrm{k}^{\text {th }}$ individual in the $\mathrm{j}^{\text {th }}$ cluster in the $\mathrm{i}^{\text {th }}$ treatment arm; $\beta_{i}$ is the intervention effect, and $\gamma_{1}$ represent the effects of a set of individual-level covariates $z_{1} z_{2} z_{3}$ $z_{4} \ldots . z_{1}$. The term $\alpha$ is the intercept that represents the average outcome in the control arm when all covariates are set to zero.

A similar equation may be written for non-dichotomous quantitative outcomes;

$$
\mu_{i j k}=\alpha+\beta_{i}+\sum_{l} \gamma_{l} z_{i j k l}
$$

\section{Effect of the Do Kadam programme on attitudes of boys}

As in Chapter 2, we explore the attitudes reported by boys in the endline survey in four broad areas: gender role attitudes and notions of masculinity, perceptions about peer reactions to boys acting in gender equitable ways, perceptions about a man's or boy's right to control women and girls, and the acceptability of a man's or boy's right to perpetrate violence on women and girls. Summary measures constructed to summarise the responses provided by boys in each of these four domains as well as the baseline levels of individual components of the indexes used have been described in Chapter 2. Endline levels of individual components of all summary measures are presented in Appendices 1.3-1.6.

Table 5.1 describes the findings on the effect of the intervention on the attitudes of boys in the above-mentioned four domains. It presents both the endline values (means or percentages) of each indicator, as well as the effect estimate (that is, the difference in the proportion or mean at endline between intervention and control arms), along with its confidence interval and significance levels. There is strong evidence that the intervention was able to change their gender role attitudes and notions of masculinity $(p=0.0439)$, attitudes about a man's or boy's right to exercise controlling behaviours over women or girls $(p=0.0035)$, and attitudes about a man's or boy's right to perpetrate violence on a woman or girl $(p=0.0019)$. Thus, a larger proportion of boys in the intervention than control arm expressed egalitarian gender role attitudes and notions of masculinity (6.6 versus 6.2 of 9 attitudes), rejected men's and boys' right to exercise control over women (4.9 versus 4.2 of 9 behaviours), and rejected men's and boys' right to exercise violence against women and girls (11.7 versus 10.3 of 17 situations). There was strong evidence, in addition, to suggest that perceptions about peer reactions to boys acting in gender equitable ways had been affected by their participation in the intervention; 20 percent of boys in the intervention arm compared with 13 percent of those in the control arm believed that their peers would respect them for demonstrating non-traditional behaviours in at least three of the four situations probed (effect estimate $7.2, p=0.0426$ ).

\section{Effect of the project on boys' behaviours}

The secondary outcomes that the project sought to affect were to encourage boys to intervene if they witnessed violence perpetrated against women and girls and to reduce the perpetration of gender-based violence by boys. 


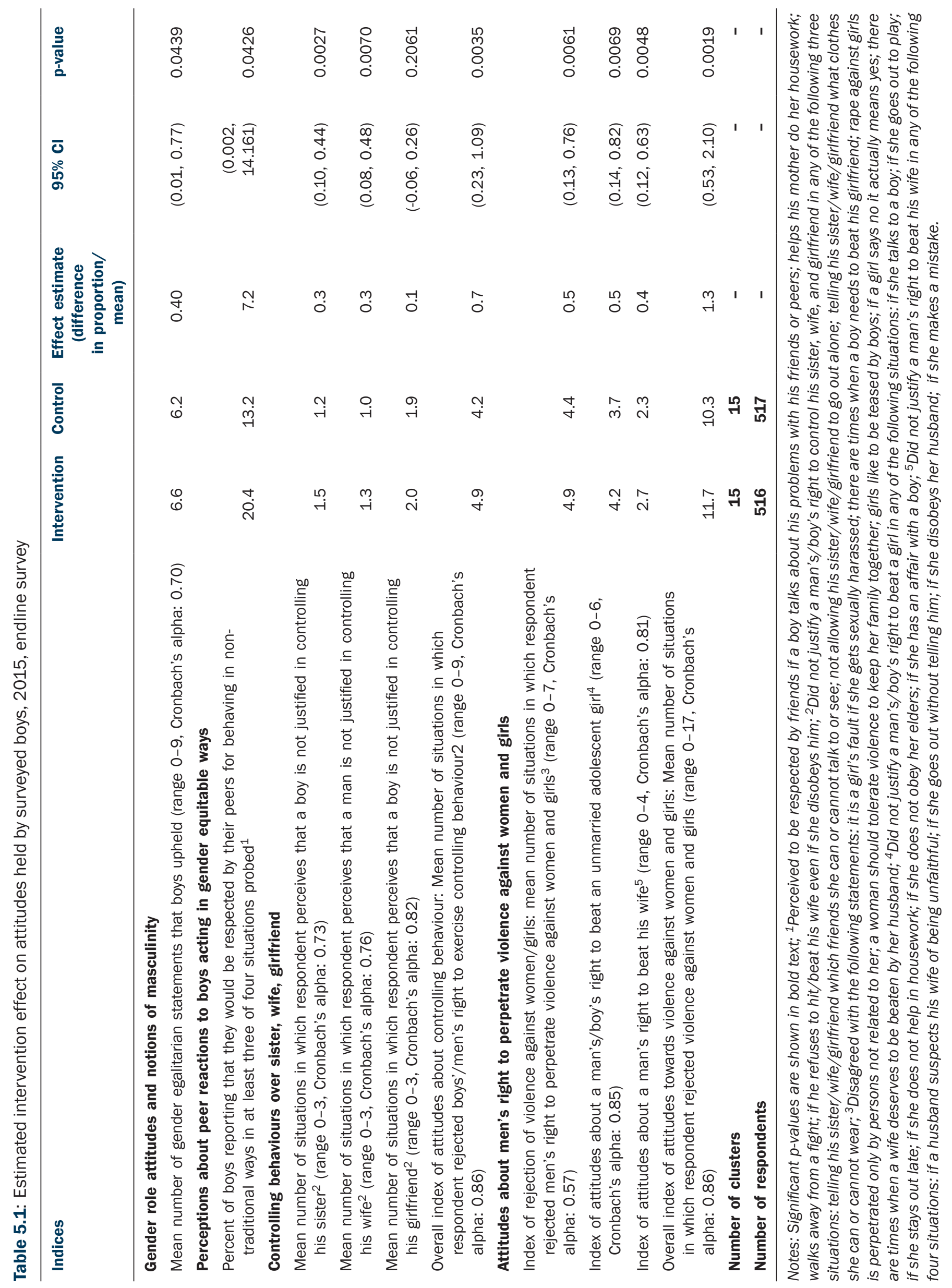




\section{Effect of the project on boys' intervention to halt incidents of violence against women and girls}

Table 5.2 describes findings on the effect of the project on boys' intervention on incidents of violence against women and girls. A larger proportion of boys in the intervention than control arm reported that they had intervened when they observed incidents of teasing and other forms of verbal abuse against a girl or woman, spreading sexual rumours about a woman or girl, or perpetration of unwanted touch on a woman or girl, with a mean difference of 13 percentage points; statistical analysis suggests that there is strong evidence that the intervention was effective in making boys take action more than those in the control arm $(p=0.0143)$.

Table 5.2: Estimated intervention effect on attitudes held by surveyed boys, 2015, endline survey

\begin{tabular}{|c|c|c|c|c|c|}
\hline Boys' action & Intervention & Control & $\begin{array}{c}\text { Effect } \\
\text { estimate } \\
\text { (difference } \\
\text { in proportion) }\end{array}$ & $95 \% \mathrm{Cl}$ & p-value \\
\hline $\begin{array}{l}\text { Told perpetrator to stop or intervened } \\
\text { himself, or reported the incident }{ }^{1} \text {, or } \\
\text { confided to someone (\%) }\end{array}$ & 39.8 & 26.5 & 13.3 & $(2.88,23.80)$ & 0.0143 \\
\hline Number of clusters & 15 & 15 & - & - & - \\
\hline $\begin{array}{l}\text { Number of respondents who saw any } \\
\text { incidents of violence against women } \\
\text { and girls in the } 6 \text { months prior to } \\
\text { interview }\end{array}$ & 356 & 322 & - & - & - \\
\hline
\end{tabular}

Note: Significant p-values are shown in bold text; ${ }^{1}$ includes someone teasing a girl/woman, pushing/grabbing/shoving of a girl/ woman, making dirty comments about a girl, spreading sexual rumours about a girl.

\section{Effect of the intervention programme on boys' perpetration of violence}

As described in Chapter 2, because boys aged less than 15 years were not asked questions about the perpetration of forced sex either through face-to-face interview or through the anonymous format, we present findings separately for all boys in ages 14-23 and for all those in ages 15-23, for which age group these details are available.

Findings with regard to behaviour change were not encouraging. Table 5.3 shows the effect of the project on the perpetration of various acts of violence against girls, identified as verbal harassment and other non-contact forms of violence and physical and sexual violence, during the six months preceding the interview. Findings suggest that among boys in ages 14-23, a weak effect of the intervention was evident on just one indicator, namely, stalking a girl. No differences were observed between boys in the intervention and control arms on other indicators.

Table 5.3 also presents responses to questions relating to the perpetration of violence over the six months preceding the interview that were posed to older boys, that is, those in ages 15-23, both in the face-to-face interview and in the anonymous format. There was no evidence to suggest that the intervention had contributed to behaviour change in the perpetration of violence on any indicator probed.

\section{Effect of regular participation in intervention activities on the attitudes of boys: Results from GEE models}

Table 5.4 presents the findings on the effect of regular participation in intervention activities on attitudes of boys in the four domains as discussed before. Clearly, results, presented by way of odds ratios or regression coefficients show that irrespective of the domain, the effect of the intervention was most pronounced among those who had attended the intervention regularly (that is, attended gender transformative life skills sessions as well as cricket sessions at least twice in a month). Thus, after adjusting for covariates, the mean number of gender egalitarian attitudes espoused by regular intervention participants was 0.572 higher than those espoused by boys in control 


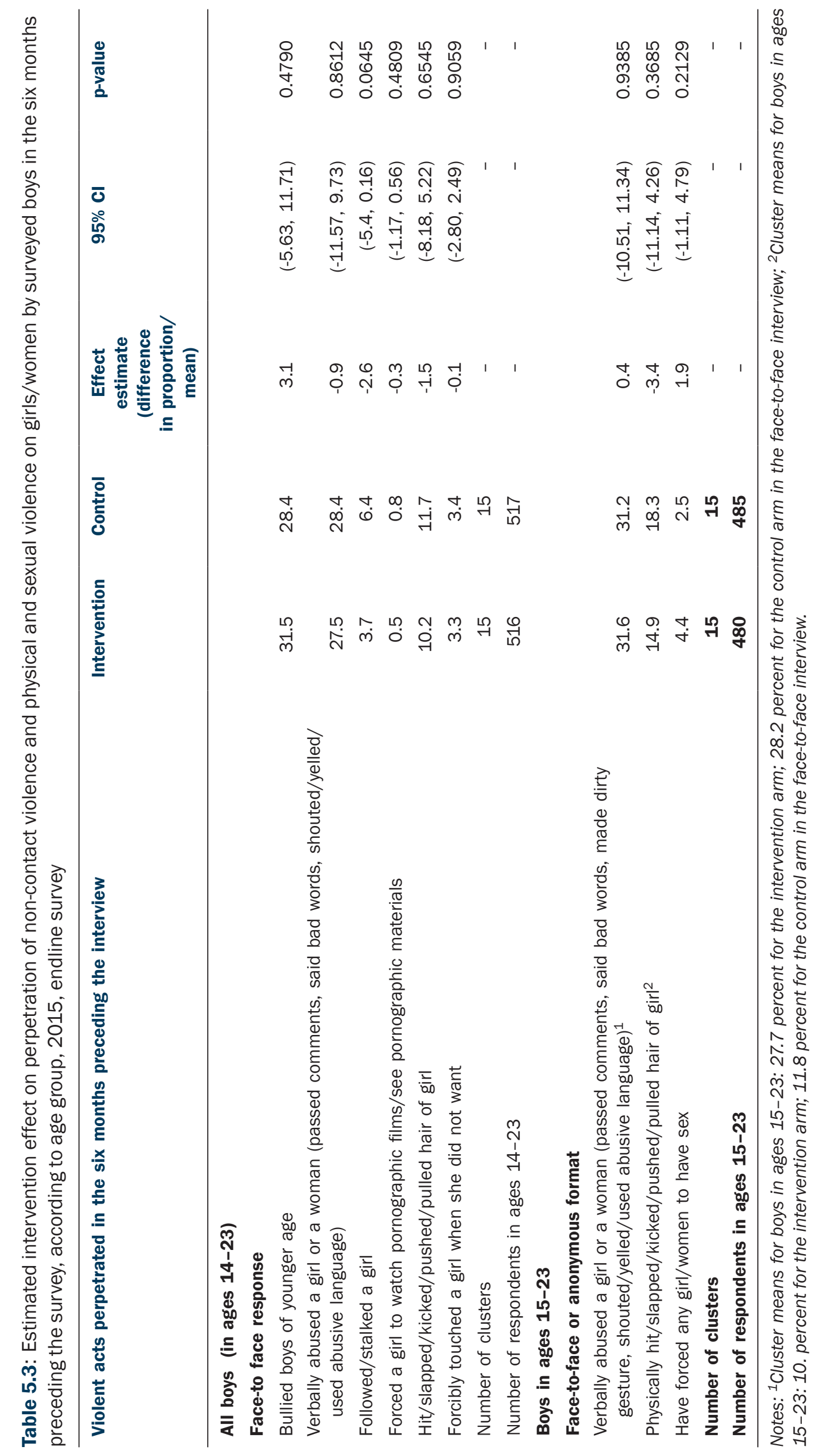




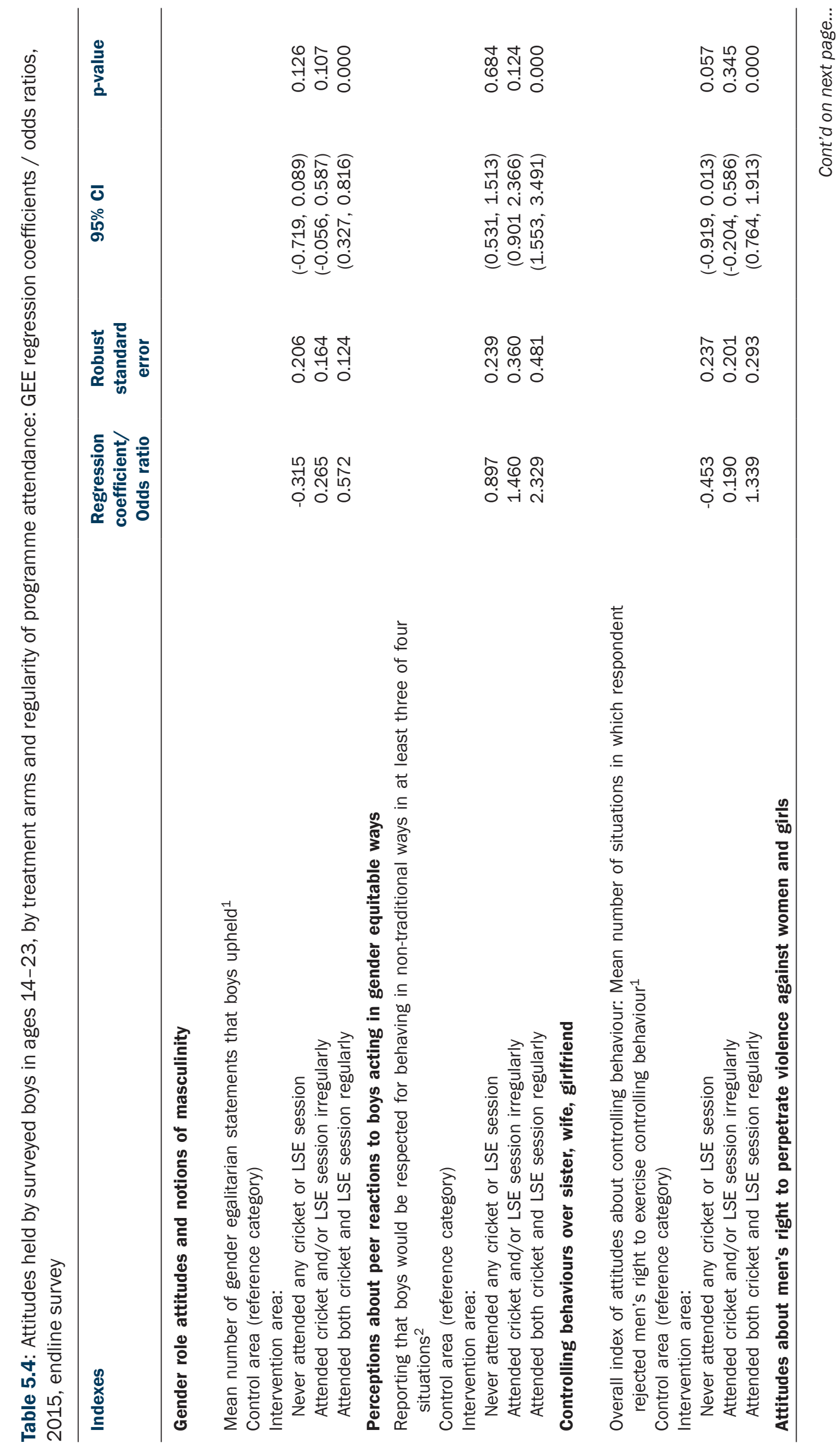




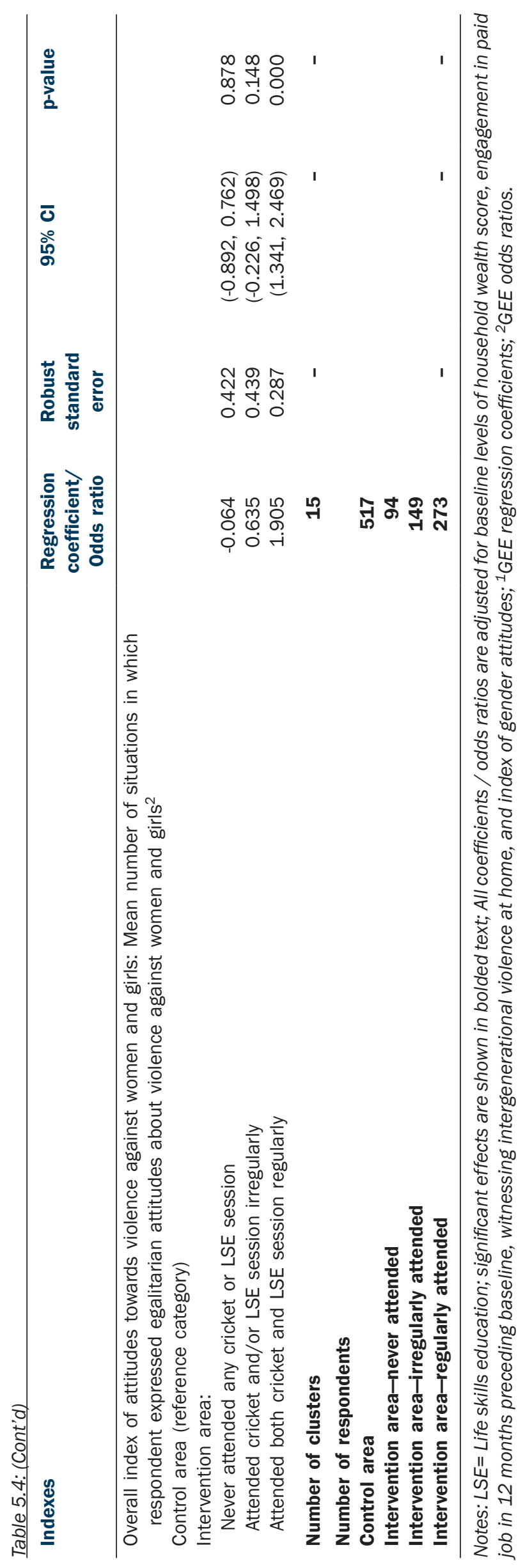


clubs (standard error 0.124 and p-value 0.000). Similarly, after adjusting for covariates, boys in the intervention arm were 1.339 times more likely than those in the control arm to reject men's and boys' right to exercise controlling behaviour on women and girls (standard error 0.293, p-value 0.000), and 1.905 times more likely to express egalitarian attitudes about a man's or boy's right to perpetrate violence against women and girls (standard error 0.287, p-value 0.000). Finally, the analysis showed that regular attendance in intervention activities had a strong effect on the perceptions of boys that they would be respected for behaving in nontraditional ways in at least three of four situations: boys who had attended the programme regularly were 2.3 times more likely than those from control clubs to report peer acceptance of non-traditional behaviours practised by respondents.

It is important to note here that boys in the intervention arm who attended the programme irregularly were no different from those in the control arm. In fact, a comparison of findings presented in Table 5.1 and 5.4 reveals that almost the entire effect of the intervention may be attributed to regular attendance in the programme, which underscored the importance of regular attendance in the programme.

\section{Effect of regular participation in project activities on intervention by boys to halt incidents of violence against women and girls}

Table 5.5 presents findings on the effect that regular attendance in project activities had on the intervention of boys in incidents of violence against women and girls. Odds ratios (OR) show that boys who participated regularly in the intervention programme were 2.0 times more likely than those in the control arm to have intervened when they observed incidents of verbal abuse or the perpetration of unwanted touch on a woman or girl. A weak positive effect of the intervention was also observed among those who participated in the programme irregularly.

Table 5.5: Action boys took against harassment of or violence on girls/women in the six months preceding the survey, by treatment arms and regularity of programme attendance: GEE regression odds ratios, 2015, endline survey

\begin{tabular}{|c|c|c|c|c|}
\hline Indicators of action taken when abuse was witnessed & Odds ratio & $\begin{array}{l}\text { Robust } \\
\text { standard } \\
\text { error }\end{array}$ & $95 \% \mathrm{Cl}$ & p-value \\
\hline \multicolumn{5}{|l|}{$\begin{array}{l}\text { Told perpetrator to stop or intervened himself or } \\
\text { reported the incident or confided to someone (\%) }\end{array}$} \\
\hline \multicolumn{5}{|l|}{ Control area (reference category) } \\
\hline \multicolumn{5}{|l|}{ Intervention area: } \\
\hline Never attended any cricket or LSE session & 0.613 & 0.271 & $(0.257,1.458)$ & 0.269 \\
\hline Attended cricket and/or LSE session irregularly & 1.756 & 0.554 & $(0.945,3.262)$ & 0.074 \\
\hline Attended both cricket and LSE session regularly & 2.044 & 0.455 & $(1.321,3.163)$ & 0.001 \\
\hline
\end{tabular}

Notes: LSE= Life skills education; significant effects are shown in bolded text; Odds ratios are adjusted for baseline levels of household wealth score, engagement in paid job in 12 months preceding baseline, witnessing intergenerational violence at home, index of gender attitudes, action taken by boys when they saw someone harassing or committing violence against girls and women.

\section{Effect of regular participation in project activities on boys' perpetration of violence}

Findings with regard to behaviour change in boys were less encouraging even for those who had participated regularly. Table 5.6 shows the effect of the regularity of attendance in intervention activities on the perpetration of various acts of violence identified as verbal harassment and other non-contact forms of violence and physical and sexual violence during the six months preceding the interview. Findings suggest that among boys in ages 14-23, regular attendance in the intervention activities had a strong effect on one of the six behaviours presented in Table 5.6, namely, stalking a girl (OR: 0.477, p-value 0.050). No differences were observed between boys in the intervention and control arms on other indicators, irrespective of the regularity of programme attendance. 
Table 5.6: Perpetration of non-contact violence and physical and sexual violence on girls/women by surveyed boys in the six months preceding the survey, by treatment arms and regularity of programme attendance: GEE regression odds ratios, 2015, endline survey

\begin{tabular}{|c|c|c|c|c|}
\hline Indicators of perpetration & Odds ratio & $\begin{array}{l}\text { Robust } \\
\text { standard } \\
\text { error }\end{array}$ & $95 \% \mathrm{Cl}$ & p-value \\
\hline $\begin{array}{l}\text { Bullied boys of younger age in last } 6 \text { months } \\
\text { Control area (reference category) } \\
\text { Intervention area: }\end{array}$ & & & & \\
\hline $\begin{array}{l}\text { Never attended any cricket or LSE session } \\
\text { Attended cricket and/or LSE session irregularly } \\
\text { Attended both cricket and LSE session regularly }\end{array}$ & $\begin{array}{l}1.086 \\
1.211 \\
1.081\end{array}$ & $\begin{array}{l}0.271 \\
0.279 \\
0.239\end{array}$ & $\begin{array}{l}(0.665,0.771) \\
(0.771,1.669) \\
(0.700,1.669)\end{array}$ & $\begin{array}{l}0.740 \\
0.405 \\
0.723\end{array}$ \\
\hline \multicolumn{5}{|l|}{$\begin{array}{l}\text { Verbally abused a girl or a woman (passed comments, } \\
\text { said bad words, made dirty gesture, shouted/yelled/ } \\
\text { used abusive language) in last } 6 \text { months }\end{array}$} \\
\hline \multicolumn{5}{|l|}{ Control area (reference category) } \\
\hline $\begin{array}{l}\text { Never attended any cricket or LSE session } \\
\text { Attended cricket and/or LSE session irregularly } \\
\text { Attended both cricket and LSE session regularly }\end{array}$ & $\begin{array}{l}0.709 \\
1.209 \\
0.900\end{array}$ & $\begin{array}{l}0.211 \\
0.338 \\
0.251\end{array}$ & $\begin{array}{l}(0.395,1.270) \\
(0.699,2.093) \\
(0.521,1.556)\end{array}$ & $\begin{array}{l}0.248 \\
0.496 \\
0.708\end{array}$ \\
\hline $\begin{array}{l}\text { Followed/stalked a girl in last } 6 \text { months } \\
\text { Control area (reference category) } \\
\text { Intervention area: }\end{array}$ & & & & \\
\hline $\begin{array}{l}\text { Never attended any cricket or LSE session } \\
\text { Attended cricket and/or LSE session irregularly } \\
\text { Attended both cricket and LSE session regularly }\end{array}$ & $\begin{array}{l}0.367 \\
0.644 \\
0.477\end{array}$ & $\begin{array}{l}0.203 \\
0.285 \\
0.179\end{array}$ & $\begin{array}{l}(0.124,1.084) \\
(0.270,1.533) \\
(0.228,0.999)\end{array}$ & $\begin{array}{l}0.070 \\
0.320 \\
0.050\end{array}$ \\
\hline \multicolumn{5}{|l|}{$\begin{array}{l}\text { Hit/ slapped/kicked/pushed/ pulled hair of girl in last } 6 \\
\text { months }\end{array}$} \\
\hline $\begin{array}{l}\text { Never attended any cricket or LSE session } \\
\text { Attended cricket and/or LSE session irregularly } \\
\text { Attended both cricket and LSE session regularly }\end{array}$ & $\begin{array}{l}0.800 \\
1.059 \\
0.711\end{array}$ & $\begin{array}{l}0.321 \\
0.286 \\
0.271\end{array}$ & $\begin{array}{l}(0.364,1.757) \\
(0.623,1.799) \\
(0.337,1.502)\end{array}$ & $\begin{array}{l}0.579 \\
0.831 \\
0.373\end{array}$ \\
\hline \multicolumn{4}{|l|}{$\begin{array}{l}\text { Forcibly touched a girl in last } 6 \text { months when she did } \\
\text { not want }\end{array}$} & \\
\hline $\begin{array}{l}\text { Never attended any cricket or LSE session } \\
\text { Attended cricket and/or LSE session irregularly } \\
\text { Attended both cricket and LSE session regularly }\end{array}$ & $\begin{array}{l}1.553 \\
0.350 \\
1.002\end{array}$ & $\begin{array}{l}0.819 \\
0.269 \\
0.469\end{array}$ & $\begin{array}{l}(0.553,4.366) \\
(0.077,1.580) \\
(0.399,2.511)\end{array}$ & $\begin{array}{l}0.403 \\
0.172 \\
0.996\end{array}$ \\
\hline Number of clusters & 15 & - & - & - \\
\hline \multicolumn{5}{|l|}{ Number of respondents } \\
\hline Control area & 517 & & & \\
\hline Intervention area -never attended & 94 & & & \\
\hline Intervention area-irregularly attended & 149 & & & \\
\hline Intervention area-regularly attended & 273 & - & - & - \\
\hline
\end{tabular}

Notes: LSE= Life skills education; significant effects are shown in bolded text; Odds ratios are adjusted for baseline levels of the household wealth score, engagement in paid work in the 12 months preceding the baseline, witnessing intergenerational violence at home, and index of gender attitudes. 


\section{Summary}

The project achieved its primary outcome. It succeeded in making the attitudes of boys more gender egalitarian, changing norms with regard to notions of masculinity, and enabling boys to reject men's and boys' right to exercise control over women and girls and perpetrate violence on them. For example, a larger proportion of boys in the intervention than control arm expressed egalitarian gender role attitudes and notions of masculinity (6.6 versus 6.2 of 9 attitudes), rejected men's and boys' right to exercise control over women ( 4.9 versus 4.2 of 9 behaviours), and rejected men's and boys' right to exercise violence against women and girls (11.7 versus 10.3 of 17 situations). There was strong evidence, in addition, to suggest that perceptions about peer reactions to boys acting in gender equitable ways had been affected by their participation in the intervention; 20 percent of boys in the intervention arm compared with 13 percent of those in the control arm believed that their peers would respect them for demonstrating non-traditional behaviours in at least three of the four situations probed (effect estimate 7.2, $p=0.0426$ ). The effect of programme participation on most of these indicators, moreover, was most pronounced for those who had regularly participated in the programme and had relatively little effect on those whose attendance was irregular.

With regard to our secondary objective, namely, encouraging boys to intervene if they witnessed violence perpetrated against women and girls and reducing the perpetration of gender-based violence by boys, evidence was mixed. There was evidence that the intervention had succeeded in empowering boys to intervene in order to stop verbal harassment and physical violence (effect estimate 13.3, $p=0.0143$ ). However, there was weak evidence that noncontact forms of violence, such as stalking a girl, had declined because of the intervention. However, there was no evidence of an effect on the perpetration of other forms of non-contact violence or physical and sexual violence. Behaviour change in boys was less encouraging even for those who had participated regularly. However, those who had regularly participated in the programme were less likely than those in the control arm to have followed or stalked a girl (odds ratio of 0.48). But no such effect was observed among irregular participants.

In summary, findings presented in this chapter on the effect of the Do Kadam project are largely positive. They suggest that exposure to a gender transformative life skills education and cricket-coaching programme-and particularly regular participation in the activities of such programmes-can indeed modify the attitudes of adolescent boys and young men in rural Bihar. The effect of such a programme on behaviours was more muted, with evidence suggesting only that regular participation in programme activities had resulted in a reduction in such non-contact forms of violence as stalking a girl. Overall, findings point to the promise of the Do Kadam approach of combining gender transformative life skills education and cricket-coaching as a pathway toward engendering norms and behaviours among boys and young men in disadvantaged rural settings in Bihar. 


\section{Chapter 6 \\ Changes in attitudes and practices: Self-assessments}

The study explored self-assessments of boys about changes in their own life at various points over the course of the year preceding the endline survey and in-depth interviews. For one, the survey probed, in intervention and control arms, perceptions of boys about changes they had experienced or observed in the year prior to the interview, a period which overlapped with the duration of the Do Kadam project. Second, we probed changes in their attitudes and practices from narratives of boys in the intervention arm by comparing their responses from each of the in-depth interviews held at about the time of the baseline survey, midway through the intervention (midline interview), and about the time of the endline survey. In this chapter, we focus on self-assessments of boys of these changes.

\section{Self-assessment of changes experienced or observed in the last year}

In the course of the endline survey, we probed study participants in both intervention and control arms about whether, over the year preceding the interview, their exposure to information had increased, their self-efficacy, sports skills, and peer network had expanded, and whether they believed they had become more gender sensitive. Findings are summarised in Table 6.1. They suggest that while large proportions of boys in both arms perceived changes in themselves over the year preceding the endline interview, more study participants from the intervention than the control arm perceived positive changes in their life.

Boys in the intervention arm were more likely to report that they had become better informed about a range of issues, that their self-efficacy had been enhanced, and that their gender role attitudes and practices had undergone a change (Table 6.1). Thus, those in the intervention arm were more likely than those in the control arm to report exposure to new ideas (90\% versus $70 \%$ ), awareness about respecting women and girls ( $81 \%$ versus $52 \%$ ), awareness about what happens to men and boys who commit violence on women (76\% versus $43 \%$ ), and awareness about the rights of women and girls ( $75 \%$ versus $45 \%)$. Those in the intervention arm were also more likely than those in the control arm to report greater self-confidence ( $92 \%$ versus $84 \%$ ), better communication skills ( $78 \%$ versus $54 \%$ ), better sports skills ( $70 \%$ versus $53 \%$ ) and behaviour on the sports field (62\% versus $30 \%$ ), and a larger

Table 6.1: Perceptions about changes

Percentage of boys reporting increased exposure to information, self-efficacy, sports skills, wider social networks, and greater gender sensitivity in the year preceding the endline interview, intervention and control arms, 2015, endline survey

\begin{tabular}{|c|c|c|}
\hline Perceptions of changes & Intervention & Control \\
\hline \multicolumn{3}{|l|}{ Exposure to information increased } \\
\hline Exposed to new subjects & 89.5 & 69.8 \\
\hline Better informed about the importance of respecting women and girls & 81.4 & 52.0 \\
\hline $\begin{array}{l}\text { Better informed about what can happen to men and boys who commit } \\
\text { violence on women }\end{array}$ & 76.0 & 43.1 \\
\hline Better informed about the rights of women and girls & 75.0 & 44.7 \\
\hline \multicolumn{3}{|l|}{ Increased self-efficacy and sports skills, and wider social networks } \\
\hline Made new friends & 67.8 & 57.1 \\
\hline Became more self-confident & 92.2 & 83.6 \\
\hline $\begin{array}{l}\text { Became better about speaking out when respondent disagreed with } \\
\text { somebody }\end{array}$ & 77.7 & 53.8 \\
\hline Improved sports skills & 70.2 & 52.6 \\
\hline Less likely to use abusive language even when playing cricket/sports & 61.6 & 30.4 \\
\hline \multicolumn{3}{|l|}{ Increased gender sensitivity } \\
\hline Learned that it is wrong to touch a girl against her will even in fun & 66.3 & 34.6 \\
\hline Helps more with household chores & 54.8 & 25.5 \\
\hline Number of respondents & 516 & 517 \\
\hline
\end{tabular}


network of friends (68\% versus $57 \%$ ). Finally, more boys in the intervention than in the control arm reported that their contributions to household chores had increased (55\% versus $26 \%$ ) and a greater proportion of boys in the intervention than in the control arm felt more strongly than before that it is wrong to perpetrate unwanted touch on a girl (66\% versus $35 \%)$.

\section{Observation of changes in boys by others}

In addition, we explored the perspectives of boys who had participated in the intervention activities about whether others had noticed a positive change in their behaviour over the course of their participation in the Do Kadam programme. While 42 percent reported that no one had remarked about any change in their behaviour, the remaining 58 percent noted that others had commented on the change in their behaviour following their participation in the programme (Table 6.2). Among those who reported that others had observed a positive change in them, the majority (62\%) reported that their friends had observed so, followed by their mother (45\%), father (29\%), and extended family members (27\%). Fewer reported that their siblings (10\%), teachers (3\%), or female friends $(2 \%)$ had observed changes in them.

Table 6.2: Observation of changes in boys by others Percentage of boys who participated in the intervention activities reporting changes in their behaviour observed by family members, friends, and others in the year preceding the endline interview, intervention arm, 2015, endline survey

\begin{tabular}{lc}
\hline Changes observed in boys & Percent \\
\hline No one observed change & 42.1 \\
Someone observed positive changes & 57.9 \\
Numbers of boys who had participated in any Do Kadam activities & $\mathbf{4 2 3}$ \\
Persons who observed changes in boys & \\
Mother & 44.9 \\
Father & 29.0 \\
Brother/sister & 10.2 \\
Extended family members & 26.5 \\
Friends (male) & 62.4 \\
Friend (female) & 2.4 \\
Teacher & 3.3 \\
Others & 2.9 \\
Number of respondents & $\mathbf{2 4 5}$ \\
\hline
\end{tabular}

\section{Insights about changes experienced over the course of the Do Kadam programme: in-depth interviews}

At in-depth interviews, boys provided their own assessments of personal changes experienced over the course of the Do Kadam project. They reiterated many of the changes described above. By the time of the endline survey, almost all boys (22 of 24) reported that they had indeed experienced changes in their attitudes or behaviours, and many of these boys elaborated on the specific changes they had experienced.

\section{Peer networks and self-esteem}

A few boys (seven of them) noted that the bonds of friendship had become stronger as a result of their participation in the cricket component of the Do Kadam project; a few even suggested that their self-confidence had improved and that they had developed a sense of fair play in sports. Excerpts of positive responses from boys are reproduced in the following.

Yes, I liked it. Because playing any kind of sports is a good form of exercise, your body remains healthy.... Friendships get stronger and relationships improve. We become good friends.... [Hindu, age 18, completed Class 8, selection criterion: moderately gendered, ID5]

After taking the training and bowling well it has boosted my self-esteem and confidence. [Hindu, age 16, completed Class 8, selection criterion: perpetrated physical violence, ID32] 
I liked it because earlier when we used to play, if we lost the game we would accuse the winning team of cheating or we would not talk to the wining team, but we were taught that unity is important between people, whether we lose or win the match. We should hug the other team-mates, shake their hands and should say that in future we would try our best to perform. [Hindu, age 21, completed Class 12, selection criterion: moderately gendered, ID15]

Several boys (seven of them) suggested that participation in the life skills sessions had improved their ability to communicate with others, speak in front of a group, and even how to maintain cordial relations with family and friends, as reported below.

Yes, there are changes. Earlier I used to be very shy and used to get very nervous to talk in front of 10 people. [Hindu, age 20, undergraduate student, selection criterion: perpetrated physical violence, ID16]

There are many changes. Now I know how to talk to people, I stay with everyone nicely. [Hindu, age 15, completed Class 7, selection criterion: highly gendered, ID6]

Yes, I told you before also that I got to learn how to talk to people and how to behave with people. [Hindu, age 17, completed Class 9, selection criterion: perpetrated physical violence, ID19]

\section{Relationship with parents}

Several boys reported improvements in their relationship with their parents and their ability to communicate with them. While most boys reported a good relationship with their mother, many reported that they feared their father. Even so, nine out of 24 boys reported over the period of the three in-depth interviews that their relationship and ability to communicate with their mother and/or father had improved. Responses of those who reported change in their relationships with parents are given in the following.

Baseline: Yes, I talk to my mother easily. I don't face any problem in talking to my mother but I can't talk to my father that easily. I find it difficult to talk to him because I haven't ever talked to him much. I am unable to talk to my father because my father does not fulfil my needs even if I ask him ten times.

Midline: Not discussed

Endline: Generally I am close to everyone in my family but if I have to choose between my mother and father, then I am closer to my mother. I never ask my father for money as I am scared he will scold me.... Yes, compared to last time, I talk to them more now. In this club they explained to us that one should not be reluctant to talk to one's own family about anything, rather they should honestly tell them everything or every problem. Because of this, I spend more time with my family now and share all my problems with my family. [Hindu, age 16, completed Class 8, selection criterion: moderately gendered, no violence, ID18]

Baseline: I am closer to my mother than my father; my father gets angry on small issues and scolds us whereas my mother listens.... I feel uncomfortable talking to them on some issues. I fear that my parents will scold me or get angry so I talk about very few issues comfortably and that too with my mother only. I don't talk much with my father.

Midline: I'm closer to my mother. Yes, there are some changes as compared to before. Earlier I didn't talk a lot to my mother but now I talk to her about everything easily because we are told at the club that we should discuss everything at home so that if there are problems, parents have all the information and can help.

Endline: Before I could not talk to my mother with an open heart but now I try to talk to her openly. No I don't talk to my father because I am very scared of him. [Hindu, age 16, completed Class 8, selection criterion: perpetrated physical violence, ID32]

Baseline: Yes, I talk to my mother openly and then my mother tells my father. I don't talk to my father directly.... I talk about my friends with my mother... I talk to my mother about my future.... I talk about all these matters very comfortably with my mother. I don't have any problem talking to her. I don't get much time to talk to my father because he wakes up early and goes to work and comes back drunk in evening.

Midline: As earlier, now also I am closest to my mother because she understands me, she loves me and fulfils my needs. Whenever I need something, I tell my mother about it and then she fulfils my needs. As compared to before, now I have started talking more to my father also. Earlier I did not talk to him much; I used to think that he may get angry.... Yes, as compared to before now I spend more time at my home and tell everything to my parents because we are told in the club that even after living in the same house, if we do not share our thoughts with our family then this means that our family is broken. So we should always stay with togetherness and we should tell everything to our family members. 
Endline: Yes I talk more to my parents now compared to earlier, because we were scared of getting them upset; but, now all the fear has gone, because of what the club has taught us. [Hindu, age 15, completed Class 11, selection criterion: perpetrated physical violence, ID31]

Baseline: Generally I talk with my mother or brother who is in Delhi. I don't talk much with my father because he doesn't have much time and he comes late at night; I also feel afraid to talk to him because he gets annoyed over each and every matter, thus I talk less with him.... Regarding school or college fees, I tell my mother that I need money for fees....

Midline: I'm closest to my mother as before.... I can talk to my mother nicely and don't face any problem in talking to her whereas I feel some hesitation in talking to my father. I fear that he will scold me or get angry with me.... No, there is no change like that. I talk to my parents in the same way as I used to do it earlier.

Endline: Yes, mostly I discuss it with my mother. In comparison with earlier, now I talk to both my parents more freely because if you have a problem and don't tell your family then how would they come to know about it. This change was only possible because of the club. In sessions we were told that whenever there is a problem it should be discussed openly and freely with your family. If anyone has threatened or tried to scare you or if there is any kind of problem related to your education then it is important to tell them or else how will they solve it. If I have made a mistake and I don't tell my family about it, then, how will they support me to resolve it? Therefore, it is important to tell them everything. [Hindu, age 19, completed Class 12, selection criterion: perpetrated sexual violence, ID17]

The others reported that there had been no such change in their relationship. Several suggested in all three interviews that they were able to communicate with their mother but not their father, that their father appeared threatening to them, or that their father did not spend much time at home. Given below is a narrative of a respondent reporting no change in his relationship with his parents in all three interviews.

Baseline: I speak with my mother easily, I don't hesitate while talking to her, but I never speak like this with my father because I am a bit scared that he will scold me or get angry with me. I can't speak with my father comfortably like I do with my mother.

Midline: I can talk easily to my mother. Just as I am talking to you now, I talk to my mother in the same way. In the evening, while eating, I talk to her, as much as I used to do earlier, there is no change in that.

Endline: I like my mother and we often talk to each other, and if I want to say something I tell my mother. I fear my father will get upset with me and scold me. Anyway most of the time, he is not at home. [Hindu, age 17, completed Class 10, selection criterion: physical violence, ID20]

\section{Participation in household chores}

Participation in household chores was a key area of behaviour change noted by boys. Some 16 of 24 boys, for example, who reported at the baseline in-depth interview that they did not help in housework elaborated when interviewed midway through the intervention or at endline that they had begun to spend more time doing housework than before. Many of these boys attributed the change to their participation in the project, as evident from the narratives below.

Baseline: I watch TV and listen to music on my mobile, that's how I spend my free time. I also chat with my friends, wander around with them, or play sports with them in my free time.

Midline: I help my family in farm work. I get the wheat ground, buy vegetables from the market, sometimes I fetch water, clean the house, and even cook.

Endline: I learned to help my mother in household chores.... I did these chores earlier too, but I didn't do so much of the work the way I now do, because we were taught about this in the club. We were taught that we should help in household chores, and housework should be done by everyone in the family. [Hindu, age 21, completed Class 12, selection criterion: perpetrated physical violence, ID11]

Baseline: I roam around with my friends in my free time, I play with them and we study together. I also watch television at home. I spend my free time by doing all these things.

Midline: Yes, when there is no one at home, I cook food, clean the house, mop the floor, wash the dishes, and take care of the animals, etc. I do all this work. Earlier, I was forcefully asked to do all these things but now I do them by my own wish, because in the club we were told that everyone in the family should work 
together. Till when can our mother do everything alone? If we all contribute in housework and help her, then it will be easier for her. This change has come in me only after joining the club because we are taught all this. I still roam around with my friends, talk to my friends and play with them, and at home I watch television or do household work.....Yes, earlier I used to spend my free time here and there, doing useless things with my friends. Now I have started utilising my time in a better way. Now I do household work in my free time. By doing so, household work gets done and my free time is also well spent.

Endline: Yes, I look after our animals, fetch drinking water and if my mother or sister aren't home then I prepare food for us. I have been doing this for some time but now, I am doing more work; now in my free time I do household work. Because of the club, there we were told we should always help with housework. What is the shame in a boy doing housework? We should always divide the work and help each other... By playing games with friends or hanging out, by doing work at home.... Some change is there. [Hindu, age 15, completed Class 11, selection criterion: perpetrated physical violence, ID31]

Baseline: In my free time, I watch the news on TV, sleep, and wander around with my friends here and there. I sit with my friends, gossip, wander around and play sports etc.

Midline: I do domestic work like bringing vegetables from market, filling water, grinding wheat, cleaning the house on festival days, cooking food in case of need, etc. I also help on our farm. As compared to before, now I have started to do more domestic work...

Endline: After participating in this programme there have been many changes-like earlier I did not take interest in my education and would instead waste my whole day with friends, but now I don't do all these things. Now I spend my free time in household work as I know that household chores are my responsibility as well.... I help with household work. Usually men think that household work is the responsibility of women, and if we help them, our manliness will reduce, but nothing like this will happen so we should also help women in household work. I help in household work and I don't spend my free time on useless things.... Yes, there has been change when it comes to these issues. [Hindu, age 19, completed Class 12, selection criterion: perpetrated sexual violence, ID17]

Baseline: I spend my free time at home by watching TV. In my spare time I play with friends and sometime roam around, chat with them.

Midline: Yes, I sometimes cook, take care of the animals in our house, wash the dishes, fill water, and sometimes I clean the house. I did all this earlier also but now I do much more. We were told in the group that if one person of the family does all the work then that person will be over-burdened and will have to spend more time. So all the members of the family should do the work together and they should help each other so that the work becomes easier and is distributed. I believe that after joining the club these changes have taken place in me; otherwise I did not know much about all these things... In my free time, I listen to music, watch television, I go out with my friends, and I play. I entertain myself with all these things.... Yes, earlier we friends used to only roam here and there and waste our time. But now, we friends, rather than roaming here and there, we sit together at one place and discuss about our future plans. In all, now our outlook has changed and the credit of all this goes to this project. As compared to before, now I have started giving more time to my family and my home.

Endline: Yes I do household chores. Cooking, sweeping, at times when my mother is not well then I also wash the dishes, and apart from all these things I also work on the field. I used to do some work earlier, but not that much, but now recently I have started doing it more. Because of my mother and also due to the club there has been a change in my life. In the club, the core trainer explained to us that household work is important, we should also take responsibility for household work and we should help our mother in household work...Yes, now I spend less time on roaming out and now I don't waste my time on roaming around with my friends, whereas now I invest my time more in my house. I spend most of my time with my family and when there is free time I do household work...there has been a transformation in me. Earlier I did not do household chores but now I do. [Hindu, age 14, completed Class 8; selection criterion: perpetrated physical violence, ID21]

In contrast, five boys reported in all three interviews that they did not contribute to housework, two reported that they were doing housework even at baseline level and continued to report this in subsequent interviews, and one reported that he resided mostly in a hostel and hence did not contribute to housework. Their reports are reproduced below. 
Baseline: I sit at home and watch television. I listen to music on my mobile and go out with my friends. We roam around in the village or outside the village. I go to a movie at the movie hall in Bihta.

Midline: I do some small work in the fields; apart from this I don't do anything. Six months ago it was the same.

Endline: I feed our animals, give them water. No I don't cook. There is no change in what I do at home. Spend my free time in entertainment, I watch television, go out with my friends somewhere or play sports, talk to my relatives and friends, like that.... No, it's the same as what I did earlier. [Hindu, age 19, completed Class 11, selection criterion: perpetrated physical violence, ID1]

\section{Gender role attitudes and attitudes about a man's right to perpetrate violence on women and girls}

In the course of in-depth interviews, boys discussed reasons for a man beating his wife or a boy beating his girlfriend, as well as their perceptions about circumstances in which wife beating may be justified, if any, and what can be done to stop it. Narratives suggest that attitudes about the acceptability of such violence had changed for several boys from justifying wife beating in most situations to justifying wife beating in very extreme situations, such as extramarital relations, to not justifying it under any situation. In the baseline interview, all 24 boys recognised that wife beating took place if a woman is disobedient, does not care for the children or her husband's parents, makes a mistake, does not listen to her husband, goes out without his permission, and if she has extramarital sexual relations. Two boys qualified this by suggesting that the man should first explain matters to his wife and if she repeats the behaviour, violence is justified. At midline, some 18 boys suggested that it was acceptable for a man to beat his wife in some situations, and three held that wife beating is justified if the wife repeats unacceptable behaviour; three boys reported that it was unacceptable in any situation.

By the time of the endline in-depth interviews, five out of the 24 boys rejected a husband's right to beat his wife in any situation, while the majority continued to believe that it was acceptable in extreme situations such as extramarital relations. By endline, those who had condoned violence in any situation experienced the following changes in attitudes over the course of the intervention.

Baseline: There is no benefit from doing violence on one's wife.... Violence occurs on the wife because she doesn't obey her husband, doesn't do work that the husband tells her to do.

Midline: Such men are not worth being called a man even. I believe that instead of being violent, one should explain with love. Beating anyone is not a solution for anything.... No, in any situation, it is not right for a husband to beat his wife. No matter how big is the mistake of the wife, she should not be beaten up, and explained politely with love. In my opinion, it is not right for a husband to beat his wife in any situation.

Endline: No, according to me there is no such situation where it is right for a man to beat his wife. No, not even when she is having an extramarital affair. If so, he should talk to her and make her understand that, "What you are doing is wrong and because of that everything will be ruined, and if you don't stop then I will leave you". Like this he should make her understand, hitting her is wrong.... In the club, they told us that when the husband gets involved in an extramarital affair, does his wife beat him? She too talks to him and makes him understand, so we too should make her understand. [Hindu, age 16, completed Class 10, selection criterion: moderately gendered, ID25]

Baseline: When a wife makes a mistake, like if she does something without asking her husband, spends money without asking him or if she goes out without asking him, then violence takes place. Similarly, girlfriends also do some mistakes like when the boyfriend calls them, they do not come or they do not listen to their boyfriend. Then violence takes place.

Midline: Instead of beating their wife, they should explain to her with love because violence is not the solution to any problem. A person who commits violence lacks knowledge or else it's because he consumes alcohol.... in any situation, it is not right for a husband to beat his wife. No matter how big the wife's mistake may be, she should not be beaten up and the husband should explain to her politely....

Endline: I think they should be taught to understand, so that they don't do any kind of violence. No, instead of tolerating it, the woman should protest. The husband gets violent when his wife does something wrong, but when it comes to a man doing something wrong, his wife doesn't say anything to him. So in such situations the wife should remind the husband that, "See I didn't say anything that time and look what you are doing to me...." No, according to me, there is no such situation where it is right to hit their wife, 
no matter how big a mistake she committed. It's not going to change her by beating.... Now I think there shouldn't be any violence against females. Even though most of the time it is the man's fault still it is the woman who gets the beating. Men think that women are weaker than them, that's why they do that.... Earlier, I used to think that girls cannot be our friends but now I don't think that; they can be our friends. Violence on woman or teasing girls is wrong, doing any kind of drugs is wrong. [Hindu, age 15, completed Class 11, selection criterion: perpetrated physical violence, ID31]

The majority of boys (13 out of 24) had indeed modified their views about the acceptability of violence perpetrated by a man on his wife. This group, in many instances, had shifted from views suggesting that wife beating was justified in a host of situations, to agreeing that wife beating was unacceptable, except in the extreme situation of a woman engaging in an extramarital affair. Evolving attitudes on the unacceptability of violence are apparent from the narratives of boys over the three in-depth interviews, as indicated below.

Baseline: When wives do not listen to their husbands, when they do not do housework on time, then they are beaten up. No one beats their wife without any reason. She must have made some mistake. Similarly a boy may commit violence on his girlfriend if she argues with him on small issues or does not listen to him or refuses to meet him. That's why, he may beat her.

Midline: A man who beats his wife for no reason or no mistake is a mad man, but if she does a mistake, then it is right to beat her up. If a woman does something wrong, then her husband should first explain to her, and if she does not listen, then only she should be beaten up.... Yes, if a woman is at fault, then she should bear violence, but if violence is done on her without any mistake of hers then she should never bear it.

Endline: Yes, now I have started thinking that women should not face any kind of violence and girls should also not face torture. Before I would not think about all these things, but after joining this programme I have started thinking about it. Men who beat their wife are not good human beings, such men are not actual men.... According to me, hitting for any reason is not right, but yes, if a wife cheats on her husband and she has an affair with some other man, in this situation if he is hitting her is fine, but except this if she doesn't listen to her husband even after explaining to her time and again or she doesn't follow what her husband has asked her to do, then also hitting her is fine. [Hindu, age 17, completed Class 9, selection criterion: perpetrated physical violence, ID19]

Baseline: Such men are not good; they should not do violence on women. But if a woman repeats her mistakes again and again and does not improve herself after her husband has explained to her, then in such situations violence toward wife is not wrong. In such situations, those husbands who do violence with their wives are not bad.

Midline: Such men are not good. A woman should not be beaten up; her husband should explain to her with love.... Yes, in a way, she should bear it because if she does something, then a family matter will become public and this will be an insult to the family in the society. So, to be safe from any kind of insult in the society, family issues should be kept within the home only. At most, she can talk to her in-laws and tell them how their son behaves with her, then they will explain her and like this the matter will be solved.

Endline: Violence is not a way to show masculinity. Masculinity or manliness is when there is some work to be done in the house, and the husband does it himself, not letting his wife do it. This is masculinity. Yes, the men who abuse their wife should be punished. From prison, police, people in village should explain to him... But if his wife forms a sexual relationship with some random man, then the man is correct in beating her. Aside from this situation, hitting is never right. [Hindu, age 18, completed Class 8, selection criterion: moderately gendered, ID5]

Finally, even at the time of the endline survey, some four boys continued to hold traditional attitudes and suggested that a man is justified in beating his wife if she disobeys him or makes a mistake. The narrative of one such respondent is reported below.

Baseline: Such men are not good, they are bad and should not beat their wives so much that they get hurt or break their bones. But of course, if there is a small fight, then it is fine because a husband will beat or scold his wife only when she is at fault.

Midline: These types of men are not good if they do violence on their wife when they are drunk. Otherwise, when wife don't finish her house work on time, when she doesn't listen to her husband, doesn't follow the instructions from her husband or if she does anything without informing her husband, all these are the reasons for the violence on wives. Like this violence happens with the woman. 
Endline: A man who is hitting his wife for no reason should be punished but if a man is hitting his woman because she committed a mistake then he should not be punished. [Hindu, age 18, completed Class 11, selection criterion: perpetrated physical violence, ID1]

\section{Intervention in cases of perpetration of violence on girls}

Aside from refraining from perpetrating violence on girls, several boys (11 boys) reported that as a result of the programme, they now intervened when they witnessed violence in their community or home. Several boys described incidents in which they had tried to intervene when a man was beating his wife or when a boy was harassing a girl. Some reported that they would ask the boy to think about his own sister and his feelings if she were harassed; some reported that they reminded boys that their harassment of a girl may be the cause of her withdrawal from school or community life. The following reports are evidence of intervention by boys when they witnessed violence against girls.

Earlier in our village we did not have any kind of discussion or debate on domestic violence as an issue, but now I also go and explain to a couple if there is violence.... Now if I hear someone or see someone spreading rumours or exaggerating stories about girls then I talk to them and try to stop them.... Yes, now if in this village there is a case of domestic violence or any violence against women then I personally go and try to make them understand. If any boy or anyone in this village tries to spread rumours and exaggerate a normal incident about a girl then I try and stop them. [Hindu, age 20, undergraduate student, selection criterion: perpetrated physical violence, ID16]

Yes, I have changed. Now if I go to the market and see that a boy is harassing a girl, then I scold the guy. If I see someone doing wrong to a girl then I go to them and tell them that if you don't stop such thing then you will be behind the bars. I explain to them. [Hindu, age 18, completed Class 8, selection criterion: moderately gendered, ID5]

If anyone fights in this village then I tell them not to do so because it is not good.... It is because of this programme that boys in my village who used to tease girls who happened to be walking on the street, no longer do these kinds of things. [Hindu, age 15, completed Class 7, selection criterion: highly gendered, ID6]

There is also change regarding violence against women/girls. If someone is teasing a girl on the road then we stop them and tell them, "She too has the right to work or go out of the home, and because of your behaviour her family might not let her get out of house ever again". Even in the market, I have told off boys who are harassing a girl. One time one boy asked, "Who is she to you?" I said, "My sister, what will you do?" What could he have done, especially when he thought that girl was my sister. So he went away. [Hindu, age 16, completed Class 10, selection criterion: moderately gendered, ID25]

Yes, there is change in me. Yes there has been change, like now when I see any boy commenting or teasing a girl then I explain to him that the girl also has a family. I tell them, "If tomorrow some random boy teases or comments on your mother or sister, how would you feel?" But these kinds of boys don't always understand.... [Hindu, age 16, completed Class 8, selection criterion: perpetrated physical violence, ID32]

\section{Perpetration of violence against women and girls}

While five boys reported in each of the three interviews that they had never harassed a girl, a number of boys (14 boys) reported in the first and/or sometimes the second interview as well that they had done so, but they had changed their behaviour toward girls and no longer teased, harassed, passed comments, or spread rumours about them or perpetrated violence on them. In many instances, boys reported that even their friends had stopped perpetrating violence on girls. Changes indicating respectful behaviour towards girls can be seen in the following narratives from the three in-depth interviews.

Baseline: Yes, around two years ago I said something to one of my classmates. Actually it happened that she was healthy (overweight) and once when she was going somewhere so I said that, "Look, the bulldozer is going". On hearing this that girl didn't say anything to me, but one of the men in the village heard this and he said, "Do you go to school to study or to look at the bulldozer?" (started laughing). Other than this, I have never teased any girl.

Midline: Yes, I have 1-2 friends at coaching class, who still tease girls and pass comments about them. They pull the dupatta (scarf) of the girls sitting in front of the class, touch their hair, but the girls don't do 
anything. Maybe she also likes it because if she doesn't like it, she would have definitely complained about it to the teacher, but she didn't complain. But I have stopped doing all these things that I used to do before.

Endline: I liked what they taught us about not commenting on girls. I have changed, now I do not comment on any women. [Hindu, age 19, completed Class 12, selection criterion: perpetrated sexual violence, ID17]

Baseline: Yes, a few days ago, we friends were sitting outside by the road, then my friends did this. A girl was walking along, and my friend sang a song and when he did this that girl said she will beat him with her shoes. Then that boy ran from there and went back home and that girl went back to her home. After coming back home, we scolded him a lot and when we said that we will tell his parents then he started apologising and said that he will not repeat this in future.... Two of my friends snatched the dupatta of a girl who was passing them and then people nearby beat them up badly and handed them to the police later. After this incident I broke up my friendship with them and now I don't know where they are.

Midline: Not addressed at midline.

Endline: I don't harass girls. Earlier, my friends and I would tease or harass girls but since this club started, no one in our group behaves this way. [Hindu, age 16, completed Class 8, selection criterion: moderately gendered, ID18]

Baseline: Yes, I have a few friends who do all this. They whistle at girls who are passing by, they follow them on their bicycle, make a sharp turn on their bicycle so they overtake the girl, perform stunts, comment about the girl, say things like, "I will snatch away your dupatta", "You are beautiful". Yes, once or twice I have whistled at girls, It happened like this, we were coming back after finishing out game and my friends were troubling girls who were passing; they were commenting about them and whistling at them, then because of them, I also whistled, but the girl didn't said anything, quietly she passed.

Midline: Yes, some of my friends used to do all this earlier. They used to whistle at girls passing by, they used to do stunts in front of them, they used to suddenly stop their cycle in front of their cycles, etc. They used to do all this and tease girls, but all this happened earlier. Now for the past few months, nothing like this has happened. They don't do all this now because they all are also associated with the club and in the club we are taught to not to do all this at all. Because of this, there has been a change in them.... Yes, I also used to do all this sometimes with those friends, but now I do not do all this. Earlier, I also used to whistle at girls, I used to say something or the other wrong to them, I used to try to snatch their dupatta, etc., but for past few months I have not done anything like this because after being associated with the group I have learnt that I should not do all this, because if someone will do the same with my sister then I will feel very sad.

Endline: Earlier my friends would tease girls on the road, would snatch their dupatta. They used to say all this, but now they don't do all this; since they joined the club they have changed.... With them I too would tease girls, but now I don't do that. [Hindu, age 17, completed Class 10, selection criterion: physical violence, ID20]

Five boys reported teasing or harassing a girl in all three interviews. Some of them focused on teasing and harassing by their peers, and others discussed peer pressure to tease or harass a girl, as reported in the following narratives.

Baseline: Yes, my friends irritate girls and comment on girls who are passing by. They whistle at them and follow them.

Midline: I have one or two friends who trouble girls when they are returning from school. They whistle at them, or take their bicycle behind them and say things like: "Where are you going?" or whisper to her, "Why are you doing nakhra (playing hard to get)?" They do this often. Only four or five days ago, a boy said this to a girl passing by. Girls don't do anything, they just continue quietly. Once I too did it, 8-9 months ago, because my friends insisted, I whistled at a girl. But I don't like doing this. A year ago, a friend pulled off a girl's dupatta. She was going home after school, and when she went home she told her family and they came to the boy's house and told his family. I too did that once. A girl pushed me and I fell, so I shouted at her and abused her.

Endline: My friends whistle at girls passing by, they say, "Where are you going? Let's go together". And then the girl gets scared and just continues on her way. In the last six months, once we were on the bridge playing ball and a girl went by so they asked her where she was going. A long time ago, I had whistled at girls, and once, my friend told me to, so I pulled a girl's dupatta a little but she didn't say anything and just continued on her way. [Hindu, age 17, completed Class 9, selection criterion: moderately gendered, ID10] 


\section{Perspectives about action against men who perpetrate violence}

In the course of in-depth interviews, boys discussed options available to women who face domestic violence and courses of action that may be taken to stem violence. A notable change in the discourse was apparent between attitudes held at the time of the baseline survey and those at the endline survey; indeed, while at the time of the baseline survey, only two boys suggested that women had options other than tolerating the violence, this number increased to nine at the time of the midline in-depth interview and to 14 at the endline in-depth interview. The options that they articulated for women experiencing domestic violence ranged from familial options, such as informing parents and parents-in-law and obtaining their intervention and moving temporarily to the natal home to options that entailed more formal recourse, such as requesting intervention from locally elected representatives, filing a case in the police station, seeking helpline support, and even obtaining a divorce. Several boys, especially in the interview held midway through the intervention, suggested that "mild" violence should be tolerated, but it was imperative for women to take action if the violence is severe or sustained, as seen in the reports that follow.

Baseline: Not mentioned

Midline: Such men should be punished for sure. Such men should be punished by their guardians. If they do not listen to their guardians, they should be punished by the Panchayat. These days there are women helplines too, she can complain there and get them punished. Such men can also be punished by the police or by the law also....

Endline: Women shouldn't tolerate violence...they should file a complaint with the police helpline, should tell their family so that they take some action.... [Hindu, age 16, completed Class 10, selection criterion: moderately gendered, ID25]

Baseline: Not mentioned

Midline: Yes, she should bear the violence because if she does something then the family issue will go out and this will be insulting for them in the society. At most, she can talk to her in-laws and tell them how their son behaves with her, then they will explain to him and like this the matter will be solved.

Endline: Men who abuse their wife should be punished. They should be sent to prison, the woman should go to the police, people in the village should explain to him. [Hindu, age 18, completed Class 8, selection criterion: moderately gendered, ID5]

Baseline: Not mentioned

Midline: Not mentioned

Endline: I cannot stand such men; torture or atrocity is not right. Even I have mother and sister; this can be the case with them as well. No, women should not tolerate it. If the man does not stop, then he should be taken to court. Yes, if he is abusing his wife then he should be punished. [Hindu, age 17, completed Class 9, selection criterion: highly gendered, ID13]

Baseline: Not mentioned

Midline: According to me, instead of tolerating violence, a woman should take the help of the police, but before doing this, she should consult people in the village or in the society or in the Panchayat, and if even then the condition doesn't get under control, then she should go to the police. She can also take help from her parents or her in-laws. Such men should be punished by others in the village, society or Panchayat, else by the police, etc.

Endline: When the torture crosses the limit, then she should not tolerate it at all. She should tolerate violence only to the extent of her mistake, beyond that, she should not. Men should be punished by their mother-father, village and society people, Panchayat, headmen, police station, and by police... [Hindu, age 21, completed Class 12, selection criterion: moderately gendered, ID15]

\section{Summary}

Boys in both arms perceived that over the year preceding the endline interview, they had become better informed and more gender sensitive, had exhibited greater self-efficacy and sportsmanship, and had a larger peer network. However, on each issue explored, more boys in the intervention than control arm reported improvements. For example, among boys in the intervention arm, between 75 percent and 90 percent reported increased exposure to information, 62 percent to 92 percent reported increased self-efficacy, sports skill and a larger peer network, and 55 
percent to 66 percent reported increased gender sensitivity, corresponding percentages among those in the control arm were considerably lower (43-70\%; 30-84\% and 26-35\%, respectively). Many boys in the intervention arm almost two-thirds -- reported, moreover, that their family and friends had noticed the changes that had taken place in them over the course of the year.

In-depth interviews were held with boys in the intervention arm prior to the initiation of the intervention, midway through the intervention, and at its conclusion. Narratives suggest that notions of masculinity and men's right to perpetrate violence had been considerably tempered over the three interviews, with more boys at the final interview suggesting that violence is unacceptable in any situation, and that women who experience marital violence should seek legal and other options for redressal.

Findings also showed that large numbers of boys who reported at the baseline in-depth interview that they rarely helped in household chores indicated at the endline in-depth interview that they were doing so more regularly. Likewise, several boys whose narratives suggested at the time of the baseline in-depth interview and/or the midline in-depth interview that they had participated in teasing girls in different ways reported by the time of the endline indepth interview that they no longer did so. Finally, by the time of the endline interview, many boys reported that they had intervened to stop a boy from harassing or perpetrating violence on a girl over the year preceding the interview. Many attributed the change they had experienced directly to what was conveyed in the Do Kadam programme. 


\section{Chapter 7 \\ Summary and way forward}

This chapter summarises the major findings of the project with regard to the acceptability and effectiveness of the Do Kadam Barabari Ki Ore model, which was implemented among adolescent boys and young men who were members of youth clubs falling under NYKS in Patna district, Bihar. This chapter also highlights lessons learnt for programme implementation, sustainability, and upscaling.

\section{Summary}

\section{Programme participation}

Most boys in the intervention arm had participated in Do Kadam activities. Almost four in five had attended gender transformative life skills sessions, three in four had attended cricket sessions, and half had participated in community-level events organised by the club. Regular attendance in gender transformative life skills sessions and cricket sessions was, however, reported by fewer: 64 percent and 57 percent, respectively. Most boys exposed to the gender transformative life skills sessions had attended sessions covering, on average, 10 of the 14 broad topics covered and reported that they had both liked the sessions on each topic and learned something new from them. Boys were, moreover, largely positive about the quality of the programme. They looked forward to sessions (89\%), found that the peer mentors were approachable and that they explained issues clearly and could answer their questions. Some boys reported, however, that the sessions had not been held punctually or regularly, that the peer mentor could not manage the session, and that he could not always convey its messages appropriately.

\section{Programme effects}

Programme effects were generally promising, and lend support to our hypothesis that gender transformative life skills education combined with sports coaching can go a long way in engendering boys' attitudes to girls, and enabling boys to take steps to stop violence against women and girls.

\section{Attitudes}

The project achieved its primary objective. Evidence strongly suggests that the intervention was able to change gender role attitudes and notions of masculinity of boys. Moreover, perceptions about peer reactions to men and boys acting in gender equitable ways-for example, helping in housework, sharing personal problems with a peer, refusing to participate in a physical fight, and refusing to beat their wife even if she has "erred"-had been affected by their participation in the intervention. Exposure to the intervention also had a significant effect on fostering more egalitarian attitudes regarding the right of men and boys to control the women and girls in their life. Finally, findings confirmed that exposure to the intervention had a significant effect on enabling boys to reject men's and boys' right to perpetrate violence on women and girls. For example, a larger proportion of boys in the intervention than control arm expressed egalitarian gender role attitudes and notions of masculinity (6.6 versus 6.2 of 9 attitudes, $p=0.0439$ ), rejected men's and boys' right to exercise control over women (4.9 versus 4.2 of 9 behaviours, $p=0.0035$ ), and rejected men's and boys' right to exercise violence against women and girls (11.7 versus 10.3 of 17 situations, $p=-.0019)$. There was strong evidence, in addition, to suggest that perceptions about peer reactions to boys acting in gender equitable ways had been affected by their participation in the intervention; 20 percent of boys in the intervention arm compared with 13 percent of those in the control arm believed that their peers would respect them for demonstrating non-traditional behaviours in at least three of the four situations probed (effect estimate 7.2, $p=0.0426)$.

Findings from in-depth interviews confirm, moreover, that notions of masculinity and men's right to perpetrate violence had been considerably tempered over the three interviews, with more boys at the endline in-depth interview expressing the view that violence is unacceptable in any situation and describing various legal and other options for women who experience marital violence.

\section{Action taken to stop the perpetration of violence by others}

The programme also succeeded in motivating boys to take action to stop violence being perpetrated on a woman or girl by others. Indeed, compared with boys in the control arm, those in the intervention arm were significantly less likely to report that they had done nothing, had felt badly or had joined in when they observed an incident of 
violence, and far more likely to report that they had intervened, informed someone in a position of authority, or taken other action to stop the violence (effect estimate 13.3, $p=0.0143$ ).

Narratives of boys in in-depth interviews also suggest that by the time of the endline in-depth interview, many more boys than at the time of the baseline in-depth interview reported that they had intervened to stop a boy from harassing or perpetrating violence on a girl over the year preceding the interview. Many attributed the change they had experienced directly to what was conveyed in the Do Kadam programme.

\section{Perpetration of violence}

With regard to reduction in the perpetration of various forms of gender-based violence, there was weak evidence that non-contact forms of violence, such as stalking a girl, had declined because of the intervention. However, there was no evidence of an effect on the perpetration of other forms of non-contact violence or physical and sexual violence.

In in-depth interviews, several boys whose narratives suggested at the baseline and/or midline interview that they had participated in teasing girls in different ways reported at the endline interview that they no longer did so. Some of these boys specifically attributed the change they had experienced directly to what was conveyed in the Do Kadam programme.

\section{Regularity of exposure}

Findings highlight that the effects of exposure to the programme were most pronounced for those who had regularly participated in the programme and had relatively little effect on those whose attendance was irregular. These findings confirm that a minimum of attendance in at least half of all sessions of both gender transformative life skills and sports was essential to effect a change in boys' attitudes and practices.

\section{Self-perceived changes}

Boys in both intervention and control arms perceived that over the year preceding the interview, they had become better informed and more gender sensitive, that they exhibited greater self-efficacy and sportsmanship, and had a larger peer network. However, on each issue explored, more boys in the intervention than control arm reported improvements. Many boys in the intervention arm reported, moreover, that their family and friends had noticed the changes that had taken place in them over the course of the year.

In in-depth interviews, moreover, boys described other ways in which the intervention had changed their behaviour. Thus while large numbers of boys reported at the baseline in-depth interview that they rarely helped in household chores, many more described by the time of the endline in-depth interview that they were doing so or doing so more regularly.

\section{Potential for models relying on peer mentors}

Findings also add to the evidence about the feasibility and effectiveness of programmes for youth employing the peer mentor approach. While many studies report mixed and inconsistent results, the Do Kadam programme experience was positive. It showed that peer mentors did take on leadership roles, and that club members did indeed accept their leadership, perceive them as mentors and take the messages they transmitted seriously. Even so, we recognised that peer mentors often lacked confidence and communication skills, and were uncomfortable conveying sensitive messages (such as, for example, sexual violence). Our model incorporated two activities to overcome these challenges: repeated capacity building workshops for peer mentors on the one hand, and the inclusion of an adult mentor (in the form of the core trainer and the coach) who attended sessions and supported the peer mentor in delivering the gender transformative life skills education programme, and the spirit of fair play.

\section{Lessons for scaling up}

The Do Kadam Barabari Ki Ore project has proven to be feasible to implement, acceptable to young people and effective in engendering boys' attitudes and commitment to reducing violence against women and girls. This success was achieved notwithstanding many potentially insurmountable challenges. These included, most notably a setting characterised by deeply entrenched inegalitarian gender norms, a sense of entitlement among boys to control the women in their life and to perpetrate violence on them, as well as a weak and poorly-resourced platform, namely NYKS clubs on which to layer the Do Kadam programme. The success of the model, given these challenges, is all the more encouraging, and the programme holds great promise for replication in and upscaling to other parts of the district or state. 
While the NYKS offered an appropriate platform for the Do Kadam programme, it represents, by no means, the only platform for housing an upscaled programme. Indeed, the Do Kadam programme is flexible enough to be incorporated within any programme that has potential for the formation of boys' group. The RKSK platform, with its emphasis on peer mentors, offers one such opportunity.

Several questions arise from our experience that must be addressed while replicating or up-scaling the Do Kadam programme. For one, efforts are needed to determine the ideal length of an upscaled intervention: 42 sessions may be too short to change behaviours in a sustainable way, and many boys themselves suggested the need for a longer duration intervention.

Second, our findings have confirmed that the intervention had little effect on those who attended irregularly, that is, those who attended fewer than half of the gender transformative life skills sessions and cricket sessions. Findings reiterate the importance of regular attendance, and they call for measures that accommodate work- and educationrelated time commitments of boys, are responsive to their own preferences about intervention activities during each session, and ensure that sessions are interactive and fun.

Third, programme designs are needed that offer gender transformative life skills exposure that take into consideration boys' own preferences with regard to other components. Our programme was designed keeping in mind the interest that boys had expressed in a cricket-coaching component. However, in other settings, boys may express interest in other sports and even components other than sports, such as livelihood skill building or training in English language and/or computer skills. It is important therefore to engage with club leadership at the district level to arrive at a mutually acceptable intervention design prior to initiating the intervention.

Fourth, our findings have suggested the need to invest in peer mentor capacity-building on a regular basis. While the peer mentor model is ideal in many ways to encourage behaviour change, in our programme, it required extensive efforts to change the norms held by peer mentors and build their capacity and confidence about imparting the programme. An upscaled programme would need to invest in pre-intervention and regular refresher training programmes for peer leaders as well as supportive supervision of intervention progress.

Fifth, the NYKS membership in general tends to include young adults rather than adolescents, and it is critical that membership drives are undertaken prior to the introduction of programmes, such as the Do Kadam Barabari Ki Ore programme, that will encourage young people to become members of NYKS clubs.

Finally, we note that while the NYKS structure is an ideal home for an upscaled Do Kadam programme, activities will require committed human and financial resources that the NYKS structure, in its current form, may not possess. Other platforms need to be identified, and their potential for housing the Do Kadam programme investigated.

The RKSK platform, with its emphasis on peer mentors whose role is to raise awareness, build gender egalitarian norms and attitudes, and enable informed and empowered decision making among adolescents, offers one such opportunity.

The NYKS youth club structure is ideal for engaging boys to foster social change at scale; the goal of the NYKS is to build leadership skills and citizenship values among the young, and the Do Kadam intervention works directly to achieve these goals. Our model has demonstrated a considerable impact on changing traditional norms and attitudes, building leadership skills and citizenship values, and laying the groundwork for a reduction in the perpetration of violence against women and girls. Findings point to the promise of the Do Kadam approach of combining gender transformative life skills education and sports coaching as a pathway toward engendering norms and behaviours among boys and young men in disadvantaged rural settings in Bihar. They also suggest that the programme is flexible and may be implemented successfully within programmes aside from NYKS clubs, such as, for example, the RKSK model and other peer-led and group forums. 
Appendix 1.1: Construction of the wealth index

Type of house: 2 for pucca; 1 for semi-pucca; 0 for kachcha

House owned: 1 if the household owns a house; 0 if not

Agricultural land owned: 1 if the household owns some land; 0 for no land

Main source of light: 3 for electricity 0 for kerosene or other fuel

Access to toilet facility: 4 for own flush toilet; 2 for shared flush toilet or own pit toilet; 1 for shared pit toilet or other types of toilet; 0 for no toilet facility

Cooking fuel used: 2 for liquid petroleum gas, electricity, or bio-gas; 1 for kerosene, wood, crop residue, dung cakes, coal or charcoal; 0 for other types of cooking fuel, for example, straw, shrubs, or grass

Access to drinking water facility: 4 for own piped water, hand-pump or covered well; 3 for own open well; 2 for public or shared piped water, hand-pump or covered well; 1 for public or shared open well; 0 for other sources of drinking water, for example, surface water, tanker/truck, or rainwater

Access to electricity: 3 for electricity; 0 for no electricity

Ownership of household assets: 4 for car or truck or tractor; 3 each for motorcycle or scooter, refrigerator, computer/ laptop, telephone (landline or mobile); 2 each for bicycle, electric fan, television, sewing machine, water pump, animal-drawn cart, thresher; 1 for watch or clock; 0 for each of the above items that the household does not possess.

Minimum score: 0; maximum score: 56 


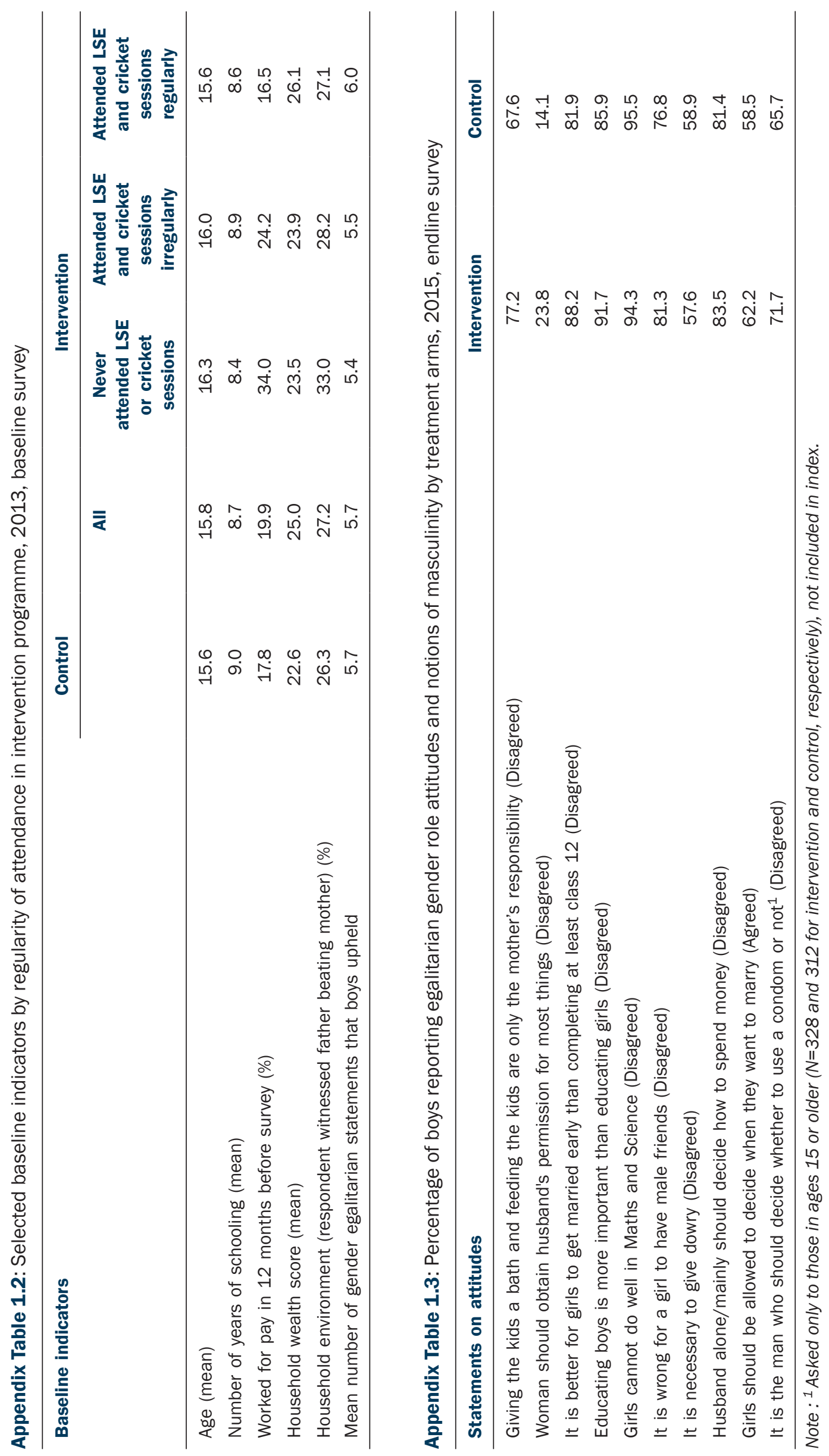




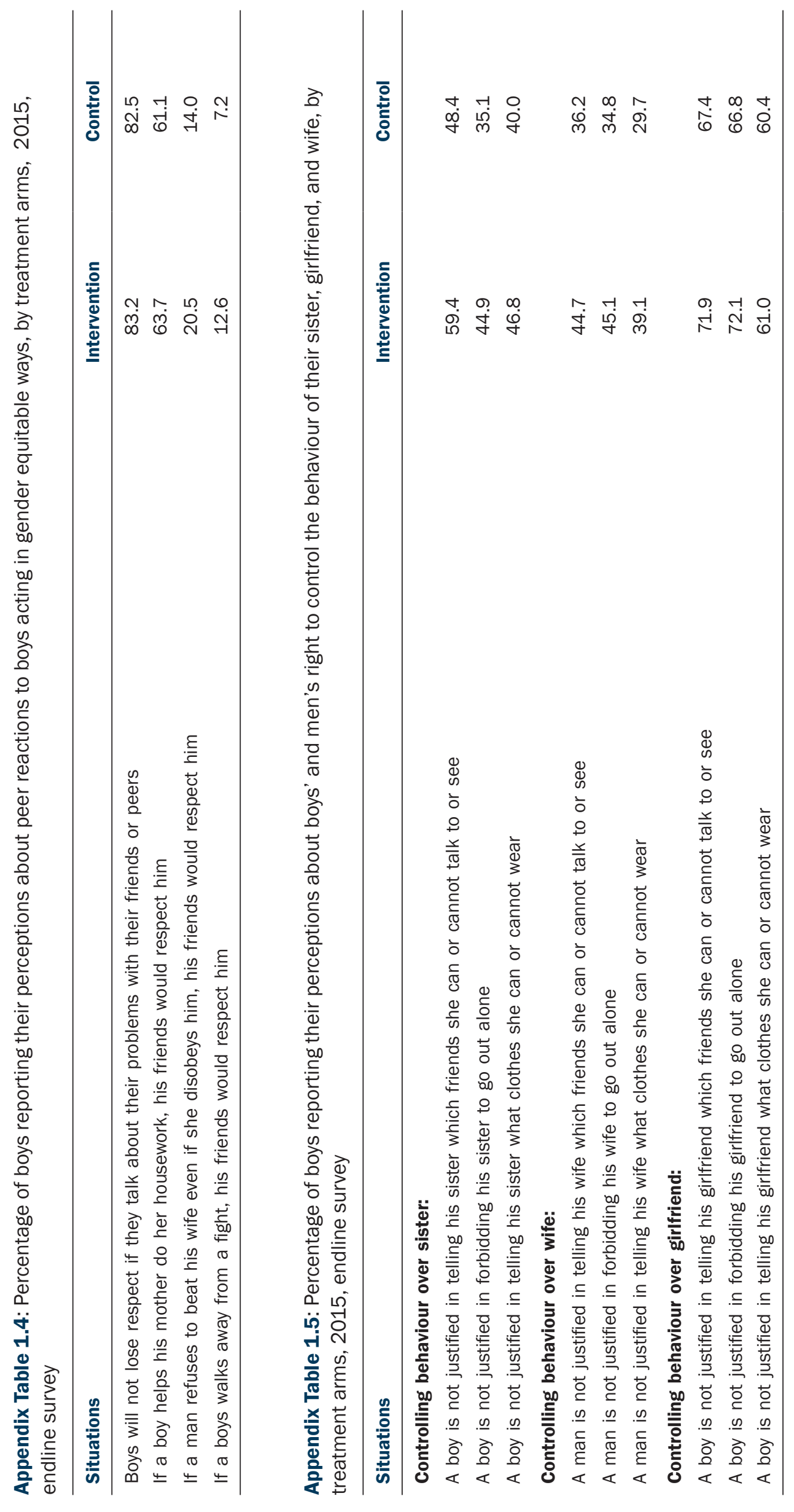




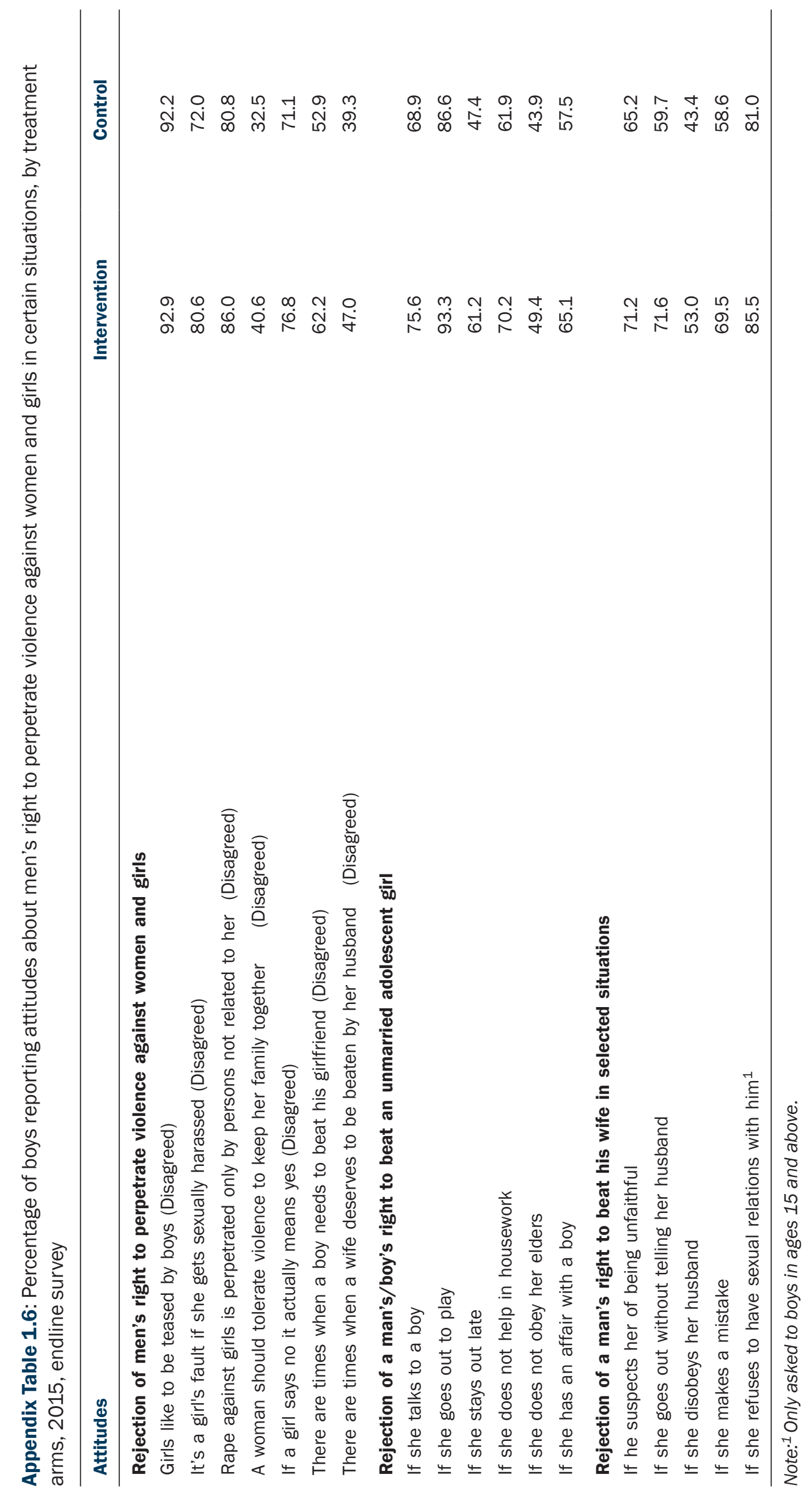




\section{References}

Achyut P., N. Bhatla, S. Khandekar, et al. 2011. Building Support for Gender Equality among Young Adolescents in School: Findings from Mumbai, India. ICRW: New Delhi.

Centre for Development and Population Activities (CEDPA). 2003. Choose a Future! Issues and Options for Adolescent Girls in India. A Sourcebook of Participatory Learning Activities. New Delhi: CEDPA.

Centre for Development and Population Activities (CEDPA). 2006. UDAAN - Towards a better future: Training Manual. New Delhi: CEDPA.

Das M., S. Ghosh, E. Miller et al. 2012. Engaging Coaches and Athletes in Fostering Gender Equity: Findings from the Parivartan Program in Mumbai, India. New Delhi: ICRW \& Futures Without Violence.

Directorate of Census Operations, Bihar. 2014. District census handbook, Patna: Village and town wise primary census abstract (PCA). Series -11, Part XII-B. Patna: Directorate of Census Operations, Bihar. Accessed at http://www.censusindia.gov. in/2011census/dchb/1028 PART B DCHB PATNA.pdf on 3 March 2016.

Fernandes, A., D. Sharma, P. Kukade, et al. 2005. Working with Men on Gender, Sexuality, Violence and Health Trainers' Manual. Vadodara: SAHAJ.

Fulu, E., X. Warner, S. Miedema, et al. 2013. Why Do Some Men Use Violence Against Women and How Can We Prevent It? Quantitative Findings from the United National Multi-country Study on Men and Violence in Asia and the Pacific. Bangkok: UNDP, UNFPA, UN women and UNV.

Government of India, Ministry of Youth Affairs \& Sports, Nehru Yuva Kendra Sangathan. n.d. Annual Report 2010-11. Accessed on 5 January 2016 http://www.nyks.org/resources/pdf/ap201011.pdf.

Haberland, N., D. Rogow, O. Aguilar, et. al. 2009. It's all in one curriculum: Guidelines and Activities for a unified approach to sexuality, gender, HIV, and humans rights education. New York: Population Council.

Hayes, R.J. and L.H. Moulton. 2009. Cluster Randomised Trials. Boca Raton, FL: Chapman \& Hall/CRC.

International Center for Research on Women (ICRW). n.d. Parivartan: Coaching Boys Into Men. Accessed on 15 March, 2016 at http://www.icrw.org/where-we-work/parivartan-coaching-boys-men.

2009. Parivartan - Coaching Boys Into Men: Card Series. New Delhi: ICRW.

International Institute for Population Sciences (IIPS) and Macro International. 2007. National Family Health Survey (NFHS-3), 2005-06: India. Mumbai: IIPS.

International Institute for Population Sciences and Population Council. 2009. Youth in India, Situation and Needs 2006-07: Bihar. Mumbai: IIPS.

— 2010. Youth in India, Situation and Needs 2006-07. Mumbai: IIPS.

International Institute for Population Sciences (IIPS). 2016. National Family Health Survey-4, 2015-2016, State Factsheet, Bihar. Mumbai: IIPS.

Jejeebhoy, S.J. and R. Acharya. 2014. Adolescents in Rajasthan 2012: Changing Situations and Needs. New Delhi: Population Council.

Jewkes, R., M. Nduna, J. Levin, et al. 2006. “A cluster randomized-controlled trial to determine the effectiveness of Stepping Stones in preventing HIV infections and promoting safer sexual behaviour amongst youth in the rural Eastern Cape, South Africa: Trial design, methods and baseline findings". Tropical Medicine and International Health, 11(1): 3-16.

Jewkes, R., M. Nduna, J. Levin, et al. 2008. “Impact of Stepping Stones on incidence of HIV and HSV-2 and sexual behaviour in rural South Africa: Cluster randomised controlled trial”. BMJ, 337: a506.

Men Engage Global Symposium. 2014. http://www.menengagedilli2014.net/delhi-declaration-and-call-to-action-eng.html accessed on 4 January 2016.

Ministry of Health and Family Welfare (MOHFW). 2014. Rashtriya Kishor Swasthya Karyakram Strategy Handbook. New Delhi: MOHFW, Government of India.

Moulton L.H. 2004. “Covariate-based constrained randomization of group-randomized trials”. Clinical Trials, 1(3): $297-305$.

Office of the Registrar General and Census Commissioner, India. 2013. Primary Census Abstract, Data Highlights, India, Series 1. New Delhi: Office of the Registrar General and Census Commissioner, India. Accessed on 1 March, 2016 at http://www. censusindia.gov.in/2011census/PCA/PCA_Highlights/pca_highlights_file/India/Chapter-3.pdf. 
— n.d. Annual Health Survey 2012-13, Fact Sheet: Bihar. New Delhi: Office of the Registrar General and Census Commissioner. Accessed on 29 February 2016 at http://www.censusindia.gov.in/vital_statistics/AHSBulletins/AHS_Factsheets_2012-13/ FACTSHEET-Bihar.pdf.

- 2015a. C -1 Population by Religious Community - 2011. Accessed on 1 March, 2016 at http://www.censusindia.gov. in/2011census/C-01/DDW10C-01\%20MDDS.XLS.

_ 2015b. C -2 Marital Status by Age and sex. Accessed on 1 March, 2016 at http://www.censusindia.gov.in/2011census/Cseries/c-2/DDW-1000C-02-fer3-MDDS.xls.

-2015c. F-1 Number of women and ever married women by present age, parity and total children ever born by sex. Accessed on 3 March, 2016 at http://www.censusindia.gov.in/2011census/F-series/f1/2011-F01-1000-Rev4-MDDS.XLSX.

Planning Commission. 2013. Press note on poverty estimates, 2011-12. Accessed on 14 October, 2015 at http:// planningcommission.nic.in/news/pre pov2307.pdf.

Population Council. 2006. Yaari Dosti: A Training Manual. New Delhi: Population Council.

Pulerwitz, J. and G. Barker. 2008. "Measuring attitudes toward gender norms among young men in Brazil: Development and psychometric evaluation of the GEM Scale". Men and Masculinities, 10: 322-338.

Santhya, K.G., S.J. Jejeebhoy, I. Saeed, et al. 2013. Growing Up in Rural India: An Exploration into the Lives of Younger and Older Adolescents in Madhya Pradesh and Uttar Pradesh. New Delhi: Population Council.

United Nations Population Fund (UNFPA). 2016. http://www.unfpa.org/engaging-men-boys\#sthash.cfgPw7Q0.dpuf Accessed on 5 January 2016.

World Health Organization. 2007. Engaging Men and Boys in Changing Gender-Based Inequity in Health: Evidence from Programme Interventions. Geneva: WHO. 


\section{Authors}

Shireen J Jejeebhoy, formerly Senior Associate, Population Council, New Delhi

Rajib Acharya, Associate II, Population Council, New Delhi

Neelanjana Pandey, Programme Officer I, Population Council, New Delhi

K G Santhya, Senior Associate, Population Council, New Delhi

A J Francis Zavier, Senior Programme Officer, Population Council, New Delhi

Santosh Kumar Singh, Assistant Programme Officer II, Population Council, New Delhi

Komal Saxena, Senior Programme Administrator, Population Council, New Delhi

Aparajita Gogoi, Executive Director, Centre for Catalyzing Change, New Delhi

Madhu Joshi, Senior Advisor, Centre for Catalyzing Change, New Delhi

Sandeep Ojha, State Programme Coordinator, Centre for Catalyzing Change, Patna 


\section{List of Investigators}

\section{Field Supervisor/Editor}

Binit Jha

Field Investigators

Hemraj Daima

Diwakar Maji

Bhaskar Mishra

Alok Pandey

Dipu Kumar Sharma

Rajanikant

Ramshankar 
Printed at :

Systems Vision

Email:systemsvision96@gmail.com

Mobile:98102 12565 
